\title{
Perceptions of Voluntourism
}

by

Cassandra Verardi

A thesis submitted to the Faculty of Graduate and Postdoctoral Affairs in partial fulfillment of the requirements for the degree of

Master of Arts

in

Anthropology

Carleton University

Ottawa, Ontario

(C) 2013

Cassandra Verardi 
Library and Archives

Canada

Published Heritage

Branch

395 Wellington Street

Ottawa ON K1A ON4

Canada
Bibliothèque et

Archives Canada

Direction du

Patrimoine de l'édition

395 , rue Wellington

Ottawa ON K1A ON4

Canada
Your file Votre référence

ISBN: 978-0-494-94593-3

Our file Notre référence

ISBN: $978-0-494-94593-3$
NOTICE:

The author has granted a nonexclusive license allowing Library and Archives Canada to reproduce, publish, archive, preserve, conserve, communicate to the public by telecommunication or on the Internet, loan, distrbute and sell theses worldwide, for commercial or noncommercial purposes, in microform, paper, electronic and/or any other formats.

The author retains copyright ownership and moral rights in this thesis. Neither the thesis nor substantial extracts from it may be printed or otherwise reproduced without the author's permission.
AVIS:

L'auteur a accordé une licence non exclusive permettant à la Bibliothèque et Archives Canada de reproduire, publier, archiver, sauvegarder, conserver, transmettre au public par télécommunication ou par l'Internet, prêter, distribuer et vendre des thèses partout dans le monde, à des fins commerciales ou autres, sur support microforme, papier, électronique et/ou autres formats.

L'auteur conserve la propriété du droit d'auteur et des droits moraux qui protege cette thèse. $\mathrm{Ni}$ la thèse ni des extraits substantiels de celle-ci ne doivent être imprimés ou autrement reproduits sans son autorisation.
In compliance with the Canadian Privacy Act some supporting forms may have been removed from this thesis.

While these forms may be included in the document page count, their removal does not represent any loss of content from the thesis.
Conformément à la loi canadienne sur la protection de la vie privée, quelques formulaires secondaires ont été enlevés de cette thèse.

Bien que ces formulaires aient inclus dans la pagination, il n'y aura aucun contenu manquant. 


\section{Abstract}

Voluntourism combines the non-profit/voluntary and tourism sectors. An individual does short-term development work and explores a different culture, while also saying she "makes a difference" abroad. Voluntourism creates an ambiguous experience for an individual through combining these two distinct activities. The structural tension in these roles creates contradictions for the voluntourist and how she makes sense of her experience.

I analyze the narratives of individuals engaged in a voluntourism trip to Cape Town, South Africa, as well as the organization's discourse, to examine the language of voluntourism. Through intersecting the concepts of Mauss' "gift" and Schutz' "lifeworld," I examine the ways the voluntourist described a shift in perspective based on her trip and how she "gives back" to the host community. Representing herself this way helps to justify an individual's involvement and limits her described shock of the poverty in the townships, while mitigating the ambiguity of voluntourism. 


\section{Acknowledgements}

I have been lucky to have had an amazing group of people supporting me during this thesis project. Thank you Morgan, for all the late night walks, endless amounts of coffee, and listening to me talk about my fieldwork-you are my school partner in crime. Thank you to my parents for your unwavering encouragement and telling me "I can do it" every single day. Thank you to my sister for injecting her sense of humour during the challenging moments of grad school. Thank you to the McCabes for keeping me grounded and being there for me.

I would also like to thank Dr. Bernhard Leistle and Dr. Jackie Kennelly for working with me to make this thesis be my best possible work. Thank you for seeing the potential in my research topic, providing guidance, and the insightful discussions along the way. You have both been very positive mentors for me on my academic journey.

Finally, enkosi to everyone who I worked with, interviewed, and met in Cape Town. It truly was a pleasure to work in Cape Town with the project partners, the voluntourists, and International Voluntourism. 


\section{Table of Contents}

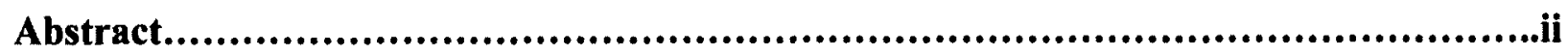

Acknowledgements................................................................................ii

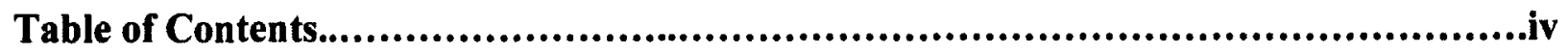

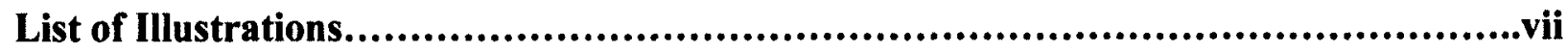

List of Appendices...............................................................................viii

1 Chapter: Introduction..........................................................................

1.1 Why Study Voluntourism Anthropologically ..................................

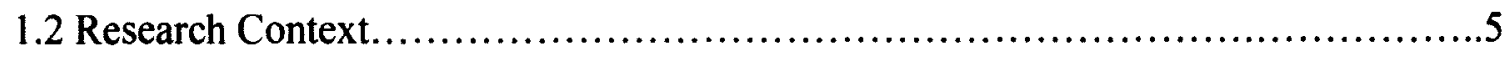

$1.3 \mathrm{My}$ Voluntourism Field Site .................................................

1.4 Introducing the Voluntourists...................................................

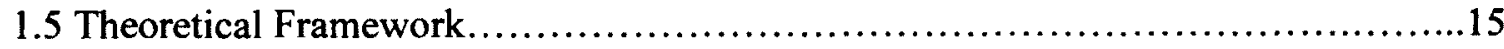

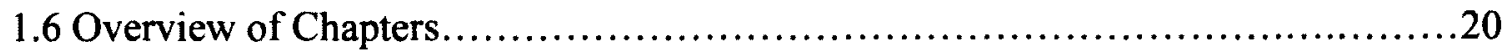

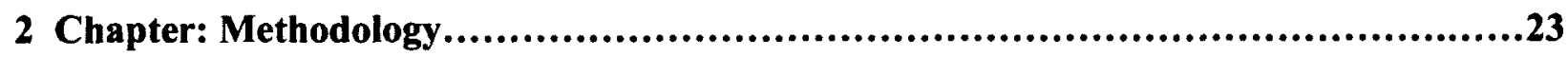

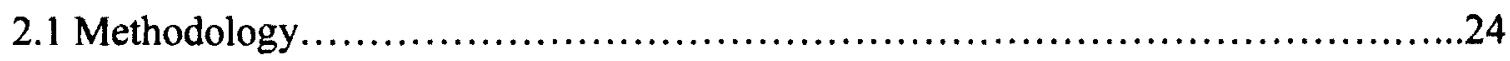

2.2 The Anthropologist as Voluntourist.......................................29

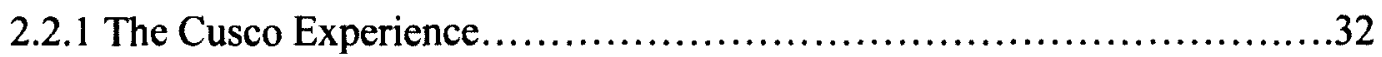

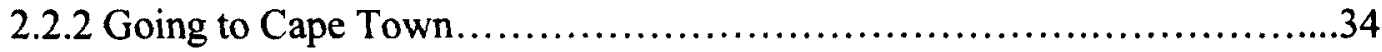

3 Chapter: Literature Review and Context of Voluntourism..................................40

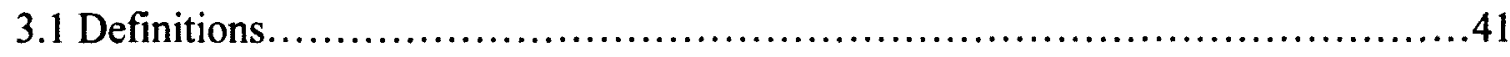

3.2 Morality of Volunteer Tourism...............................................42

3.2.1 Voluntourism: The Good...........................................43

3.2.2 Voluntourism: The Bad................................................

3.2.3. Voluntourism: The Contradictory ....................................54

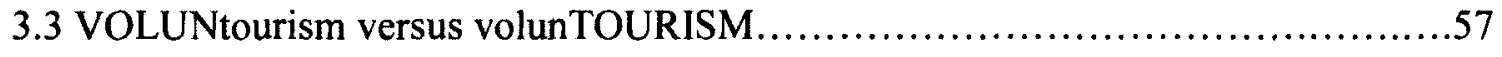


3.4 Socio-Political History of South Africa.........................................60

4 Chapter: How International Voluntourism Frames the Experience........................67

4.1 Why Conduct a Content Analysis............................................68

4.2 "You should choose International Voluntourism".................................70

4.3 This is how you "Give Back".................................................... 74

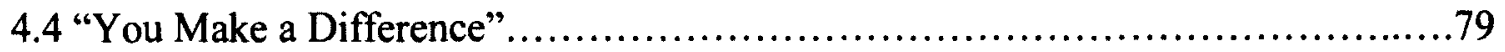

5 Chapter: The Gift...........................................................................82

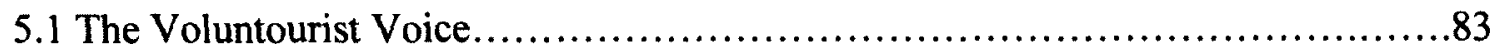

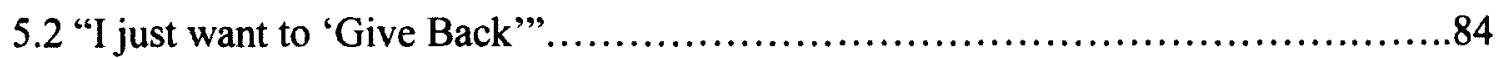

5.3 "I Want to 'Make a Difference'"..............................................87

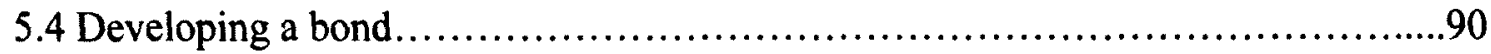

5.5 A Picture is Worth a Thousand Words.......................................93

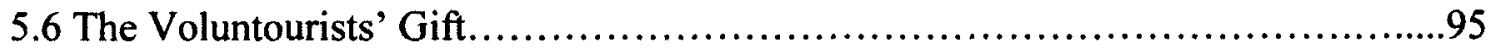

5.7 Key considerations of "The Gift" of Voluntourism...............................97

6 Chapter: Shifts in Perspective and the Life-World..........................................99

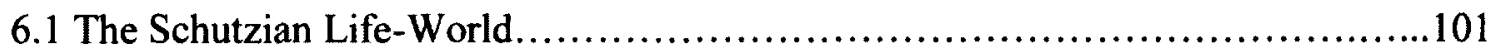

6.2 The Voluntourists' Self-Described Shift in Perspective...........................108

6.2.1 A New Perspective and the "shock" of the Townships..................109

6.2.2 Developing Relationships.........................................116

6.2.3 "Being There" and the Indescribability of the Experience...................119

6.3 Voluntourism's Impacts on Perception...........................................121

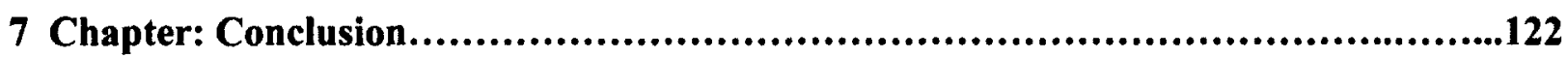

7.1 Looking Back: A Chapter Overview..........................................123

7.2 Answering my Research Questions..........................................125

7.3 Contributions to Anthropology and Voluntourism Literature.....................127 
7.4 Potential Limits to Research.......................................... 127

7.5 Future Research Considerations............................................ 128

Appendices................................................................................129

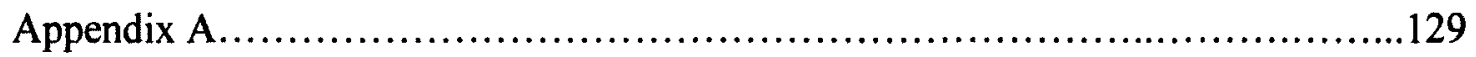

A.1 Voluntourist Early Trip Interview Questions........................... 129

A.2 Voluntourist Late Trip/ Post-Trip Interview Questions...................129

A.3 For Individuals from the Sending Organization/Project Partners..........130

Bibliography...........................................................................131 


\section{List of Illustrations}

Figure 1.1 Map of South Africa..........................................

Figure 1.2 The Cape Town area............................................. 9

Figure 1.3 Landing at the Cusco airport......................................

Figure 1.4 The Streets in Cusco, Peru..................................... 32

Figure 1.5 My visit to Machu Picchu..................................... 33

Figure 1.6 Tutoring in English at the foster home...............................

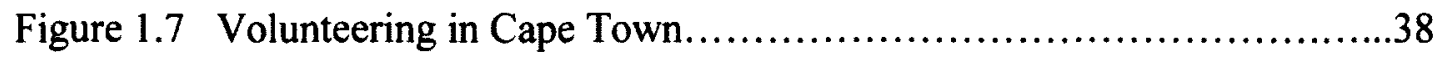

Figure 1.8 Touring in Cape Town........................................ 38

Figure 1.9 Sign in District 6 Museum, Cape Town..........................61

Figure 1.10 In a Township outside Cape Town.................................63

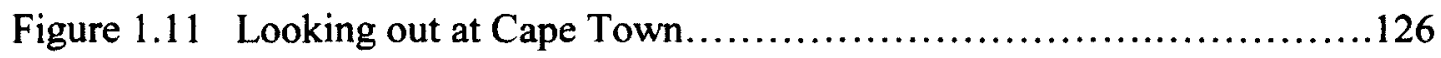




\section{List of Appendices}

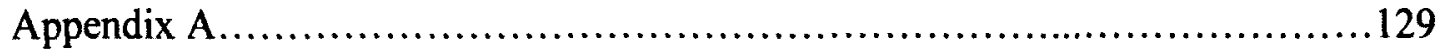

A.1 Voluntourist Early Trip Interview Questions.........................129

A.2 Voluntourist Late Trip/ Post-Trip Interview Questions................129

A.3 For Individuals from the Sending Organization/ Project Partners.....130 


\section{Chapter: Introduction}

When I landed at the Cape Town airport, I was jetlagged from my long flight from Ottawa, Ontario. Luckily, the voluntourism organization had arranged to pick me up at the airport and drive me to our accommodations. This small detail helped to reassure me that I would settle into this experience. During the drive from the airport to the accommodations, I was shocked by the discrepancy in housing around Cape Town. On one side of the road, I saw expensive-looking homes with gardens and swimming pools, surrounded by fences. Meanwhile, on the other side of the road was a township with houses closely packed together made from storage containers and corrugated metal sheets. I found this juxtaposition strange and rather alarming. When I was in Peru for a previous voluntourism trip, I was exposed to families living in impoverished conditions, but I had only worked in this community for one day and had spent most of the time in a school in Cusco. For this trip, my volunteering placement was within the townships for the full two weeks I was in Cape Town and I was unsure what to expect.

Voluntourism combines the volunteer and tourism sectors. It involves individuals travelling overseas while also completing short-term volunteer work. This intersection constructs an ambiguous role for individuals because they are simultaneously a tourist and a volunteer within the host community; it also emphasizes the inherent contradictions of voluntourism. It creates complex expectations, because the voluntourists intend to "make a difference" while also exploring a new culture. People, especially youth, are motivated by voluntourism's represented benefits for giving back, self-discovery, connections with others, and life experience, as well as its structured format because it 
offers a "safe" way to explore other cultures. In spite of these benefits, voluntourism may also have negative implications. It may be exploitative in developing countries because it only requires a short-term involvement and is linked to tourism. As well, some sending organizations focus on increasing the company's profit rather than the sustainability of the project. Thus, while individuals are involved in this experience, they must navigate the contradictory aspects of their experience, as well as the multiple implications of voluntourism.

My research explores how individual voluntourists perceive their engagement with voluntourism, and how they frame their involvement in a contradictory experience. Specifically, I looked at how individual voluntourists are embedded within voluntourism, their motivations for participation, their sense of agency in their involvement, and how this fits within the larger framework of the voluntourism project. Voluntourism offers the perceived opportunity for Westerners to respond individually to global injustices in a controlled encounter. For my research, I focused on one group of people travelling to Cape Town with International Voluntourism ${ }^{1}$ from 28 July 2012 to 11 August 2012. These individuals completed volunteer work in townships outside Cape Town, while also visiting typical tourist sites. I centered my research on the voluntourists' narratives of their experiences, which I intersected with participant-observation, a content analysis of the organization's website and training manuals, interviews with individuals from the sending organization and project partners, and my personal experience, as a way to analyze the perceptions of voluntourism.

\footnotetext{
${ }^{1}$ The organization name and all study participants' names have been changed to protect their identities.
} 
My thesis research has been guided by several research questions surrounding voluntourism, which framed my fieldwork and interpretation of my interviews and research journals. I considered the following questions: How do individuals who choose to engage in voluntourism perceive their role(s) within it? How do they frame their involvement and their perception of voluntourism? How do they represent themselves as "giving back"? How do voluntourists represent themselves as experiencing a shift in perspective based on their experience? How do they describe this experience and its impact(s) on them? Do they emphasize this shift because the experience is informed by this expectation? Through my research, I also explored: What impact does a researcher have by being a co-voluntourist on the trip and working alongside her study participants? As well, since I was both a participant and observer while conducting research, I looked at how the ambiguity of voluntourism relates to the ambiguity of the anthropologist as a participant-observer.

In my research, I engaged with individuals' experiences by discussing voluntourism through phenomenological and exchange theory lenses. Specifically, I used Alfred Schutz' concept of the life-world to look at how voluntourism may inspire a shift in being-in-the-world based on a person's novel experience, which comes up against prior knowledge. I also incorporate exchange theory by focusing on Marcel Mauss's concept of the gift. This helps deconstruct how individuals may frame their experience in voluntourism as a gift. I examined International Voluntourism's rhetoric on its website and in its training manuals to look at how its self-representation provides a framework for the voluntourists to interpret their experiences. I also explored my role as a researcher on a voluntourism trip alongside my study participants, and how this affects my perception 
of the research topic through my personal practice. By adopting these lenses, I examined how individuals view how they are embedded within voluntourism.

\subsection{Why Study Voluntourism Anthropologically?}

Through my thesis research, I hope to contribute to the body of anthropological knowledge by exploring voluntourism and how an individual is embedded within this complex, and often contradictory, experience. I go beyond the existing literature, using Kevin Lyons and Stephen Wearing's (2012) theoretical discussions of the definitions of voluntourism as a starting point. I use this to explore how voluntourists describe their ambiguous role through narratives, which I complement with my involvement on the trip. This is different from prior literature on voluntourism, which tends to focus on larger surveys or interviews without participant-observation. My involvement differentiates my work because I related to my study participants' experiences, being a voluntourist myself, and have insights into the role of ambiguity. I addressed the cross-cultural engagement in voluntourism and how individual voluntourists perceive their roles, the country they work with, and the consequences of their participation. I also looked at how this experience is positioned within people's lives and how it impacts their being-in-the-world. My research focuses primarily on individual voluntourists and how they perceive their experience; however, I also considered the larger context of the organization, host community, and voluntourism in general, in order to situate individuals.

My project also adds to prior theoretical examinations of voluntourism. I explored Alexandra Coghlan and David Fennell's (2009) discussion of altruism as a basis of voluntourism; I also looked at Alexandra Coglan and Margaret Gooch's (2011) analysis 
of volunteer tourism as a transformative learning framework. I used this research as a foundation and expanded on it by providing narrative insight into how individuals navigate through voluntourism's ethical implications and exploring how they perceived their experience. I distinguished my work by going on the voluntourism trip and participating with my study participants in a study-beside or participant-observation ethnographic method, rather than studying up or studying down. By including my experiences of voluntourism, I provided my insights and developed rapport with study participants through shared activities. Most of the research on voluntourism does not include participant-observation, which may limit the scope of the research. By adopting this strategy, I explored different aspects of voluntourism, especially since I am relatively of the same age and gender demographic as the typical voluntourist.

\subsection{Research Context}

While voluntourism as a commodified and wide-spread global practice is fairly new, it has its roots in previous forms of volunteering abroad, such as the Peace Corps and organizations like Doctors Without Borders. According to Angela Benson, there has been a long association between volunteering and travel since "...the nineteenth century when missionaries, doctors and teachers travelled to aid others; it is more recent that volunteer tourism has become a global phenomenon with future market predictions indicating growth both in size and value" (2011: 1). These past links to colonialism, as well as the predicted growth of voluntourism, establish it as an important site for further study in order to understand its implications for participants, host communities, and how it frames relationships between cultures. 
I analyzed individuals' narratives about their experience through interviews while I was on the trip, as well as conducting interviews with the sending organization staff and project partners. By focusing on one group, with whom I volunteered, and the individuals who worked with them during the experience, I hoped to gain insight into the perceptions of voluntourism from my interpretation of the voluntourists' self-representation. It is important to analyze the narratives of individuals who experience voluntourism in order to unpack their perceptions and self-representation of the experience, as well as those with whom they work. This may help to provide insight and a sense of understanding of the voluntourism experience and its implications in the host community.

I selected South Africa as a site due to the high prevalence of voluntourism organizations who offer projects in this location. According to Voluntourism.org, South Africa is one of the top growing destination choices for voluntourists. I would argue that this is due to a variety of factors, which I discovered in my fieldwork. South Africa is a desirable location because its main language is English, much like most of the United Kingdom, Australia, and North America, which makes working on projects easier since many of the participants come from these areas. Additionally, since it is located in Africa, it is depicted as exotic and far away by sending organizations, while also being framed as requiring development work due to the end of apartheid and the existence of townships. As well, Cape Town in particular is touted for its natural beauty and tourist locales, which supplement the voluntourists' experiences. The combination of these features makes South Africa an appealing site for voluntourists. 


\subsection{My Voluntourism Field Site}

In my research, I narrowed my focus to what Brown refers to as the "vacationminded voluntourist" (2005: 981). This refers to short-term voluntourism. However, International Voluntourism represents itself in its literature as providing an experience that is volunteer-minded, due to the structure of their programs (which occur in countries in Africa, Asia, Oceania, and Central/South America, while offering different focuses, such a wildlife preservation, working with children, and construction projects), their focus on sustainability, and their relationship with the project partners in the townships. They are also a fairly large organization, claiming to have sent more than 10000 voluntourists overseas since they began their projects. The trips Brown describes provide an interesting intersection of volunteering and tourism due to its relatively shorter time commitment. According to Guttentag, volunteer tourism often has individuals participate for under one month (2009:539). While longer-term programs have the potential for a larger positive impact, I was interested in shorter trips because it highlights the inherent contradictions of voluntourism. It also enhances the ambiguity of voluntourism because it is often framed by sending organizations as primarily tourist-centered with aspects of volunteering in development-style projects. This focus provided an interesting basis for exploring perceptions of voluntourism.

My field site was based on the short-term voluntourist experience of a group of individuals who travelled to Cape Town with International Voluntourism. I also included some aspects of my journal when I travelled to Cusco, Peru in June 2007 with Culture Travel; however, I did this prior to studying Anthropology and not as part of my formal research. The bulk of my fieldwork was based on my interviews, field notes, reflective 
journal, and participant-observation from 28 July 2012 to 11 August 2012 in Cape Town. During the fieldwork, my study participants and I lived near Cape Town and volunteered in a nearby township.

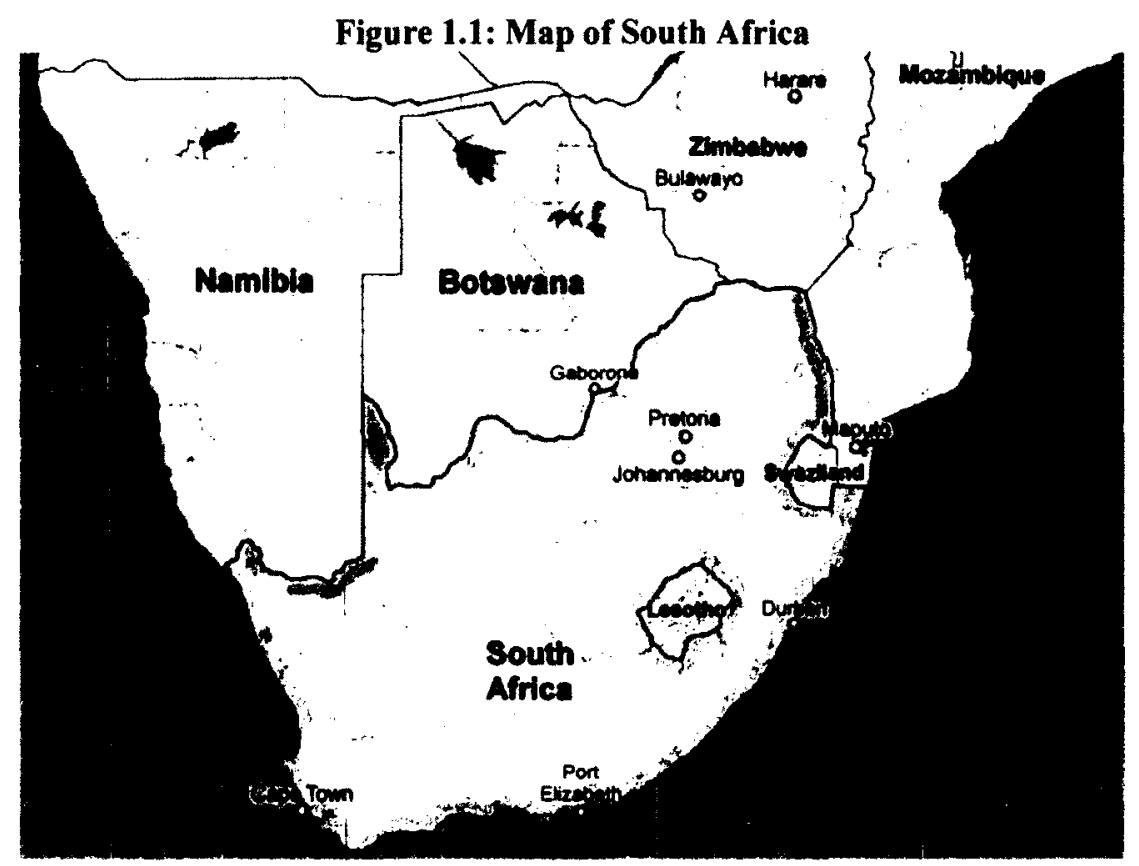

Source: Google Maps

For the duration of the trip, we, that is the voluntourists, lived in a fairly nice home (electricity, internet access, a television to watch movies, a cleaning/cooking prep staff member, and hot, running water), which was located in a predominantly middleclass, suburb. In the house, the volunteers had shared bedrooms with bunk beds, a large table for a "family-style" dinner (we also planned lessons at this table), and an open common area where we often went to relax to watch films or read. The project coordinator, Katie (Canadian), lived in a small one-room "shed" in the backyard so she was close to the volunteers, but also had her own space; she spent most of her time during the day in the main house, either hanging out or lesson planning. The project manager for the townships, John (English), lived in the company house about a fifteen minute walk 
away, while the program manager, Sarah (English), lived off-site. This meant that the voluntourists felt the staff from International Voluntourism was very involved, especially since they went with us to the projects. We were driven to our project sites in the township by another staff member, Mark (South African), from Monday to Friday. The people in the township were predominantly impoverished, Xhosa-speaking, black South Africans, which was a shocking contrast to our living environment.

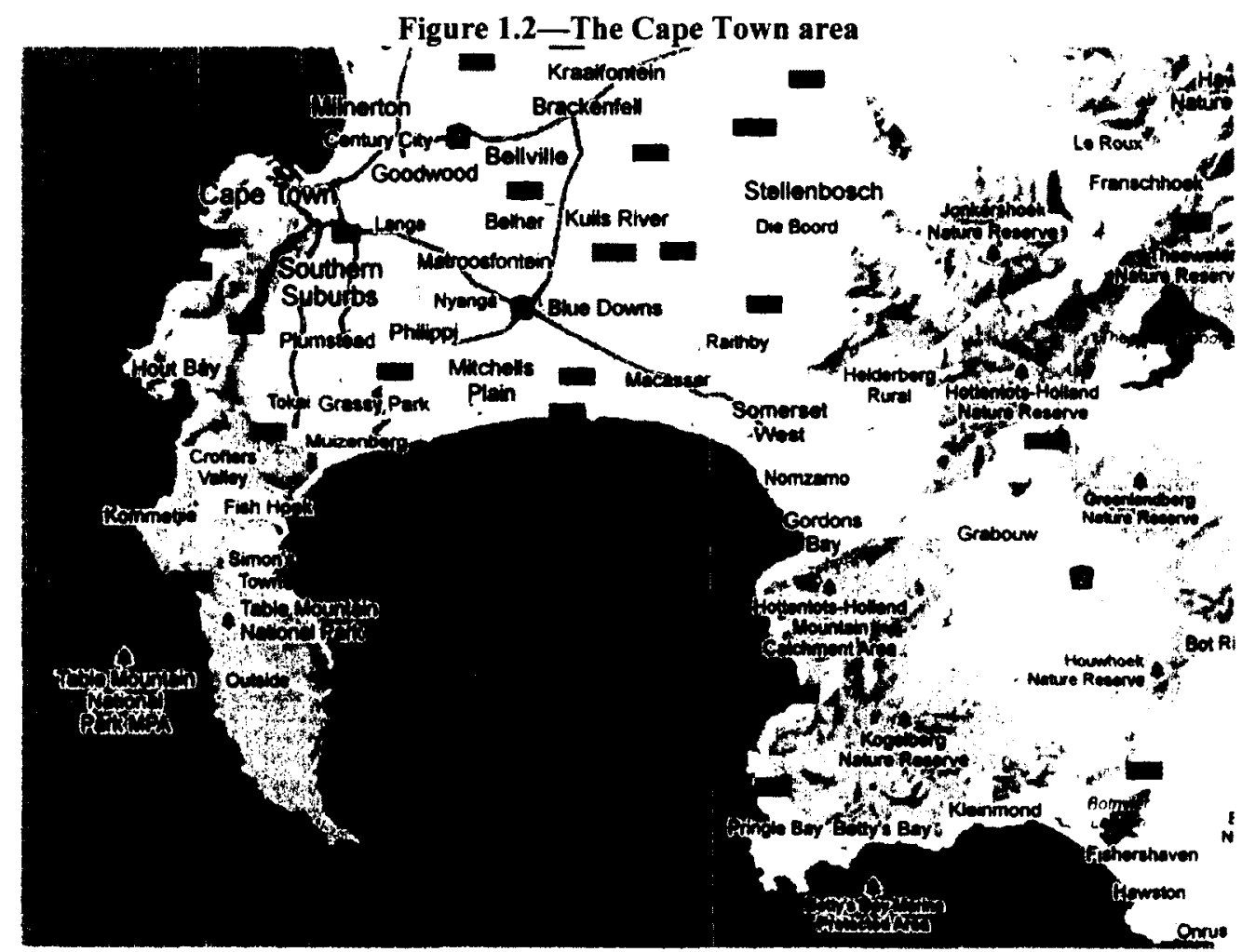

Source: Google Maps

International Voluntourism has several project sites in Cape Town, based on their project partners' needs in the townships, as well as the voluntourists' assets and skills.

During my time, the volunteers worked in two separate townships with multiple projects in each township. Most of the projects involved working with children, either through being a teaching assistant in a nursery school, tutoring school children, assisting a school's sports program, instructing teachers and children with healthcare projects (such 
as hand washing and teeth brushing techniques) or assisting at an orphanage. According to Sarah, the projects fulfill the partners' needs, but one of the main focuses of these projects is to teach English because it is the main language of instruction at the schools. Having native English speakers work with the children helps the Xhosa-speaking children improve their skills, which benefits them by making learning more accessible.

While the volunteers teaching English to the Xhosa-speaking children in the townships may be perceived as a form of neo-colonialism, it is a complex issue because it does benefit the children in school. I will explore the socio-political context of South Africa and the implications of English school instruction in Chapter 3 of this thesis. During my fieldwork, Angela (South African), the woman who owned and ran the nursery school I volunteered at in Cape Town, told me that volunteers are critical for the children to interact with native English speakers and improve their language skills so they could do well in school and eventually get a good job. Although this does not address the systemic issues of school instruction being in English rather than Xhosa, it does support the need for English-speaking volunteers within the townships.

In addition to the home we lived in by Cape Town and the volunteer projects in the townships, another field site was the tourist sites around Cape Town. During my two weekends while I was in South Africa, I travelled to various destinations with the other volunteers, such as Boulder's Beach, the Cape of Good Hope, Cape Point, Table Mountain, Long Street in Cape Town, and we attempted to do a safari (which was cancelled due to inclement weather). These provided additional insight into the volunteers' perspectives because it gave us the opportunity to talk in a more informal setting and to talk frankly about our reasons for participating on the trips. 
As an aside, approximately two weeks after I returned to Ottawa from my voluntourism trip to Cape Town, International Voluntourism ended their project partnership in the township in which I had worked. The organization claimed this was due to a lack of consistent volunteers for this specific program, as well as completing the project aims, which eventually required them to leave the project as a form of sustainability so the partner was able to continue new styles of teaching without support. By leaving the project, it ended the children's regular interaction with native English speakers since the nursery schools did not have the resources to continue this activity. This complicated International Voluntourism's original claim that they leave the projects as a form of sustainability, since English language instruction was not continued.

\subsection{Introducing the Voluntourists}

The voluntourists I interviewed had many similar traits, such as being 20something-year-old, female university students, self-describing as being socially aware, and interested in travel; they also had individual characteristics that made their perceptions of their experiences distinct. For example, prior experience travelling overseas, where an individual was born, the university program of study, prior volunteer experience, and expectations for the trip shaped the details of how the voluntourist represented her involvement.

The two travelers who came to Cape Town without friends from their home were Megan and Emilie. Megan was a 24-year-old woman from Wales who was studying History. She had volunteered with International Voluntourism the previous summer and said she enjoyed her experiences with the kids so much, she felt she had to return. While 
she does not volunteer back home in Wales, she was motivated to work overseas after a switch in school programs. Megan felt her transfer from nursing to history limited her impact on people and it was selfish, so she decided to volunteer overseas after her first year in history. She felt drawn towards Cape Town and working with children, but could not pinpoint an exact reason. Emilie also came to Cape Town by herself. She was 21 years old and from Belgium and was going to commence her Master's degree in Psychology after her trip. She had participated in volunteer work in Belgium, in particular, coordinating girls' scouts programs and working with youth. Emilie was very clear about her reasons for volunteering with International Voluntourism; she wanted to be immersed in English to improve her second language, she studies child psychology so this would be good practice for her future work, and she wanted to discover South Africa. While she was overseas, Emilie had some family troubles, but instead of going home early, she focused on her volunteering to get her through the turmoil.

On the voluntourism trip, there were also some individuals who decided to go abroad with friends. Colleen and Kerry both were aged 21, studied Dentistry in Ireland, and decided to volunteer in Cape Town together instead of inter-railing through Europe. Colleen is from Northern Ireland and had done a significant amount of volunteer work with individuals with special needs, such as hospice work and with her church. She had decided to go on this trip because she wanted to see the world from a new perspective, she had wanted to travel, and since dentistry is a caring profession, she felt it will help her future career. Kerry is from the Republic of Ireland; however, she was born and spent her early years in Zimbabwe. She had wanted to do something "big" during her short 8week summer break and her cousins' experience with voluntourism inspired her to 
explore this option. Kerry felt she had to come to volunteer in Africa because "it is in her bones" and she has had experience being in townships. She explained the voluntourism trip as a way to get back in touch with her roots in Africa, which she was forced to leave when her family returned to Ireland. Colleen and Kerry decided to travel together because they said they know they get along and that they both wanted to volunteer abroad.

Shaina, Sasha, and Hillary, three 19-year-old friends from Scotland, also travelled to Cape Town together to volunteer with International Voluntourism. Shaina and Sasha both study social work, while Hillary studies Psychology. These three women had been friends since kindergarten and had decided to volunteer abroad together because of their future career goals of working with children and a general interest in travel. All three noted that they were concerned that coming as a group of three may make them less approachable and appear inseparable, so they deliberately tried to spend time separate from each other as well. Shaina said she wanted to go on this trip because she wanted to volunteer, travel, and down the road say she had "done this," because she had only been on standard beach-style trips. Meanwhile, Sasha had studied South African socio-political history in school and had been interested in travelling to see the country, while also "giving back." Hillary was interested in the trip because of her experience working with children. These three friends also fundraised together to help reduce the cost of the trip. As these brief biographies highlight, although the seven voluntourists I interviewed have backgrounds that are slightly different, they have similar personal goals, are from Western countries, attend university, and decided to volunteer in Cape Town. This emphasizes that voluntourism seems to attract a similar type of person. According to both John and Sarah, who had worked with International Voluntourism for 
several years and had seen many cycles of voluntourists, the majority of people who come overseas are female. They explained that approximately $80-90 \%$ of voluntourists in the childcare programs are women and that males do not typically choose to work with small children. John said that although he started as a volunteer for the childcare program, he noted that most males seem to prefer working with the sports program, but most of the voluntourists in general are women. This was reaffirmed by my experience, where all the volunteers at my program site were female. Arguably, this could be because of gendered notions of labour, where women are depicted as more nurturing toward young children; however, according to Wearing (2001), it could also be because the structured nature of voluntourism makes it more appealing to younger women while men may choose a more adventurous style of trip.

In addition to the gendered aspect of voluntourism, since it typically costs upwards of $\$ 1500(\mathrm{CAD})$ for a two-week trip, plus a flight, it also attracts people with disposable income who can afford the high cost. While I did not explicitly discuss this with the voluntourists I interviewed, most of them noted that they did some fundraising to help pay for the cost of the trip. Based on my literature review and fieldwork, I noticed that the majority of voluntourists come from a similar demographic as I do (Western female, approximately 20-something, who has additional money for leisure), which made the group I interviewed a relatively typical voluntourist group.

The voluntourists' specific background impacted their perception of their trips, as well as how they represented their rationale for their involvement with International Voluntourism. Although there were many similarities between the voluntourists, they all attempted to individualize their motivations for coming to Cape Town, even if they 
highlighted similar rationales. They all framed this experience as giving back, making a difference, and developing relationships with South Africans.

\subsection{Theoretical Framework}

In my research, I explored voluntourists' perceptions of their experience. In order to examine voluntourism's complexity, I focused on two theories to frame my thesis research, exchange theory and phenomenology. Specifically, I employed Marcel Mauss' concept of the gift and Alfred Schutz' life-world to interpret the voluntourists' experiences. These two theories complement each other by emphasizing the way the voluntourists self-represent their interpretation of their ambiguous experience in their roles as both a volunteer and tourist. Through describing their involvement as "giving back," the voluntourists are able to make sense of the shock and new perspective they may develop overseas by internalizing this discourse. By using these theories, I looked at what motivated these individuals to become involved in voluntourism, how they framed their involvement, and how this impacted their life.

An individual's involvement in voluntourism is motivated by several factors, which are personal and complex, but these motivations are also cultural and structured in typical ways, hence I can apply Mauss and Schutz' concepts. While there is arguably an aspect of altruism inherent in the desire to help others overseas, a more complex theoretical account might be found by applying exchange theory. The way voluntourists explain why they decided to go overseas is defined in relational terms, I would suggest, based on their perspective of themselves and the experience, as well as its perceived benefits and costs. Typically, the benefits must outweigh any costs; however, what is 
defined as a cost or benefit is dependent on the individual (Pancer et al. 2007: 19). Although the relationship between these costs and benefits vary, they all contribute to why a person would participate in voluntourism. The individual must view these benefits as a worthwhile time commitment which outweighs any potential costs. Thus, individuals themselves portray their experience in terms of an exchange, wherein they gain through their involvement in the activity.

The most relevant aspect of exchange theory that pertains to voluntourism is Mauss' concept of the gift because it is often described by voluntourists as "giving back" to underdeveloped countries. This frames voluntourism as a gift of time and free labour to overseas host communities. Yet, it also masks the asymmetry of exchange between the privileged Westerner and the host community. Mauss explains that even something as seemingly selfless as a gift is rooted in obligation and self-interest, while also containing a total social fact or part of the giver. In The Gift, Mauss argues about aspects of gifts:

which are in theory voluntary, disinterested and spontaneous, but are in fact all obligatory and interested. The form usually taken is that of the gift generously offered; but the accompanying behavior is formal pretense and social deception, while the transaction itself is based on obligation and economic self-interest (1974: 1).

Although Mauss is referring to gift economies in non-Western countries, this is also applicable to Westerners going overseas to help those they perceive of as "in need." While individuals are engaged on the trip, the relationship can be analyzed through the concept of the gift as the individual gives her time and money, while developing a bond with the recipient through the gift's total social fact. It is given as an inalienable gift that inextricably ties the voluntourist to those whom she gives the gift. 
In the context of voluntourism, exchange is not simply a matter of two individuals swapping goods or services-it is much more complex. In The Gift, Mauss explains the gift as a total social fact that encompasses the whole social existences of those involved (1974: 80). While Jonathan Parry (1986) does not explore voluntourism specifically in "The Gift, The Indian Gift, and the 'Indian Gift,"” his description of the idealized gift can be applied here. Using Parry's analysis of the gift, the exchanges in voluntourism are often framed by the voluntourists as: "essentially dyadic transactions between selfinterested individuals, and as premised on some kind of balance" (1986: 454). In this framework, voluntourists give their money to pay for the trip, time to go on the trip, and energy while on the trip to complete the mini development projects. Although they may not expect a physical return, in spite of their paying to participate in the experience, there is a sense of balance and an investment in the experience due to the bond between the giver and recipient. This sense of balance can be perceived in several different regards, such as a sense of personal fulfillment, a moral obligation, experience for a future career, or even generalized reciprocity, as well as a a relationship or bond with those whom they help. Yet this balance, premised on the wording of voluntourism as "giving back," also masks the inequality of the exchange between the voluntourist and the host community.

By analyzing voluntourists' motivations for involvement through the theoretical lens of Mauss' gift, the rationale they have regarding their experience is highlighted. The people who participate in this form of volunteering are typically inspired to work overseas because of several types of benefits, such as feelings of moral obligation to individuals perceived to be in need or a future benefit related to educational or career goals. Exchange theory can frame what motivates someone to become involved in 
overseas volunteer work, such as "giving back," "making a difference" or developing a bond with those whom she helps. The experience affects people in their whole being because it is a total social fact; it is not simply a rational calculation of concrete costs versus benefits, but a bond between the two groups based on the gift given. Yet, it is important to note, since the voluntourists initiates the exchange by going overseas, it is not a bidirectional bond because the voluntourist is in a position of relative power.

While the motivations of voluntourism may be explored through the gift, this does not entirely account for its impact on the individual and how she perceives of her involvement. By also adopting a phenomenological approach, I investigated voluntourism as a mode of experience/experiential process and how it affects their beingin-the-world. Specifically, I utilized Schutz' concept of the life-world to look at how voluntourism may inspire a shift in being-in-the-world based on a person's novel experience, which comes up against prior knowledge. Often individuals' voluntourism trip is their first time going overseas to a developing country, which means it may affect their prior knowledge about the world. This may mean that the voluntourists experience a shift in their life-world based on the new experience of volunteering and engaging with a different culture. While this shift is not an absolute fact, since voluntourism may create cynical feelings or create further confusion, how an individual represents her experience still provides a framework to interpret her perceptions abroad.

According to Schutz in Structures of the Life-World, individuals' taken-forgranted daily life is called their life-world. He explains that: "The everyday life-world is the region of reality in which man [sic] can engage himself and which he can change while he operates in it by means of his animate organism" (Schutz and Luckmann 1973: 
3). This could be used to explain how individuals are situated within their everyday experience prior to their involvement on a voluntourism trip. By undertaking this kind of trip, the everyday life-world is disrupted. As Schutz describes: "In the natural attitude, I only become aware of the deficient tone of my stock of knowledge if a novel experience does not fit into what has up until now been taken as the taken-for-granted valid reference scheme" (1973: 8). When individuals' new experience does not fit a previously held "taken for granted" life-world, they are forced to re-evaluate it.

Re-evaluating their perceptions in the light of their experiences in voluntourism, may cause voluntourists to change their perspective. Thus, when faced with a disruption in one's life-world, individuals must re-evaluate:

What has until then been taken for granted is in consequence brought into question. The reality of the life-world demands of me, so to speak, the reexplication of my experience and interrupts the course of the chain of selfevidency (Schutz and Luckmann 1973: 11).

While this may not describe all the aspects of voluntourists' involvement, the concept of the life-world does provide a framework to understand changes that may occur as a result of people's experiences. They must break down aspects of their involvement and attempt to make it feel natural by reconstructing their perception of their life-world through integrating their new knowledge; this may create contradictions and tensions when these perceptions do not combine easily, which highlight the ambiguous experience of voluntourism. Through applying the concepts of "the gift" and the "lifeworld," I hope to provide a means of access to the highly personal and complex experience of voluntourism and how a person is impacted by it. 


\subsection{Overview of Chapters}

This thesis is divided into seven chapters. This chapter has provided an introduction to voluntourism, addressed the question of why one might want to study voluntourism anthropologically, described the research context, and given an overview of my field site and where the study participants worked, as well as the theoretical framework. It creates a basis for understanding the rest of the project. In Chapter Two, I outline my research methodology and explore my experience as a researcher participating on a voluntourism trip. I begin by analyzing my role as an anthropologist-voluntourist and its effects on my research. Then, I briefly look at my past experience as a voluntourist in Cusco, Peru and how it framed my understanding of voluntourism. I compare this to my recent voluntourist experience to Cape Town, South Africa and how it affected me in my research. Through this, I provide insight into how I approached my fieldwork and my analysis of voluntourism.

Chapter Three provides an overview of voluntourism, including a working definition, which I use as a basis, and explores the morality of voluntourism. The focus on the morality of volunteer tourism is because it occupies a complex, and often contradictory, role that has both positive and negative features, but is ultimately ambiguous. In addition, I discuss the different focuses of VOLUNtourism versus volunTOURISM and how this shapes the nature of an individual's experience. I also examine the socio-political history of South Africa, especially in the shadow of apartheid, and how voluntourists know what they are going into, which affects their experience. This provides the larger context of voluntourism, insight into previous research, and an 
understanding of the field site in South Africa, which contextualizes the voluntourists' narratives in later chapters.

In Chapter Four, I conduct a content analysis of International Voluntourism's website, training manuals, and staff interviews. By doing this, I look at its selfrepresentation, which may provide a framework for how the participants interpret their experience. This focuses on the organization's self-representation and their use of photographs to entice potential voluntourists. I unpack their use of key terms in order to look at the reciprocal expectations of the organization and voluntourist, as well as perceptions of overseas volunteering. Through this examination, I also highlight how the organization's rhetoric glosses over the inherent ambiguities of voluntourism and attempts to reconcile these contradictions by using "feel good" terminology.

Throughout Chapter Five, I look at how the voluntourists frame their experiences as giving a gift by adopting Mauss' concept of the gift, focusing on their use of terms such as "making a difference" and "giving back." I use this to examine voluntourism as involving a total social fact. I discuss voluntourists' experiences by triangulating information gathered from interviews/personal narratives, participant observation, and literature on voluntourism. In particular, I examine how the voluntourists discuss the relationships formed overseas, as well as the cultural exchange that they describe as occurring on the trip.

In order to create further depth of analysis, I use a phenomenological framework to explore my fieldwork in Chapter Six. I incorporate Schutz' concept of the life-world to look at how voluntourists represent themselves by describing a possible shift in perspective, especially when entering the townships for the first time and interacting with 
individuals in the projects. In addition to this shift, I also look at voluntourism as being explained as an indescribable experience and that you "have to be there" to understand because the experience affects their perspective. This explores the impact of voluntourism on the individual, as well as how they describe their involvement.

In closing, Chapter Seven provides my conclusion that voluntourism forges an ambiguous understanding of a culture because it combines tourism and volunteering, thereby introducing contradictory aspects into individuals' experiences. Through their involvement, the voluntourists intersect their tourism experiences in Cape Town and their volunteer experiences in the township. While International Voluntourism claims this combination provides voluntourists with better insight, personal growth, and experience, it may create further confusion for an individual. This is because voluntourism is rife with positive and negative implications and multiple roles for the individuals involved in the process. 


\section{Chapter: Methodology: Phenomenology, Reflexivity and the Anthropologist as Voluntourist}

My last night in Cape Town, when we were all preparing to fly home, we watched a touching slideshow of all the photographs International Voluntourism had prepared to thank us for our hard work and "making a difference" at the projects. Several of the voluntourists cried and said they would miss the project partners and the children with whom they worked. Afterwards, when the staff had left and only the voluntourists remained in the main room to talk, the topic moved towards the no-photo policy. Several of the other voluntourists explained their frustration that they could not take pictures to show people back home "what is was like" or that they did not have a picture of them with their "favourite" child. One voluntourist noted that several photos she remembered being taken were not in the slideshow, which meant there may be a stash of all the photographs and that there had to be a way to get these from the staff.

During this moment, I felt an internal conflict. I sympathized with their

frustrations about the lack of photographs, but also appreciated the organization's photo policy. It also made me feel as though the tourist aspect of the trip contradicted the volunteering because these individuals expected to get photographs to bring home, like from any other type of trip. I became unsure about my role in this moment because as a voluntourist, I could understand why they wanted the pictures, but as an anthropologist, I had to register that they were focusing on this commodified aspect of the experience. 


\subsection{Methodology}

Since individuals' perceptions of volunteer tourism are complex, I used a multimethod qualitative approach to collect my research data. I incorporated participantobservation while on my voluntourism trip, content analysis of International Voluntourism's training manuals and website, and interviews with fellow voluntourists, International Voluntourism staff, and project partners in order to explore the topic. In addition, I used my own voluntourist journals as data sources. I maintained a journal of my personal experience and my research to unpack relevant issues and examine my own perspective of the trip. I also used my previous journal from my past experience as a voluntourist to Cusco, Peru with Culture Travel in conjunction with my fieldwork experience in Cape Town, South Africa with International Voluntourism to look at voluntourism experiences comparatively. Through using a multi-method qualitative approach, I explored how an individual experiences the ambiguity of voluntourism.

I chose to go on a two-week voluntourism trip because this is a relatively typical trip length. While longer fieldwork would provide more in-depth analysis and a larger range of individuals to interview, most of the people I volunteered with were only in South Africa for two weeks, so it would not have increased rapport significantly. I attempted to contact my co-voluntourists prior to the trip and conduct follow-up interviews, but was limited by their availability and willingness to respond. In addition, to support my fieldwork, I interviewed International Voluntourism staff and project staff in order to situate my study participants within the organization. This provided context for my two weeks of voluntourism fieldwork in Cape Town. 
To research volunteer tourism experientially involves following individuals from their home country to their overseas destinations and back, while also looking at the context of the country, sending organization, and project partners. This enhances its complexity as a topic because it creates multiple sites. Since my research aims at integrating the perspectives of the voluntourists, the International Voluntourism staff and project partners' perceptions of voluntourism, my personal experiences, and the sociopolitical context of South Africa, I was drawn to George Marcus' concept of multi-sited fieldwork, which:

...is designed around chains, paths, threads, conjunctions, or juxtapositions of locations in which the ethnographer establishes some form of literal, physical presence, with an explicit, posited logic of association or connection among sites that in fact defines the argument of the ethnography (1995: 105).

Thus, my "site" is the international journey of voluntourism. Through having several field sites, which followed the journeys of my fellow voluntourists, I was able to explore both the volunteer and tourism aspects of my study participants' experiences. This helped me to gain insight into their perspectives and how they framed this experience and its impacts on their life. While my project only provides one perspective on the reality of voluntourism, I argue that it provides a realistic image of voluntourism as experience because I mirrored my study participants' trips.

The majority of my analysis will focus on one group of individuals travelling to Cape Town, South Africa to volunteer through the sending organization, International Voluntourism. This trip took place 28 July 2012 to 11 August 2012 and included volunteering in a nursery school Monday to Friday from $9 \mathrm{am}$ until $4 \mathrm{pm}$, as well as tourist excursions on weekends. I was involved on this trip in all typical voluntourist capacities 
in order to conduct participant-observation and develop rapport with my study participants. In this role, I would describe myself as an active participant because I was involved in experiences similar to the study participants, but I attempted to maintain a critical distance to observe the experience. Through completing a two-week voluntourism trip for my participant-observation, I negotiated how the aspects of tourism and volunteering intersected, as well as its implications for the study participants, by looking at how individuals perceived of the experience.

To recruit my study participants, I asked International Voluntourism to send a letter on my behalf requesting participants for my research project (because of confidentiality issues, I was not allowed access to the list of potential participants directly). These were directed toward voluntourists from the time period I was signed up for and the Cape Town staff from the sending organization. However, this recruitment strategy did not go as planned. I was unable to conduct pre-trip interviews because most of the individuals either did not receive the email or left it in their inbox to "deal with it" later. Additionally, most of the staff members I interviewed were unaware of my research project. This created some problems because I was unable to get a baseline of pre-trip concerns and perspectives to compare to interviews during and after the trip. To compensate for this, I modified my interview questions and conducted several interviews early in the trip before the voluntourists were able to settle into the environment. Another challenge I faced was getting post-trip interviews. Unfortunately, most of my study participants are university students, so upon their returns in mid-August, they had to begin preparing for the school year and seemed to get "lost" in school work. Thus, I was 
unable to conduct formal post-trip interviews on Skype and had to rely on informal emails to gauge how the voluntourists adjusted to their returns home.

While I was on the trip, I conducted individual semi-structured formal interviews with eight voluntourists, four International Voluntourism staff members, and three project partners in the townships. By keeping all the interviews semi-structured, I was able to ensure that the discussion was applicable to the study participant, yet still on topic. In my interviews I used a sample list of interview questions to prompt responses (see Appendix 1), dependent on each type of participant. I also recorded the interviews on a digital recorder and took notes. I tried to keep discussion conversational and build rapport. The group I formally interviewed was eight female university students, aged 1924 years old from Scotland, Ireland, Wales, and Belgium. In addition, I interviewed four International Voluntourism staff members, the female project coordinator (Canadian, 24), the male project coordinator (South African, 25), the male project manager at the townships (English, 26), and the female Cape Town program manager (English, 30), as well as three project partners from the townships (all female South African, 23 to 45). Through interviewing other voluntourists, the voluntourism organization staff, and the project partners in the township, I hoped to develop a more in-depth perspective and analysis of the voluntourism experience.

Since my research focuses on exploring voluntourists' perspectives of their experiences in Cape Town, as well as how they navigate its ambiguous aspects, I chose to use phenomenology as a theoretical framework. In particular, I used Schutz' concept of the life-world to analyze my research, which I will look at more closely in Chapter Six. I used phenomenology to examine how the voluntourists may describe a shift in 
perspective due to experiencing a novel situation that challenged their prior world-view. My methodological approach to use the voluntourists' experiential narratives is compatible with this theory since it enabled me to explore the significance of the voluntourists' self-representation and how they stated the experience impacts them. By using Schutz' concept, I was able to access the highly personal perceptions of an individual's voluntourism experience by analyzing its structured conventions.

O'Reilly challenges me to think of my ethical responsibility and a way to give back to my informants (2008: 67). For my fieldwork, I obtained ongoing informed consent with my informants, kept responses confidential through the use of pseudonyms, modified the name of the sending organizations, and gave full disclosure about my research topic. I also intend to give back to the people I interviewed by providing a final report of my research findings, if they request it. Although this does not come close to compensating for the knowledge they offered, I hope it can provide a sense of reciprocity.

My literature review of journal articles and books guided my qualitative research and provided background information, which helped to focus my research on key themes, such as "making a difference" and "giving back." I also conducted a content analysis of International Voluntourism's website and training manuals to explore its self-presentation and proposed intentions. This helped demonstrate how it provided a framework for participants to interpret their experience, while also highlighting how the organization used specific rhetoric to smooth over any ambiguous aspects. My analysis of International Voluntourism's website and training manual was an important feature of my project because the voluntourists stated it was what initially enticed them to participate on the trip. As well, the key phrases the organization used, such as "giving back" and 
"making a difference," were echoed by the voluntourists, which showed its impact on their perceptions of their experience.

I integrated the literature review and content analysis of International Voluntourism's website and training manuals with questions I asked the voluntourists about their perceptions of the sending organization in order to interpret their representation. I utilized participant-observation, my photographs, and interviews to contextualize the data and provide an example of people's lived experiences with voluntourism. As well, in my research I did not simply look at the voluntourists' perspectives because this would only support one half of the story (Guttentag 2009: 540). Instead, I also interviewed individuals from the sending organization and the project partners in the townships in order to look at the larger context of the project within Cape Town. Through triangulating my various data, I believe that I gained a more in-depth analysis into the representations of the perceptions of voluntourism.

\subsection{The Anthropologist as Voluntourist}

While I conducted my fieldwork, I occupied an ambiguous role because I was both an observer conducting research and a voluntourist participating on the trip.

Throughout the trip I tried to maintain a critically reflective position and acknowledge the impact I may have on those whom I observed and interviewed. However, I also participated fully as a voluntourist in order to immerse myself in the experience, provide support at the nursery school and foster home, and develop rapport with my study participants. I kept a private joumal of my thoughts, feelings, and experiences in order to identify any challenges or concerns I faced, as well as to document my perception of the 
trip. As a piece of my methodology, I explored my role as an anthropologist-voluntourist. I also looked at my past voluntourist trip to Cusco, Peru in June 2007 and how it framed my understanding of voluntourism. I then compared this to my recent voluntourist experience to Cape Town, South Africa and how it affected my research.

One of the practices I adopted in my research is reflexivity and critical thinking in my ethnographic methodology. As Bob Scholte explains, I need to maintain a reflective and critical perspective in both my ethnographic writing and ethnological thinking in order to position myself within it and question my relationship to my research (1974: 438). However, as Scholte highlights, this should run parallel to, and not substitute for, the research itself; it should be used as a tool for enhancing an understanding of how knowledge is produced and shaped, as well as the researcher's role within it (Scholte 1974: 443). I did this when I explored my research practice, which situated me within my fieldwork, as well as highlighted my two perspectives-that of being on a voluntourism trip and that of conducting research. This was primarily focused on my journal notes while in the field, through which I can show how I navigated the messiness of voluntourism and show my struggles, as well as my emotional responses.

The main struggles I had while conducting my research was balancing my roles as both a peer and a researcher, as well as how to represent my study participants. This was especially difficult because I would spend all day working with the children and then spend all evening writing more field notes and interviewing; by conducting my research, I was unable to just "hang out." While I had a fairly good relationship with the other people in the house, it was noted that it felt strange when I held the individual interviews. At the beginning of most of the interviews, the study participant and I would joke about 
how "serious" this felt, giggle nervously, and then there would be an audible sigh as the tone changed from informal to more formal to answer the questions. Several of the participants told me that: "You already know everything about me," "I don't know if I'll answer your questions right," or "I have nothing special to say." I felt these statements emphasized the switch from peers to researcher and study participant because it changed our interactions by creating a power dynamic when I turned on the tape recorder. While analyzing my interviews and writing up my research, I also felt conflicted about how to best represent my study participants. While I attempted to describe their actions and feelings accurately, I feel I was impacted by my relationship with the staff, volunteers, and project partners in the township. In particular, since I became friends with the staff and other voluntourists due to living in the same house, it was difficult to analyze voluntourism critically and not just promote International Voluntourism. I became caught between being an academic researcher and wanting to make these individuals "look good." This realization meant I cannot distance my relationship to my study participants or ignore how my representation is based on my personal experiences. My interpretation of my research data is closely intertwined with my positionality as a young female university student researcher who is of a similar demographic and background as my voluntourist research participants. In order to begin examining my positionality as a researcher and how this impacted my fieldwork, I must look back at my first experiences with volunteer tourism. 


\subsubsection{The Cusco Experience}

Figure 1.3: Landing at the Cusco airport ${ }^{2}$
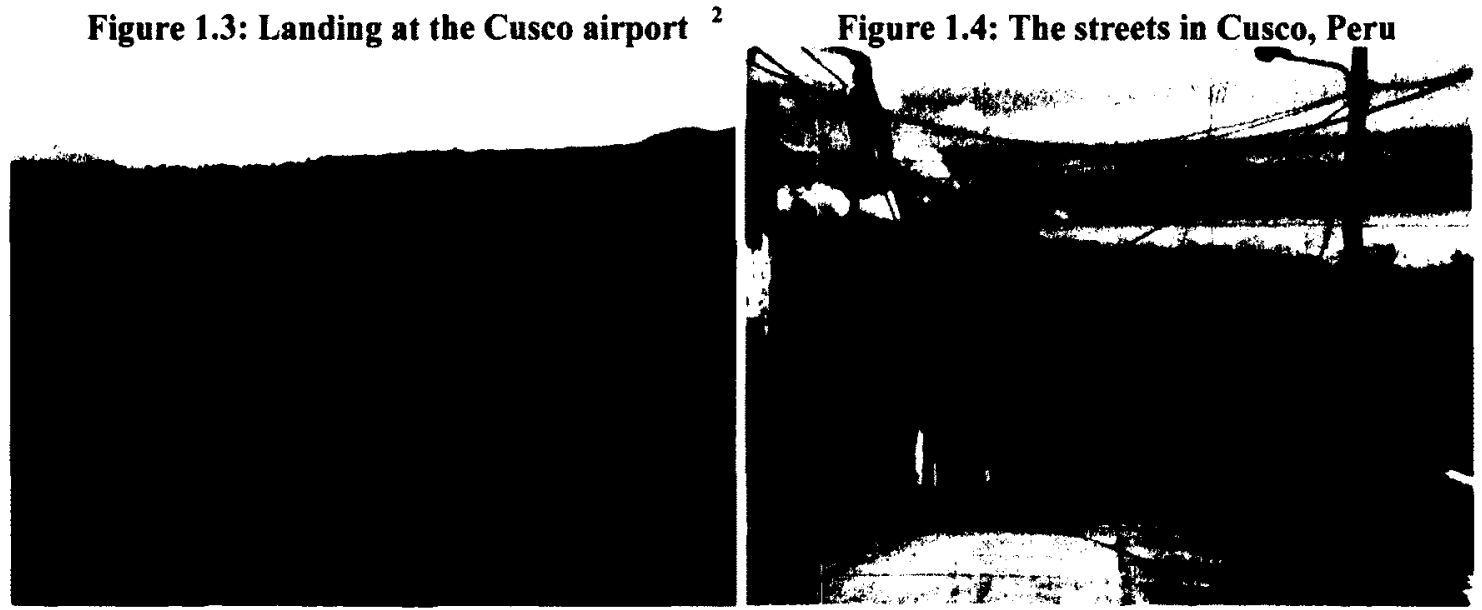

Source: Personal Photograph-June 22, 2007

Source: Personal Photograph-June 23, 2007

After the first year of my undergraduate degree, I decided I wanted to do

something I considered to be "big." I became interested in travelling overseas to spend time volunteering with those who I assumed to be less fortunate than myself. I discovered an organization, called Culture Travel, which facilitated overseas voluntourism. This appealed to me because $\mathrm{I}$ had not travelled by myself before and the company organized the trip, coordinated where I was staying, and set me up with the volunteer project. I was able to have a sense of security that the unknown realm I was exploring was relatively safe and it reassured my parents that their nineteen-year-old daughter would be in the experienced care of Culture Travel. After a great deal of deliberation, I decided to go to Cusco, Peru and help at a centre that housed rural children and orphaned children so they were able to attend school in Cusco. This was partially due to an interest in Peru, as well as a passion for teaching. During the one week trip, I helped repair the children's playground, built a stove and chimney at one of the children's homes in the rural Andes, visited Machu Picchu, as well as played Spanish-English games and explored Cusco with

\footnotetext{
${ }^{2}$ The picture locations are all left intentionally vague in order to maintain anonymity.
} 
the children. The organization's official statement declared that the focus of the trip was not simply to "give back" to the community, but also to teach voluntourists about global experiences and cultural awareness.

Figure 1.5: My visit to Machu Picchu

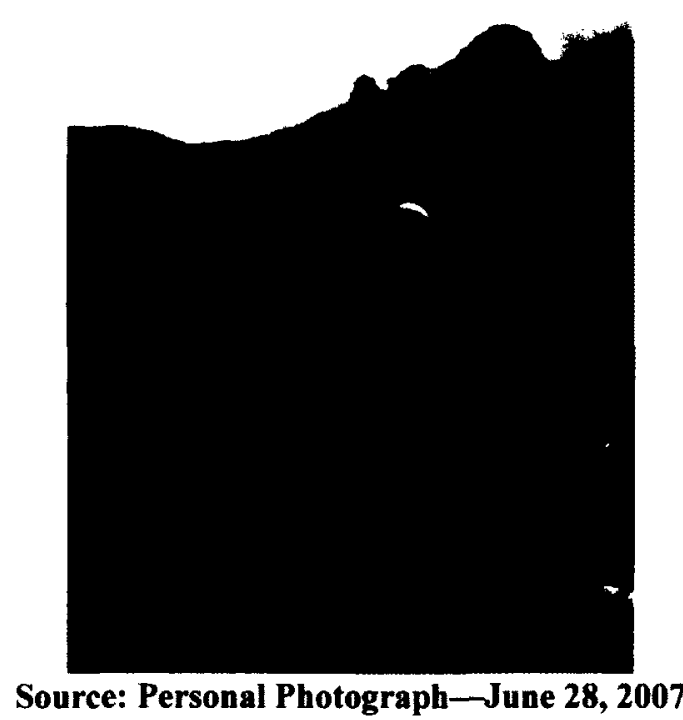

In my journal, I noted that my week-long voluntourism journey to Peru made a profound impression on me and I also felt I left a "positive impact" at the project. I met and helped children in Cusco, learned about Inca culture through watching the Inca Sun Ceremony, visited Machu Picchu, and generally described myself as immersed in Peruvian culture. Previously, I had not been on a trip on my own, nor had I experienced what life was like in a developing country. During this experience, I commented about how fortunate I was and how I felt I was "making a difference" through "giving back." By looking back at my experience, this seems naïve and uncritical, but it also provided an understanding of how voluntourists frame their experiences based on my personal example. I used similar language and phrases as the sending organizations, as well as the 
voluntourists I interviewed in Cape Town. By looking back at my past experiences, I was able to empathize with the voluntourists' statements.

My voluntourism trip seemed to me as exposing me to different ways of life in diverse cultural contexts and the shared sense of humanity within the world. I thoroughly enjoyed the intersection of touring around Peru to see places, such as Machu Picchu and Sacsayhuamán, as well as volunteering at the school. But these also emphasized the structural tensions of the experience; as I wrote in my journal, my motivation to get through a difficult day of building a clay stove in the Andes was that: “...I get to visit Machu Picchu tomorrow after an emotionally draining experience in a poor rural village." Yet I glossed over this contradiction, stating that my experience inspired me to switch my major to Anthropology and solidified my decision to go into teaching as a career. I also noted that I came away from this experience with a strong sense of attachment to the children I worked with in Peru, a better sense of myself, and a clearer focus for my future ${ }^{3}$. In addition, it seemed to me that I had a sense of fulfillment that I helped these children by bettering the center they lived in, as well as by creating a "relationship" with them. I gained the sense that I came away from my voluntourism trip experiencing a shift in my perspective through exposure to a different way of life.

\subsubsection{Going to Cape Town}

As a result of my prior exposure to voluntourism and upon further consideration of its implications, I decided to explore it as a research topic for my Master's thesis. I

\footnotetext{
${ }^{3}$ These journal entries were written while I was in Cusco, Peru and smoothed over the inherent structural tensions of my experience. Reflecting back, I did not maintain long-term connections with the orphanage or project partners. I also noted that the experience was developed in order to benefit the voluntourist by intersecting mini-development style work and tourist trips, rather than being development-centred.
} 
looked at various voluntourism organizations and locations, and finally selected International Voluntourism's teaching program in Cape Town. Since I already had a familiarity with the basic structure of voluntourism and I was going to conduct research, I would be going into this trip with a different perspective and a relatively more critical stance; yet, I acknowledged I would be impacted by my experience. It is important to reflect on my experiences in Cusco with Culture Travel because it framed my thesis fieldwork in Cape Town and my positionality as a researcher. For example, I felt I was relatively less shocked going into the townships because I had already volunteered in an impoverished area and I expected it would be a focus point in the volunteers' interviews. I also had an expectation of voluntourism being framed by participants and the organization as "making a difference" and "giving back." Additionally, I was aware of the contradictory intersection of the volunteer and tourism aspects of the experience. The fact that voluntourism was not a new experience thus affected my personal experience on the trip, my reflection of my past trip, as well as how I approached my interviews and observations with study participants.

My main activity during my stay in Cape Town was volunteer work. After spending the night planning basic English lessons, I would be dropped off in the township with the other volunteers and we would assist the teachers in the school. We would help the teacher with songs and games in English, read stories, and implement our short lessons. The volunteers were each placed in different rooms of the nursery school to spread out our assistance and work with more children. I worked with Diana in the toddler room with about 25 three and four-year-old children. While I enjoyed working with Diana, I was very conflicted about my role as a volunteer. I noted that I felt like a 
novelty for the children because they would ignore their lessons to run to the volunteers. Specifically, they would climb on me, push each other to hold my hand, ignore any attempts I made disciplining them to be quiet or sit down, and constantly touch my hair. I questioned whether I was making a positive impact and helping the children learn English or if I was more of a distraction that hindered their work.

The nursery school was owned by Angela and she lived upstairs with her family. The downstairs was divided into three rooms-the main entrance room with the kitchen and shelves, the baby room on the side, and the toddler room in the back. The house also had a fenced in yard, a small bathroom that was accessed from outside the house, and a covered tent area for the "edu-care learning centre" for the older preschool children. While I enjoyed working with the children and assisting Diana, it was difficult not to compare the resources to nursery schools in Ontario. For example, in Cape Town, the children had very few toys and books, such as a few small blocks, a shared toy cash register, wooden puzzles, and crayons. Meanwhile, in the schools I volunteered at in Ontario, kids of a similar age had dress up corners, a puppet stage, a water table, a sand table, and endless interactive plastic toys/figurines. Even something as simple as the crooked and stained carpet in the South African nursery school, shocked me compared to the "roadway carpet" and story-time carpets found in Ontario nursery schools.

Yet, the main pivotal moment for me at the nursery school was when Diana had to turn off the light in the classroom in order to plug in the space heater because it was cold in the room. This moment made me question my role as a researcher and collapse into being the voluntourist, wherein I yearned to "make a difference" with the children. This moment also highlighted the structural tension of voluntourism because although I 
wanted to help, I simultaneously became aware that I was just a tourist passing through the township for two weeks and could not make a significant change. Still, I felt it was difficult to maintain a critical and reflective stance as a researcher, and instead, I was present in the lived reality of the nursery school. It also made me question the actions of my research, how I influenced the people I was working with, the implications of voluntourism, and if I should be doing "more" for the people with whom I was working in the townships. This is not to say I pitied Diana and the school children, nor did I idealize the "simple happiness" of their lives; yet, it made me question my own stance in my life, which I felt was reiterated by the other voluntourists during our interviews. However, this tension was not just troubling, but was also productive because it helped me to gain insight into the voluntourists' perspectives and how they attempted to navigate their ambiguous experiences.

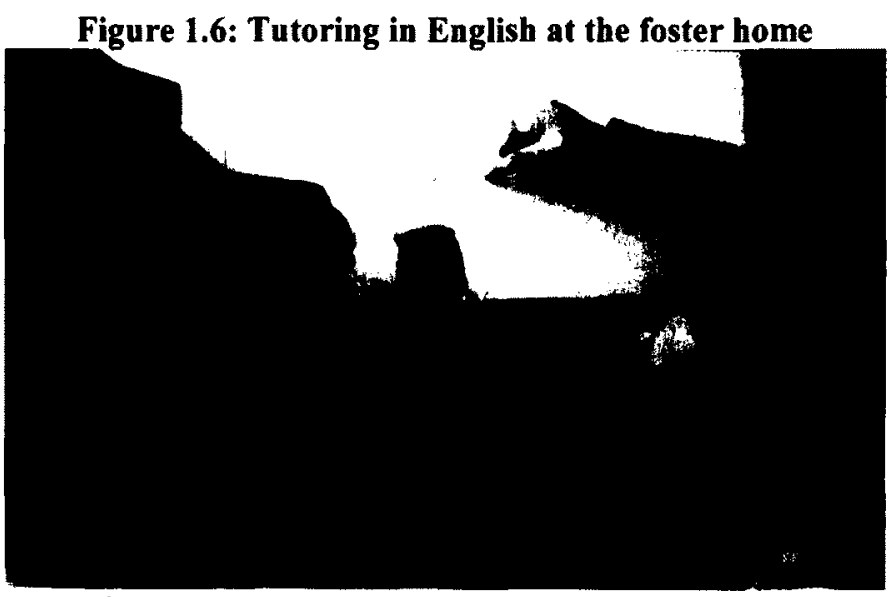

Source: Personal Photograph-August 2, 2012

In addition to my volunteer work at the nursery school, I also spent the afternoons tutoring children in a foster home. There were two foster homes, side-by-side, that we worked at and they each had 6 children, ranging in age from two to eighteen. I planned educational games and activities with the other voluntourists and we engaged the children 
in the activities after homework help. The foster houses were welcoming, especially since the moms offered us cups of rooibos tea and the children drew pictures for us because "they loved teacher." While I noted the impact of assisting the younger kids at the nursery school, the impression we made became more palpable when I helped the kids at the foster home. Since the schools are taught primarily in English, instead of Xhosa, some of the children struggled and flourished with the individualized academic attention that they might not otherwise receive. The two foster moms both noted how much the tutoring had improved their children's confidence in school. Through tutoring the children, I felt like I was giving them an advantage in school and the other volunteers noted that this was an experience where they felt they were "giving back" the most.

Figure 1.7: Volunteering in Cape Town

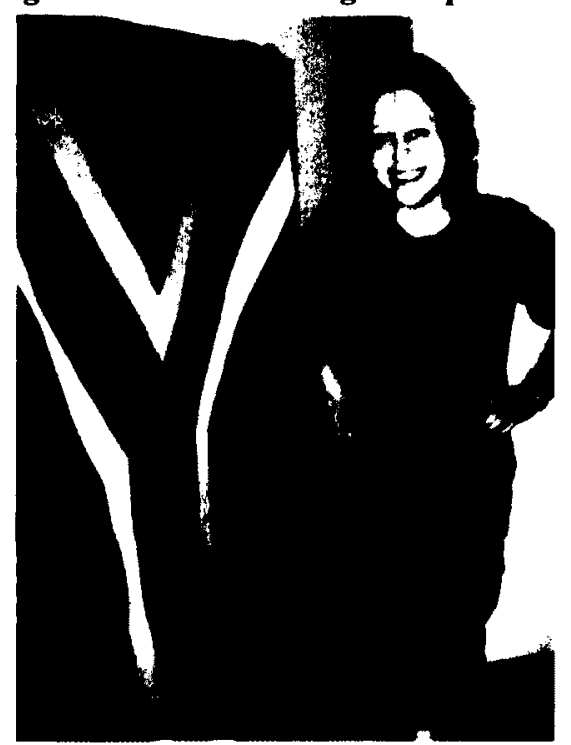

Source: Personal Photograph-August 7, 2012
Figure 1.8: Touring in Cape Town

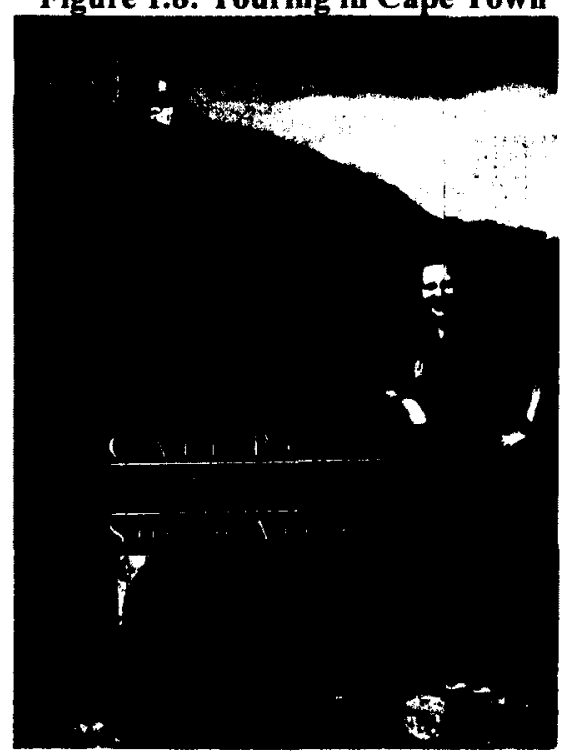

Source: Personal Photograph-August 5, 2012

While I was conducting my fieldwork, I interacted with the other voluntourists in several different scenarios. We would volunteer together at the nursery school and foster homes during the day, at night we would work on lesson plans and discuss weekend travel plans, and during the weekends, we toured around the city. These differing 
contexts emphasized the contradictory aspects of the volunteering and tourism components of the experience. Most of the voluntourists explained that they came on the trip to help out in the township, as well as to see a location they had dreamed of visiting. During my trip, I maintained a similar balance. Due to my background in Education in Ontario, I valued the volunteer work with children, but I also enjoyed visiting Cape Town as a perk of my fieldwork. I also tried to balance my dual roles as a voluntourist and as a researcher. While I did the best I could in both positions, I felt as though my shared experiences as a voluntourist developed rapport with my study participants and also provided insight into their experiences. In particular, my anthropologist-as-a-voluntourist status felt crucial during moments in the interviews when an individual would state “...you have to be there to understand...it's just, you know..." While I do not claim "to know," I felt my active participation enhanced my understanding and my ability to examine my research data and gave me access to the voluntourist experience. 


\section{Chapter: Literature Review and Context of Voluntourism}

My first day of going into the township was ripe with ambiguities. My mind kept wandering between the volunteer work in the township and my tourist side trips on the weekend. This was enhanced by the visual juxtaposition of the makeshift township houses in the foreground to the beautiful Cape Town landscape. Even during our initial training, we stopped our teaching workshop to discuss the available tourist trips suggested by the organization, such as a safari and shark cage diving. While the volunteer work was meant to be the focus of International Voluntourism's program, it was difficult not to think of the amazing things I would see in South Africa in my other role as a tourist.

When we first entered the township, we drove to visit all the organization's project locations to get a sense of its involvement in the community. I noted the limited resources and space at the nursery schools, how close the houses were together, the poor conditions of the road, the significant amount of people hanging around without occupation, and the garbage in the streets. When talking to the other voluntourists, they noted similar things and told me they felt overwhelmed because they felt like they had so much, while the people here had so little. This feeling conflicted with my initial thoughts of tourist locales in South Africa because it made the volunteer work seem more urgent. It also made me think if it was possible to be both a tourist and a volunteer and if these roles contradicted each other. 


\subsection{Definitions}

According to the VolunTourism website ${ }^{4}$, voluntourism is an intersection of the tourism and voluntary sectors, which enables an individual to learn about other cultures by becoming involved in short-term development work. Based on this definition, voluntourism is often regarded as an appropriate fit for youth to learn more about the world, themselves, and their role within it. Typically, it is framed as privileged Westerner going to an exotic third world country to help with a mini development project, such as building a well or teaching English, while also providing a global education for the volunteers. The experience is supposed to enable an individual to become involved on a global scale, act as a "citizen of the world," get involved in development work, discover other cultures, explore personal interests or career options, and "give back" in a structured manner.

Voluntourism is an ambiguous experience because it can be seen by some theorists as detrimental and by others as beneficial for the local community. These divergent interpretations are because of the ambiguity and structural tensions of voluntourism that arise from its combination of volunteering and tourism. Voluntourism may be problematic because of its potentially exploitive nature in developing countries through links to top-down agencies and simply channeling people through the voluntourism program to generate profit. But, it can also be made relevant and beneficial to the community it is being implemented in by involving community members and being sustainable, while also creating meaningful engagement for the voluntourists. In addition, it attempts to combine the voluntourist's interest in "giving back" with her desire to travel

\footnotetext{
${ }^{4}$ http://www.voluntourism.org/inside.html consulted on May 7, 2013
} 
and visit tourist locales. Since these are different types of activities, they are in structural tension with one another. Due to the contradictions of the structures of voluntourism, it is important to examine the various literature and authors' perspectives on this phenomenon in order to situate my study participants' experiences.

\subsection{Morality of Volunteer Tourism}

In order to research how voluntourism is perceived by the voluntourists I interviewed, I will first examine what I interpret as its moral representation that emerges from the literature. Initially, this may seem dichotomous and simplistic; yet, it demonstrates the ambiguity of voluntourism as a topic of study. Through looking at the context of voluntourism and how I perceive it as morally complex, I will later be able to unpack how I interpreted voluntourists' representations of their experience. My analysis also provides a foundation to examine voluntourism theoretically; in particular, through adopting Mauss' gift exchange and Schutz' life-world to look at how voluntourists frame their experiences. Thus, my literature review on voluntourism is based on the morality of voluntourism, rather than a theoretical understanding.

From an ethical perspective, voluntourism is an ambiguous and messy topic. It is described as beneficial for the host community and voluntourist by supporting development projects. Voluntourism can also allow the voluntourist to represent themselves as acting altruistically to "make a difference" in less developed countries. Conversely, from a critical perspective, it can be perceived as propagating neocolonialism, reinforcing negative cultural stereotypes, and creating a dependency on unskilled, short-term voluntary work. Through examining various literatures, I explore 
the ethically murky topic of volunteer tourism and how this impacts voluntourists' perspective.

Part of the difficulty in analyzing volunteer tourism is the range of definitions proposed by researchers. Some researchers classify it as a form of alternative tourism that provides an authentic, niche experience, which is contrasted to the consumptive practices of mass tourism (Lyons and Wearing 2008: 3). Others describe it as a form of development for both the individual and the host community (Brown 2005: 493). It is also perceived as a way for middle-class North Americans to "wash away" their Western guilt through make-work projects, while touring exotic locales (Kwa 2007 In Sin 2009: 480). Rather than adopting these definitions, in my paper, I will use Wearing's description of voluntourism as an initial reference, which states it involves:

...tourists who, for various reasons, volunteer in an organized way to undertake holidays that might involve aiding or alleviating the material poverty of some groups in society, the restoration of certain environments or research into certain aspects of society or environment (2001: 1).

While his definition already makes an ethical stance on voluntourism, Wearing's definition is the most commonly referenced in literature on the topic. It provides a common basis of understanding for describing the intersection of volunteering and tourism. Through initially utilizing this definition as a baseline, I will attempt to unpack other researchers' perspectives of volunteer tourism.

\subsubsection{Voluntourism: The Good}

One perspective of volunteer tourism is that it is perceived as predominantly positive and beneficial for those involved. These positive features are said to impact both 
the individual voluntourist, as well as the host community. Voluntourism is posited here as a relatively sustainable form of travel. Generally, the positive features of voluntourism are seen in its potential to foster cultural sensitivity and understanding between both the tourist and host communities (Connan 2011: 1459); this is presented as promoting a mutual relationship, wherein both groups can prosper. The proposed benefits of voluntourism are generally divided into those which impact the voluntourist and those that affect the host community and environment. Although the benefits may be unbalanced in favour of the voluntourist, arguably, the rewards for the host community situate the phenomenon as ultimately being "good" (Coghlan and Gooch 2011: 713). In their article, "Reflections on the Ambiguous Intersections between Volunteering and Tourism," Kevin Lyons and Stephen Wearing (2012) discuss how volunteer tourism combines the voluntary and tourism sectors. They state that the voluntourism experience can foster feelings of altruism, enable individuals to travel, create social connections, and enhance career skills for the voluntourist (Lyons and Wearing, 2012: 89). As a whole, it can also foster cross-cultural engagement and global awareness, which can promote tolerance, goodwill, and cultural understanding (Lyons and Wearing 2012: 90). While these are not tangible items, the potential for generating positive global attitudes and understanding is regarded as a promising feature of voluntourism. Such approaches highlight voluntourism's potential as a platform for positive change, which may result in attempts to alleviate aspects of poverty in "underdeveloped countries" and create greater global awareness for individuals from "developed countries" who participate in these programs. 
Harng Luh Sin (2010) discusses how host communities perceive of the implications of volunteer tourism in her article, "Who are we responsible to? Locals' tales of volunteer tourism." One of the claimed benefits that Sin highlights is the host community's recognition of the Westerners' increased scope of concern for the "developing world," which is emphasized within voluntourism (2010). This enables "caring at a distance" in a globalized world, which creates a more inter-connected world. Sin explains that this encourages people:

...to recognize the sameness or close similarity between their "selves" and "others" as human beings, and to see that "traditional differences" (of tribe, religion, race, customs, and the like) are unimportant when compared with the similarities with respect to pain and humiliation and the ability to think of people wildly different from ourselves as included in the range of "us" (2010: 985).

This is a relatively idealistic interpretation, which is represented as benefitting both the host community and voluntourists. While this is not exclusive to voluntourism, Sin explores how the recognition of innate humanity can be developed through the voluntourists working with individuals in the host communities. Thus, by meeting individuals from around the world, the voluntourist has the potential to solidify the similarities between humans and collapse the divide between "us" and "them," thereby creating a more inclusive perspective.

The integration of the voluntourist within an overseas host community is also explored by Sally Brown (2005) in her article, "Travelling with a Purpose: Understanding the Motives and Benefits of Volunteer Vacationers." She describes how one of the benefits of voluntourism for the voluntourist is the physical and emotional immersion in a local culture and community, which can facilitate a more "authentic" experience in the community (2005: 487). By volunteering, rather than simply being a tourist, the 
voluntourist is able to engage in a more meaningful way with the local people, which allows her "...to experience and learn beyond the typical tourist platform, where one is surrounded by staged settings typified by beautiful beaches and fancy resorts, to see the people as they really are, their lives and their living environments" (Brown 2005: 488). While this is fairly uncritical, Brown argues that this cultural immersion also supports more long-term relationships between hosts and visitors (2005: 488). According to Joanne Ingram in her chapter, "Volunteer Tourism: How do we know it is "Making a Difference," the post-modern tourist seeks out an alternative to mass tourism and desires an authentic experience where she is able to interact with local people in their real environments (2010: 212). Thus, according to Brown and Ingram, voluntourism offers the potential to engage in a host community in a less artificial manner, create relationships with locals, and as Sin argues, emphasize the shared innate humanness worldwide. This can arguably be described as a more appropriate form of tourism because the tourists are posited as more sensitive towards host communities.

In addition to researchers' representation of the potential for cultural sensitivity and understanding, there are also individual benefits for the voluntourist. Specifically, Brown describes voluntourism as a vehicle for individuals to "give back" and enact their sense of purpose through offering their help overseas (2005: 487). She explains that voluntourists want to reach out to those perceived as less privileged, which is appealing because it is a chance to help others while travelling and not simply focus on pure selfenjoyment (Brown 2005: 488). Similar to volunteering in general, the act of volunteering overseas gives individuals a sense of purpose and provides them with the benefits of “...self-actualization, self-enrichment, recreation or renewal of self, feelings of 
accomplishment, enhancement of self-image, self-expression, social interaction and belongingness" (Brown 2005: 484). Thus, voluntourism offers the potential for personal growth and self-development for the individual through her experiential involvement (Brown 2005: 491). Sin also explains in her article, "Volunteer Tourism-'Involve Me and I Will Learn," that this experience is motivated by an individual's desire to "make a difference" by helping individuals overseas (2009:489). As Brown and Sin explore, the positives of volunteer tourism extend past the direct impact on the host community and also benefit the voluntourist through her sense of engagement while volunteering.

The experience of volunteer tourism offers an individual the opportunity to interact with people around the world and a chance for self-development through enacting her sense of purpose by volunteering with those perceived as "less privileged." Additionally, since it removes someone from her normal environment in her home country, it also may provide the opportunity for critical reflection and a shift in perspective. In Coghlan and Gooch's (2011) article, "Applying a transformative learning framework to volunteer tourism," they explore how volunteer tourism affects the voluntourist through creating an altered sense of being-in-the-world. They argue that voluntourism can be perceived through a transformative learning perspective, which emphasizes that it is a: “...deep structural shift in the basic premises of thoughts, feelings, and actions. It is a shift of consciousness that dramatically and irreversibly alters our way of being in the world..." which in turn changes an individual's sense of self, as well as her relationships with others and the world (Coghlan and Gooch 2011: 716). An individual's involvement in voluntourism cannot be understood exclusively as a spiritual search for meaning, but also has to be seen as a means to make sense of one's world 
through entering a new environment and critically reflecting on the world and one's position within it (Coghlan and Gooch 2011: 719). This change in one's positionality is considered a benefit because it helps a person create meaning in her life as a result of her involvement in voluntourism.

Voluntourism may also be considered in a positive manner due to its value as an act of experiential learning. According to Sin, it can help an individual through exploring new roles and skills, while also engaging with a new form of work (2009: 482). Similarly, Coglan and Gooch (2011) explain that voluntourism can help an individual develop new competencies, which will be effective in future educational or career positions. This can also impact an individual's perspective of her school by creating a link between theoretical and practical knowledge, which may help create meaning for someone in her university or college program (Sin 2009: 492). Liam Fee and Anna Mdee also argue in their chapter, "How does it make a difference? Towards the 'accreditation' of the development impact of volunteer tourism," that volunteer tourism helps the individual develop "soft skills" and increase employability (2010: 227). By leaving a familiar home environment and taking "good" intentions to an unknown place, the voluntourist is forced to enhance her confidence, as well as interpersonal, problemsolving, and communication skills (Fee and Mdee 2010: 228). These skills can be transferable to future jobs, which has long-term benefits for the voluntourist.

Volunteer tourism is described by some researchers as offering a variety of positive aspects for both the voluntourist and the host community. It enables the voluntourist to contribute and the host community to receive necessary support for development projects (Sin 2009: 490). It also provides an opportunity for personal 
development for the voluntourist as she is faced with the challenge of working overseas in a new environment ( $\operatorname{Sin} 2009: 490$ ). As well, from a pragmatic stance, it is also more convenient for the tourist because it makes exotic locales seem more accessible and "safe" through travelling with an organization (Sin 2009: 490). Unfortunately, the majority of the benefits described by researchers are directed primarily at the voluntourists and may neglect the perspective of the host community. While this does not negate the potentially positive aspects of the experience, it does require a critical perspective to analyze the impacts of voluntourism to discuss its negative features.

\subsubsection{Voluntourism: The Bad}

In contrast to the proposed benefits, voluntourism can also be represented as an exploitive and detrimental practice. Some theorists explain that the reason why voluntourism may be purported as positive is because researchers focus primarily on the individual's motivations, experiences, and perspectives, while neglecting the opinions of the host communities (Sin 2010: 984; Connan 2011: 1454). By focusing on the positive emotive and self-development aspects of volunteer tourism, there is a risk of ignoring the structural inequalities that may arise and thus disregard its negative aspects (Guttentag 2009: 539). In critically analyzing the possible drawbacks of voluntourism, researchers believe that they can evaluate the negative impacts it may have on both the voluntourist and the host communities and represent its drawbacks.

One of the major criticisms of voluntourism is that it is framed as a neo-colonial encounter with the Western voluntourist coming to aid the supposedly "needy" lessdeveloped host community. In Mary Connan's article, "They Really Love Me! Intimacy 
in Volunteer Tourism," she explains that there is too much of a focus on the tourist's motivations, experiences, and impact on their self, which creates an unequal discussion of the topic (2011: 1454). The claimed intimacy between the host community and voluntourist masks potential structural inequalities (Connan 2011: 1455). Specifically, the narrative of the tourists helping "...perpetuates a logic which suggests a binary opposition which creates an "us" (the West) vs. "them" (the Orient) dynamic" (Connan 2011: 1464). This is emphasized by the fact that the volunteer is placed in the position of relative power to teach the host community, when they often do not know the local context (Sin 2010: 987). By assuming the Western voluntourist has more knowledge than the host community, this experience creates an unequal relationship that negatively impacts the host community by reifying their status as "less-developed" and requiring external intervention.

In Daniel Guttentag's (2009) article, "The Possible Negative Impacts of Volunteer Tourism," he explains that volunteer tourism may have some unintended negative impacts because it focuses on the voluntourist wanting to "make a difference" instead of sustainable development. Volunteer tourism may neglect local desires (such as what the community defines as its needs) and focus on creating what "outsiders" claim as progress in the host community, while generating a profit for the sending organization (Guttentag 2009: 541). While Guttentag explains that it is not necessarily worse than other forms of tourism, the illusion of its benefits may be harmful. For example, Guttentag argues that voluntourism is centered primarily on the tourist's desire to help and she may only have minimal or non-existent skill sets to fulfill the volunteer work (2009: 543). This means voluntourists are often unskilled, hinder the work process, and 
may complete unsatisfactory work as a result of their inability (Guttentag 2009: 543). It is risky to have new, untrained volunteers cycling through projects because they lack local knowledge, as well as long-term information about the project.

Volunteer tourism may also be detrimental because having external volunteers carry out tasks may decrease local employment opportunities and promote dependency based on the presence of volunteer labour (Guttentag 2009: 537). As Guttentag argues "...volunteer tourists frequently perform jobs that locals could do instead..." and since they work for free "...they may undercut competing local labourers" (2009: 544). This in turn disrupts local economies as host communities become dependent on the volunteer work. It may also reinforce the concept of an "other" in need, which can underline negative stereotypes or an essentialized representation (Guttentag 2009: 546). As Sin explains, it presents the notion of a "distant other" who requires the responsibility of care with the privileged "developed world" caring for the less-privileged "developing world" (Sin 2010: 984). It also supports the problematic notion of the divide between affluent and poor countries and that the more affluent are responsible, which perpetuates an unequal relationship ( $\operatorname{Sin} 2010: 985$ ).

Volunteer tourism is also viewed critically in terms of long-term sustainability. By creating a framework of voluntourists "giving" to host communities, it creates dependency and may not be practical to maintain (Sin 2010: 990). Voluntourism can act as an artificial support, but it does not address larger structural issues that can create longterm positive social change. It may also romanticize the supposed "poverty" of the host country by associating them with social and emotional wealth in spite of a lack of material items (Guttentag 2009: 546). These notions reproduce existing structures of 
power, while positioning the tourist as elevated. It also focuses on short-term projects instead of long-term, sustainable development programs. While the work done on voluntourism projects may be positive, the larger repercussions may create negative impacts and stifle growth within the country.

In addition, the voluntourist herself may be problematic because of her motivations and perceptions of her involvement. While voluntourism is framed as development-style projects, the volunteer's motivations may not prioritize this, and instead, could be relatively selfish. As Alexandra Coghlan and David Fennell (2009) discuss in "Myth or Substance: An Examination of Altruism as the basis of Volunteer Tourism," voluntourists derive personal benefits from the experience, in spite of their (sometimes) altruistic intentions. These include experiencing new and different things, having an enjoyable personal experience, making friends on the trip, taking part in a rare opportunity of meeting locals, and exploring new places (Coghlan and Fennell 2009: 391). This also creates the occurrence of social egoism, wherein the volunteer tourist ultimately benefits oneself through the experience of the trip (Coghlan and Fennell 2009: 393). The personal benefits tend to dominate the experience, instead of focusing on benefits for the host community, which highlight the possibly selfish intents (Coghlan and Fennel 2009: 378). While it is not problematic for the voluntourist to benefit from the experience, it becomes detrimental when it is the emphasis of the programs, the individual, or the structure of volunteer tourism as a whole.

The focus on the egocentric, rather than altruistic, elements of voluntourism can also be problematic. Not only does the individual receive personal benefits through the experience, but discussion about it afterwards acts as a form of self-gratification 
(Guttentag 2009: 540). Coghlan and Fennell refer to this illusion of altruism with an egocentric undertone as reciprocal altruism because the voluntourist expects social approval and respect from others (2009: 381). This is not to discredit individuals who do intend to "do good" for host communities, or even unintentionally do good in spite of egocentric motives; however, it does emphasize that most voluntourists are motivated by personal rewards (Coghlan and Gooch 2011: 715). Voluntourists become involved through a cost-benefit analysis of their involvement in which they perceive of the outcomes (such as personal rewards, "making a difference" or their impact overseas) as outweighing the costs (time, money). Thus, volunteer tourism can be represented as creating a negative impact by focusing on the voluntourist and not the intended beneficiaries of the project.

The experience of voluntourism may even have a negative impact on the voluntourist herself. According to Sin's research, voluntourists may simply be "rich kids" who know nothing about the developing world and simply want to "change the world" in one month's time without actually learning from other cultures (2010: 988). Instead of acknowledging that other cultures may have insightful perspectives, the voluntourist could solidify their concept of self as superior and more knowledgeable. The experience can also reinforce negative stereotypes about other cultures as simple, primitive or less developed (Guttentag 2009: 546). Additionally, voluntourism may unintentionally corrupt the individual because she becomes passionate about travelling, not volunteering, and may not engage in any further volunteer work (Sin 2009:494). While this is not necessarily harmful, it discredits other theorists' perspectives of voluntourism as a lifealtering experience and presents it as a glorified form of tourism. 
The underlying problem with voluntourism may be that it is focused too much on the voluntourist or generating profit, which ignores the needs of the host community. This is problematic because the host community is claimed to be the primary beneficiary of the projects. Instead, these programs can be profiteering (Fee and Mdee 2010: 223). They focus on the tourist's desires when selecting projects and opt for tourist-friendly options, such as building a school, playing with exotic animals or caring for children. It creates a commodified product of "development tourism" to attract voluntourists, which in turn attempts to generate profit and may ignore actual development in the process (Guttentag 2009: 541). Thus, researchers state that while voluntourism may have claimed benefits, they are overshadowed by its potential for negative implications. They claim it may be detrimental for the host community because it does not focus on benefitting them.

\subsubsection{Volunteer Tourism: The Contradictory}

Voluntourism is an ethically messy topic because it can be perceived as having "good" or "bad" implications. As well, its structural tensions highlight the contradictory aspects of voluntourism in its combination of volunteering and tourism. This creates an ambiguous experience for the voluntourist as she attempts to navigate these aspects and represent herself within her experience. Through acknowledging the positive and negative features of voluntourism, it provides a basis for understanding it, the rationale why individuals undertake it, as well as its possible implications for an individual and the host community. While voluntourism does offer benefits for the individuals, host communities, and development as a whole, it is not predominantly virtuous. Similarly, while there are several negative impacts, voluntourism can also create a positive effect 
for those involved. As Sin explains, there is ultimately a lack of a middle ground with a balanced view when analyzing volunteer tourism (2009: 481). This perspective also embraces the often messy and unclear impact of volunteer tourism. While it may not be perfect, there are other aspects that should not be rejected without additional consideration because voluntourism may be a platform for larger social change.

Since voluntourism combines the voluntary and tourism sectors, it is rife with ambiguity and fuzziness through the intersection of these elements (Lyons and Wearing 2012: 92); the voluntourist is neither completely a tourist nor a volunteer. Voluntourism has its early roots in missionary work when individuals would go overseas to modernize other cultures, which can align it with neo-colonialism (Guttentag 2009: 548). Yet, as some host communities have stated, typically the voluntourists come over with good intentions to work with local communities ( $\operatorname{Sin} 20120$ : 987). Thus, voluntourism has the potential to work collaboratively with host communities to promote relevant development projects. The negatives of it can be mitigated, as long as the projects are properly planned and managed, and the programs are of value for the communities (Guttentag 2009: 548). As Connan argues, while volunteer tourism will not make radical cultural change, it can be a central platform for raising consciousness about global inequalities (2011: 1467).

Volunteer tourism can be used as a positive tool, as long as certain limitations and criticisms are discussed openly. It must embrace and accept its ambiguous perspectives, while trying to limit negative impacts, in order to be effective as a form of development. As Connan argues, voluntourism may be a potential platform for structural change because of who it attracts-globally conscious people with cultural and economic capital, as well as an interest in social justice-who are willing to give their time to promote 
these goals (Connan 2011: 1465). It also fosters a heterogeneous space for sensuous experience based on being, doing, touching and seeing, wherein the tourist and the local interact and become involved in cross-cultural relationships ( $\operatorname{Sin} 2009: 483$ ). This generates strong emotional responses, particularly on the part of the voluntourist, which should be embraced as part of the experience (Coghlan and Gooch 2011: 720). It also has the potential for global justice because it creates a framework for embodied engagement, which creates a counter-experience to everyday life for the volunteer, as well as fostering education and advocacy (Connan 2011: 1466). It is important to recognize the type of audience interesting in voluntourism. By focusing their motivations towards the good of the host communities, it can become a powerful tool to shift global perspectives. This may in turn affect larger structural problems.

However, some of the key limitations are that voluntourism needs to develop a plan of action and create feedback for volunteers to support a long-term plan and benefit everyone (Coghlan and Gooch 2011: 724). By focusing on the organizational aspect and collaboration with local communities, voluntourism projects can have a greater and more positive impact both in its actual work and in raising awareness. As Ingram emphasizes, voluntourism should focus on creating a higher level of participation with local communities to use their relevant knowledge, create sustainable projects, and ensure they are appropriate to their needs (Ingram 2010: 218). This would also require basing the projects in good development principles, rather than focusing on tourism (Ingram 2010: 219). Through acknowledging the value of the host community, voluntourism organizations can potentially mitigate any negative impacts (Ingram 2010: 220). 
In addition to working collaboratively with local organizations, voluntourism should also become more political to question any power relations or structural inequalities it may unintentionally (or intentionally) perpetuate ( $\operatorname{Sin} 2009: 497$ ). If it remains apolitical, it will neglect critical engagement with democracy and citizenship, and will in turn ignore addressing social inequalities that the projects attempt to remedy (Sin 2009: 497). It is important to properly manage voluntourism; this creates a better framework to utilize it to positively affect host communities and voluntourists. This both acknowledges the good and bad aspects of voluntourism and attempts to compensate for any harmful impacts, while also recognizing its potential as a vehicle for changing global social attitudes. By looking at researchers' explorations of voluntourism, I can acknowledge its strengths and limitations in my fieldwork, which situates it as an ambiguous site that a voluntourist must navigate to self-represent her experience.

\subsection{VOLUNtourism versus volunTOURISM}

Voluntourism has varying definitional types and morality; it can also be categorized according to its emphasis on either volunteering or tourism. While voluntourism involves the intersection of both the voluntary and tourism sectors, the emphasis on each aspect defines its focus. Some voluntourist organizations, such as International Voluntourism, highlight the volunteer work as the main activity through intensive pre-project training, sustainability within the projects, working with project partners to make sure the volunteers fit their needs, and it taking up the bulk of the time overseas. Meanwhile, other organizations, such as Culture Travel, utilize the trip as a 
tourist activity through various sight-seeing activities and cultural events, while also providing the opportunity to "see" the locals through occasionally working at a project.

Sally Brown argues in "Travelling with a Purpose" that voluntourism is also differentiated based on participants' mindsets as either volunteer-minded or vacationminded (2005: 480). She argues that this focus impacts the intended activities, as well as the attitudes taken through the experience:

The 'volunteer-minded' individuals tend to devote most or all of their vacation time to volunteer activities at the destination. Volunteerism is the central notion for them. This type of volunteer tourism is often called a mission or service trip. The second form of volunteer tourism takes on a lighter undertone where the individual is largely 'vacation-minded', but spends a small portion of the vacation on volunteer work at the destination. (2005: 480)

This elevates the positivity of VOLUNtourism, or the volunteer-minded individual, since it appears to support the host community through volunteer work and to have an arguably more positive intention. This distinction between different forms of voluntourism also demonstrates another inherent ambiguity. As I discussed in Chapter Two, upon later reflection, my two voluntourism experiences were very different because my initial trip to Cusco, Peru in June 2007 with Culture Travel was with a more vacation-minded organization and my fieldwork trip to Cape Town, South Africa in July-August 2012 with International Voluntourism was with a volunteer-minded organization. This impacted my perspective because it altered the intersection of the volunteer and tourism elements, in spite of my initial claims that I experienced a change in perspective after my trip to Peru.

According to Sarah, the Programs Manager for Cape Town with International Voluntourism, both the volunteer and tourism aspects are necessary for the individuals who participate. It provides a more holistic experience and a sense of understanding by 
exploring the culture and interacting with the people in a meaningful way. Sarah stated that: "I think this type of holiday, this type of trip is brilliant, because you've got the best of both worlds. You get to see a country and see amazing things." She also claims it is necessary for the volunteers to have downtime to tour on the weekends because they work hard during the week. Similarly, John, the project manager for the specific township with International Voluntourism, agreed that it is necessary for volunteers to get a sense of the culture by exploring the country's tourist sites, which provides a sense of understanding when volunteering at a project. Therefore, while the differentiation between VOLUNtourism and volunTOURISM impacts the primary focus of the trip, both the volunteer and tourism elements are represented by the sending organizations as necessary for the experience.

While conducting my fieldwork in Cape Town with the other voluntourists, we discussed our volunteer work, especially lesson plans at the nursery school, and our tourist plans on weekends. In the interviews, the voluntourists spent relatively equal time talking about working with the kids and in the townships, as well as what they saw or wanted to see around Cape Town. This may have been because the bulk of the time (9am-4pm from Monday to Friday) was spent volunteering at the projects, while weekends were free to explore the region. In comparison, while I was in Cusco with Culture Travel, there was more of an emphasis on the tourism trips, like Machu Picchu and the Inca Sun Festival, and the volunteer work seemed spontaneous, such as doing upkeep at the albergue and building a stove with a chimney for one day in the Andes Mountains. As my two distinct experiences demonstrate, voluntourism is a very complex and personal experience. An individual's focus, as well as the sending organization's 
goals, impacts the overall experience and the voluntourist's perspective. Arguably, the type of experience could also impact if and how an individual describes a shift in perspective and how she describes her involvement overseas in relation to the host community.

\subsection{Socio-Political History of South Africa}

Through examining the ethnographic, socio-political, and historical context of South Africa, I highlight how this informs the voluntourists' experiences. This intersects with my initial exploration of prior literature on voluntourism to develop an understanding of the framework of my study participants' experiences voluntouring in Cape Town. Contemporary South Africa is very complex, which makes it an interesting location to examine the contradictory aspects of voluntourism. While I acknowledge that my analysis is limited by the scope of my research and is based on my interpretation of my fieldwork, I hope to look at how this specific trip was framed by South Africa's socio-political history and within the shadow of apartheid. This is particularly relevant because the program involves mostly white United Kingdom/ North American volunteers working with and teaching English to impoverished black children in the townships. While this is an oversimplification of the complex socio-political history of South Africa and context of voluntourism, it does impact and frame the relationships between International Voluntourism volunteers and the township project partners.

While South Africa is not unique in its history of racial hierarchy and segregation, apartheid is arguably "...one of the most monstrously inhuman systems of government that operated in the twentieth century" (Maylam 2001:179). Racial discrimination has a 
longstanding history in South Africa. Initially, the Dutch landed on the Cape of Good Hope in 1652, which marked the beginning of European colonization and the use of African and Asian slaves (Clark and Worger 2011: 3). While they did not immediately colonize inland, eventually, due to the Dutch East India Company, the Dutch began to settle throughout South Africa (Clark and Worger 2011: 11). They eventually became known as the Boers and developed their own Afrikaans identity that was distinct from the Dutch and Africans (Clark and Worger 2011: 13). According to Clark and Worger, this identity was further developed in opposition to the British settlers, using the Afrikaans language as a key marker of distinction (2011:28-29). This colonialism set the tone for a division between white settlers (either Afrikaans or British) and non-white African and "Coloured" people within a hierarchy. While the Afrikaans and British remained opposed, they united in their common cause of white supremacy.

Figure 1.9: Sign in District 6 Museum, Cape Town

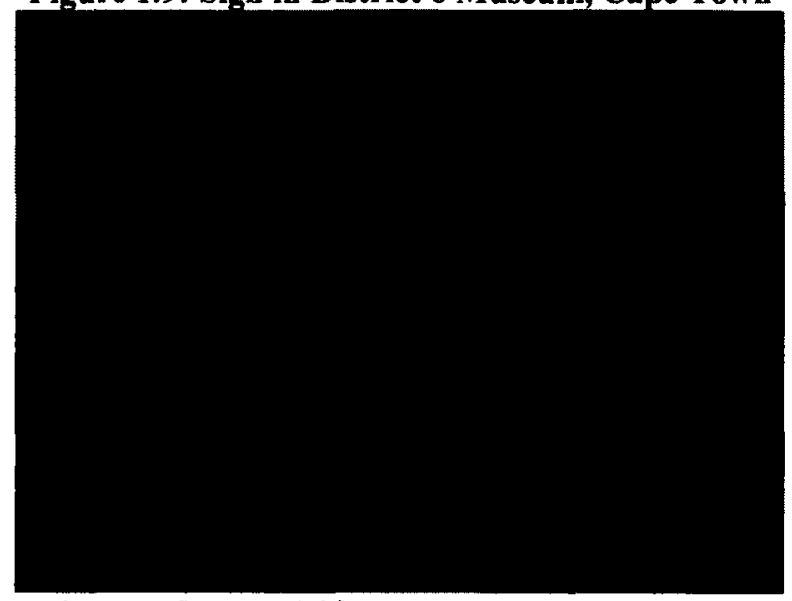

Source: Personal Photograph-August 4, 2012

After South Africa became unified in 1910, it began implementing a policy of segregation, which negatively impacted those who were non-white through restricting rights to land, access to jobs, and to political power (Clark and Worger 2011: 21). Notably, it was not just political or economic segregation, but also physical segregation, 
which included moving the Africans to segregated townships or to rural "homeland" areas (Clark and Worger 2011:23). However, this segregation became aggravated further after World War 2 with the implementation of apartheid by the National Party government in 1948 (Clark and Worger 2011: 38). According to Naboth Mokgatle, apartheid is the: "total segregation of the African people and all non-Europeans in the country, permanent denial of human rights, permanent baasskaap, master race, and inferiority for anything non-white" (Clark and Worger 2011: 47). This racial hierarchy was enforced through the pass system, wherein individuals were required to carry a pass book stating their race, homeland, and employment status, in order to gain access to "white" urban areas or move throughout South Africa (Clark and Worger 2011: 49). Through apartheid, South Africa implemented a racial hierarchy with whites at the top, blacks at the bottom, and Coloured people in the middle. The government attempted to make blacks non-persons without any rights, including not classifying them as citizens of South Africa. While the white South Africans expected apartheid to stabilize order and dominance, it caused more tension and instability because of its injustice. Individuals, such as Nelson Mandela as part of the African National Congress (ANC), fought against the inhumane actions of apartheid through strikes and various political actions in order to gain basic human rights, such as mobility, voting privileges, and the right to own land.

Eventually, apartheid was ended when the National Party government fell from power in 1994 (Clark and Worger 2011: 3). After nearly twenty-six years of being imprisoned for advocating against apartheid, Nelson Rolihlahla Mandela was elected president of South Africa on May 9, 1994 in the first democratically elected government 
(Clark and Worger 2011: 119). According to Mandela, South Africa would move forward and be a country based on equality:

Never, never, and never again shall it be that this beautiful land will again experience the oppression of one by another...The sun shall never set on so glorious a human achievement. Let freedom reign (Mandela 1994: 621).

Although life in South Africa improved significantly and moved toward equality, apartheid still casts a shadow on daily life.

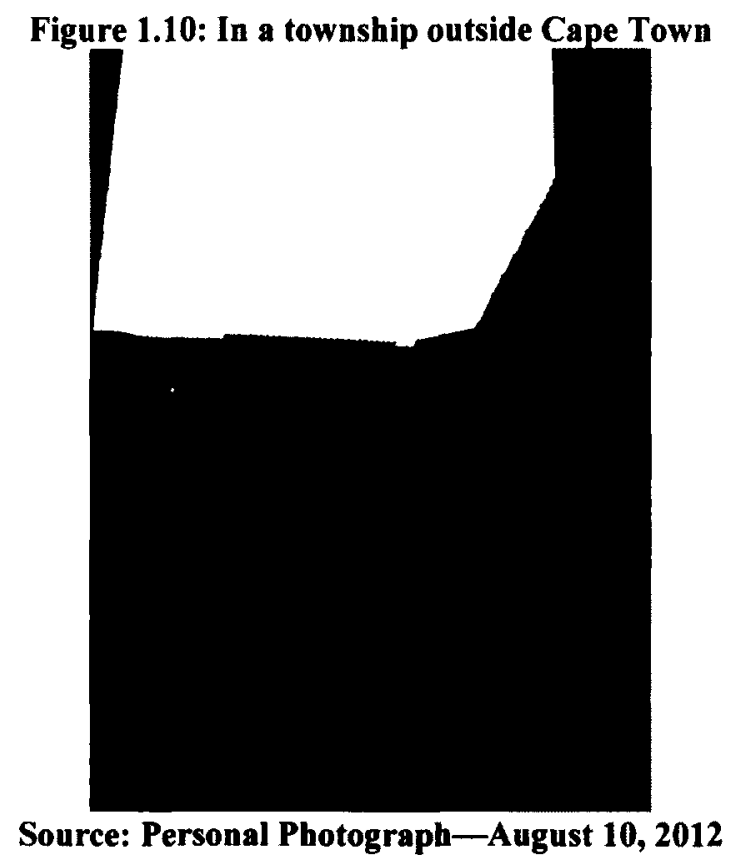

While apartheid has officially been over for nineteen years, it still has lasting repercussions. The main way in which apartheid is still impacting people in South Africa is the lack of economic and political opportunity for non-white individuals as a result of the oppressive regime. Many of the black South Africans are still living within the confines of townships in squatter settlements or makeshift housing. This is because they are moving to urban centres for job opportunities, yet are unable to afford housing or have housing built fast enough because of unequal economic growth (Clark and Worger 2011: 127). Similarly, according to Clark and Worger, only $48 \%$ of African high school 
students graduate compared to $95 \%$ of white South Africans (Clark and Worger 2011: 128). While this is a result of several different factors, one aspect could be that the language of school instruction is English, which is not the main language spoken by black South Africans. Thus, students are learning a new language when they attend school, which makes learning more difficult.

In South African schools, the language of instruction had been English and some Afrikaans. However, in 1974, the new Minister of Bantu Education decided to enforce a previously ignored Act that: "...required Afrikaans to be used on an equal basis with English as the languages of instruction" (Clark and Worger 2011: 82). The increased use of Afrikaans enraged the black Africans because they felt it was the language of the oppressor, so they fought to only be taught in English and rejected Afrikaans (Clark and Worger 2011: 82). This demonstrated the relative allegiance the black South Africans had to the British over the Afrikaans, which complicates the framework of voluntourism, especially since it is used primarily to teach English. While this highlights that the black South Africans perceived of the British as the lesser of two forms of oppression, it does mean that it is still distinct from Xhosa culture. This may create a struggle for black South Africans to succeed in the South African school system since it diverges from their cultural language and background.

According to Connan, voluntourism can be described as a neo-colonial encounter, which is enhanced by the whiteness of the volunteers in contrast to the non-white recipients (2011: 1464). This is furthered by the fact that voluntourism has its early roots in missionary work when individuals would go overseas to modernize other cultures (Guttentag 2009: 548). Similarly, voluntourism may reinforce the concept of an "other" 
that requires outside assistance because they are less developed (Guttentag 2009: 546). As Sin argues, it creates the concept of a "distant other" in the less-privileged developing world who requires care from the privileged developed world (2010: 984). International Voluntourism emphasizes the need for helping "desperate communities" on its website, which encourages Western individuals to come to aid the "needy" South Africans. This framework is relevant in South Africa because the presence of voluntourism may reinforce the racial hierarchy of the privileged white foreigner improving the lives of the black local in the township, especially in the shadow of apartheid.

Although International Voluntourism's use of foreign volunteers to teach English can appear neo-colonial, the underlying power dynamic is more complex and highlights the ambiguity of voluntourism. The black South Africans opted to be educated in English instead of Afrikaans, even though this is not their mother tongue. While this does not entirely take into account that they opted for what they perceived to be the lesser of two oppressors, it does suggest that there is some degree of black South African agency in this decision. This means the entire context of apartheid and segregation must be examined in order to understand how it frames voluntourism and relationships between the white foreign voluntourists and the black project recipients in Cape Town.

According to International Voluntourism, voluntourism fills a void to assist in teaching English since many people in the townships in South Africa cannot afford tutors. This makes a significant impact because young children cannot attend primary school until they know how to write their names, count to ten, or identify basic shapes in English. The organization also claims their involvement increases success in primary and secondary schools, which can improve graduation rates and provide better job 
opportunities. Thus, while apartheid still casts a shadow in South Africa, voluntourism should be examined through a more complex lens in order to understand the interactions between the voluntourists and the recipient communities. While voluntourism may involuntarily perpetuate the injustices that originate in apartheid, examining the sociopolitical history of South Africa can help to understand its contradictory aspects.

South African history and socio-political context are relevant to voluntourism because most individuals are aware of these aspects when deciding on it as a destination. The voluntourists I interviewed consciously selected Cape Town over other places. They also casually told me that they knew about apartheid, racial and class hierarchy, the existence of townships, and that contemporary South Africa is a complex location as a result of these aspects. This information was developed through South Africa's representation in the media, some school coursework, as well as how International Voluntourism portrayed Cape Town on their website. These informal remarks highlighted that the voluntourists had a rough idea of what they would be going into upon flying into Cape Town, which is arguably part of the appeal of it as a destination. This is also part of the voluntourism experience and framed their expectations and selfrepresentation of their journey through their prior knowledge of South Africa. 


\section{Chapter: How International Voluntourism Frames the Experience}

According to the International Voluntourism staff, the organization's website is its main place to attract potential voluntourists. This was confirmed by the voluntourists I interviewed when they explained that the website was what convinced them to come overseas with this organization. On its website, as well as later in its training manuals, International Voluntourism uses specific phrases, past participant reviews, and images to promote its programs, entice individuals to sign up with them instead of other programs, and provide context for the experience. It also includes project descriptions to give a sense of what occurs on the trip. While the staff told me the organization intends to use the website primarily as a means of promotion, I noted it also served an additional purpose. The website and training manuals are also a means of self-representation, which provides a framework for the participants to interpret their experiences.

As discussed previously in the literature review, voluntourism is a complex experience that creates an ambiguous role for the voluntourist. This is because the individual occupies the roles of both a volunteer and a tourist, which may contradict one another. The voluntourist claims she wants to go on the trip to "give back" and "make a difference" in the host community, while she also wants to "get" photos in return and visit the tourist locales. Voluntourism's inherent structural tensions create complex expectations because the volunteer and tourist aspects involve different types of activities. Through these conflicting interests, it creates an understanding of the experience that is not easily palatable and can be misunderstood.

Through its rhetoric, International Voluntourism uses its literature to attempt to smooth over and reconcile the contradictions of voluntourism in order to minimize the 
ambiguous aspects. In particular, it addresses any moral issues an individual may have in her voluntourist experience, as well as highlights the complementary aspects of the dual roles of volunteer and tourist. Thus, in examining the perceptions of voluntourism and how an individual navigates its ambiguous nature, it is important to analyze the organization's discourse since it presents an idealized version of how the voluntourist should interpret her experience; this is pertinent because the voluntourists echoed these buzzwords during their interviews, which highlighted its impact on their perspectives.

\subsection{Why Conduct a Content Analysis?}

In order to address how International Voluntourism represents itself, I conducted a content analysis of its website, training manuals, and staff interviews. This is because these were created by the organization and are used as self-representation, promotion or explanation for potential voluntourists, and to justify their involvement in the host community. I took screenshots of the organization's website, and then read through the website, training manuals, and interview transcripts to code them based on themes and key words. I highlighted the frequency of specific terms, as well as their context, in order to derive what I believe they were trying to convey. In particular, I examined their use of key terms to see how their rhetoric glosses over the inherent ambiguities of voluntourism and attempts to reconcile these contradictions by using "feel good" terminology.

I focused primarily on the discourse International Voluntourism used, but broadened my analysis to also be based on visual content because all these mediums contributed to framing the voluntourism experience. While the phrasing created more explicit representations, such as explaining how voluntourists "make a difference," the 
images also provided an immediate context through which individuals could base their trip by visually representing how a voluntourist can be involved overseas. I included International Voluntourism's website, training manuals, and staff interviews in this analysis because these were all important elements to explore its self-representation; the website provided an entry point for potential voluntourists, the training manuals guided incoming voluntourists, and the staff's discourse directed the experience during the trip. These forms of International Voluntourism's self-representation provide a framework for the participants to interpret their experience and navigate voluntourism's ambiguities.

To begin the content analysis, I sorted the data by hand, noting the incidence of words and themes by focusing on their overall significance. For example, although a phrase like "a link in the chain" may not have occurred more frequently, it was mentioned by the staff as being a critical metaphor, which made it noteworthy to analyze. Then, I looked at these qualitatively to see what these phrases or images denoted and connoted, as well as their impact on the voluntourism experience. I conducted the content analysis by hand instead of with a computer in order to account for my personal memory and context from when I did my fieldwork. While using a computer program would have been more time effective, hand sorting enabled me to assign things to different categories and analyze data throughout the process, while also integrating my memory of experiences. By doing this, I employed David Altheide's (1996: 16) term, ethnographic content analysis, which is a more reflective and iterative process that takes context, communication of meaning, and verifying theoretical relationships into account.

While examining International Voluntourism's website, training manuals, and interviews with staff, I used a semiotics-influenced approach to analyze the content. 
According to Ferdinand de Saussure, the meaning of words and images are derived from their relationships to other words or images, which requires one to look at the signifier and signified in order to analyze it as a sign and understand its system of value (de Saussure, 2004: 9). Through examining International Voluntourism's use of specific signs within their content, I explored the meaning behind their self-presentation, as well as how it framed the voluntourists' interpretation of their experience.

Through conducting my content analysis, I explored how International Voluntourism develops a tone that resonates throughout its projects and impacts the voluntourist. For example, their use of phrases, such as "you make a difference," and "a link in a chain," create a specific message, which they use to emphasize the important role the voluntourist occupies and how they positively impact the host community. This representation has implications for the voluntourists' experiences and perceptions because it generates expectations for an individual and masks any contradictions in the experience. Thus, the discourse a voluntourism organization adopts has repercussions for the voluntourist and how she interprets her experience.

\section{2 "You should choose International Voluntourism": Promotion and Recruitment}

As mentioned previously, the International Voluntourism staff stated that the website is the main place to recruit potential voluntourists. Sarah, the Cape Town programs manager, and John, the project manager, both explained how the website's use of images, past participant reviews, and project descriptions can help to inspire individuals to sign up for the program. It uses these tools for its discourse, which attempts to promote its programs, explain the merits of voluntourism, and emphasize its 
superiority over other voluntourism programs. In particular, International Voluntourism uses photographs to convey a sense of immediacy and legitimacy, as well as emphasizing its dedication to "health and safety" and training, to entice people to sign up.

On its website, International Voluntourism uses images, such as photographs and maps, to convey a sense of the voluntourists' experiences. On the main homepage of the website, a photograph of voluntourists working on an International Voluntourism project took up most of the space; there were also several smaller photograph icons so viewers could select projects based on the type of work they wanted to do. On its South Africa webpage there were photos of voluntourists volunteering, touring around, and of tourist attractions. According to the staff, this "gave a flavour" of an individual's experience by including images from the volunteer and tourist aspects. They explained that since it is a very visual website, it may help individuals see where they may be going, who they will be working with, and can help to convince them to sign up for their programs.

Through examining the screenshots from the website, I noted that the pictures are mostly of the voluntourists interacting with the children or of the local landscape. For example, one picture that stood out to me is of a young, 20-something year old white woman sitting on a small plastic chair reading a storybook to three 4-5 year old black children outside with a partially crumbling concrete wall in the background. While the initial meaning is simple-through volunteering, you can read stories and teach literacy to children in the townships - the ideological meaning is more complex. By showing the children seated outside next to a crumbling concrete wall, it depicts them as being "in need" and the white volunteer as being able to fulfill this need. This also intrigues a potential voluntourist's emotions by appealing to her desire to "make a difference" and 
develop relationships with the children with whom she will work, while showing the legitimacy of the organization, which arguably can motivate them to participate.

International Voluntourism's use of images is also a tool to gloss over the ambiguities of the experience, since it highlights the seemingly positive aspects of voluntourism, such as reading to children. By visually demonstrating the experiences a voluntourist may be involved in, International Voluntourism highlights the beauty of the people and landscape that individuals may discover in their specific program and encourages a person to imagine herself in the locale. Through using images to complement the text, it appeals to the viewer's emotional and visual senses, while also guiding expectations for the voluntourist before she arrives in Cape Town.

Sarah, John, and Katie mentioned that one of the aspects that differentiates International Voluntourism from other organizations is its focus on health and safety. According to the website, while an individual participates in a program, they have access to various safety features, such as airport pick-up and drop-off, safe accommodations, 24hour in country support, qualified and trained staff, and a 24-hour emergency phone. Since the majority of the voluntourists are young females, this could provide reassurance while they are overseas in a foreign country. The voluntourists also go through safety procedures and learn about risk management during their "first-day training."

Sarah stated that the focus on health and safety set International Voluntourism apart from other voluntourism organizations. She explained that even selecting a new project site requires attention to the safety of the volunteers, such as having a gate to regulate visitors and having fire extinguishers present, because it helps to frame their 
interactions with project partners. Sarah outlined how her job duties were to manage staff, make things run smoothly, coordinate logistics, and:

...the one big thing [International Voluntourism] is tight on is health and safety and making sure the procedures are being followed by the staff and are in place if there are any that comes up... Health and safety is a real big thing in the organization and it's my kind of responsibility to make sure the project managers and staff are following those procedures correct [ly].

Through her interview, Sarah emphasized the importance of health and safety for everyone involved with the projects. Similarly, John mentioned that: "health and safety is one of the biggest things. It's top priority and is instilled into us [the staff] during training." Through their staff training, website, and voluntourist training manuals, Voluntourism International represents itself as being committed to health and safety, which the staff said makes them appealing for potential voluntourists. Since there are so many voluntourism companies that offer trips in similar locations, an organization must differentiate itself in order to attract more customers and promote its reputation.

Another way that the organization represented itself to attract participants was its emphasis on training. Through stating that it has qualified and trained staff, while also training the voluntourists, it creates the tone of experience and knowledge. The staff described this as an attractive feature for participants. Before arriving in Cape Town, I had had teacher training in Ontario, so I felt relatively prepared to plan lessons in the nursery school. Comparatively, the other voluntourists mentioned they were nervous and had "never done anything like this before, so I'm glad they tell us what to do" (Colleen, voluntourist). They told me that one of the appealing aspects of International Voluntourism (and why they chose this program) was that it trained you before going to volunteer at the project. 
Prior to my departure, I received a training manual that described the school setting, ways to teach, how to encourage appropriate behaviour with the children, and also explained some basic "dos and don'ts for teaching," such as how to provide verbal discipline. This was added to when I arrived with a brief half day discussion-based training session. The staff explained that this training provided insight into the program, helped to prepare voluntourists, and gave the children consistent teaching, since the lessons were structured in similar ways, with similar learning goals. Katie explained that the training makes sure that the children at the projects get the "best" from the volunteers because some may not have had prior experience teaching children. After the training occurred, the other voluntourists mentioned that it had eased their worries about teaching in the nursery school and they felt more prepared (in spite of its brevity).

While the International Voluntourism staff explained that providing training, and promoting the use of training on the website, created a consistent framework for voluntourists and provided a standardized form of volunteer support, it also served another purpose. The use of training also represents International Voluntourism as a professional program that benefits the township and develops transferable skills for the voluntourist. This is an enticing promotional feature and can help to attract voluntourists. In addition, these promotional features also frame how the voluntourist interprets her experience before she even leaves her home country.

\subsection{This is how you "Give Back": Justifying Involvement}

Through analyzing International Voluntourism's website, training manuals, and staff interviews, I noted that its discourse attempts to explain how the voluntourist 
"makes a difference" through her involvement. While these mediums initially promote the programs and attract voluntourists, they also attempt to mitigate moral ambiguities or structural tensions by justifying the positive role individuals have volunteering overseas. This representation masks any contradictions during the experience using "feel good" rhetoric, which has repercussions for the voluntourist and how she interprets her experience. Through this, International Voluntourism responds to the ethical dilemmas of voluntourism by saying its programs impact the host community positively through its focus on education, sustainability, and including community members in its organization.

During the staff interviews, on the website, and within the training manual, International Voluntourism represents itself as focused on education and sustainability in its projects. This emphasis has implications, both for their relationships in the township and the expectations it creates for the voluntourists. It frames the interactions with the project partners because it means the projects are education-based, such as teaching English or tutoring, and is described by the organization as sustainable through being able to maintain the project goals after it ends its partnership (typically, within two years). For example, during the teacher training, Sarah emphasized that the voluntourists should try to use books and toys from the nursery school so that the project partners could replicate the lessons in the future without the organization's support. She explained that through doing this, as well as by providing time and support in the township, rather than giving material "gifts," the organization is able to make a positive and lasting impact. This focus creates a framework for the voluntourists to interpret their experience as providing meaningful work and that they "give a hand up instead of a hand out." 
Through these mediums, International Voluntourism claims that with its partnerships in nursery schools, it "makes a lasting impact." It says this is because the volunteers give the children access to educational opportunities they would not otherwise receive, which allows them to develop to their full potential. In particular, it explains that by using English-speaking volunteers, the children are immersed in English to improve their language skills, which will help them meet academic standards (since English is the language of instruction in the schools). Katie explained that teaching English is critical because the children at the nursery school are unable to attend primary school until they can write their name, count to ten, and identify basic shapes in English. This rhetoric of the value of English-speaking voluntourists over local teachers provides a basis for the voluntourists to interpret their involvement as fundamental and also masks structural tensions. It also attempts to justify voluntourism as being helpful and not causing harm. Another way that International Voluntourism represents itself as positively impacting its project partners is its inclusion of community members from the township. According to the staff, this is done through an internship program and by hiring South African staff. Sarah explained that International Voluntourism offers an internship program for community members, especially for individuals who had difficulty or did not graduate high school. In this program, they hire an individual from the township as an International Voluntourism staff member and have them work at the projects, take workshops (such as C.P.R., resume writing, and leadership training), and eventually provide references to help them transition into full-time work positions in South Africa. While this is not advertised on the International Voluntourism website or in the training manual, the staff members discussed the program. Sarah stated that the internship 
program helps build the capacity of individuals in the township; she also said it was a way to involve community members in the projects so that they were applicable.

One of the South African staff members I worked with was part of the International Voluntourism internship program and worked regularly with the voluntourists. Louis provided support for the volunteers at the nursery school and was developing his resume to eventually attend college. He explained to me that: "[International Voluntourism] gave me a great opportunity. To work with kids and have more work experience. I think this will really help me get a job later." Louis told me that International Voluntourism used to have a partnership with his mother's nursery school. Based on his role at his mom's nursery school, they decided to admit him to their internship program to provide him with training, work experience, and future reference letters. Louis told me he was very proud of his role with International Voluntourism because: "It shows how far you can come, even if you're from [the townships]." In addition to Louis, there were two other South African staff members I interacted with on a regular basis. While I did not formally interview Mark or Alisa, I talked to them about their roles with International Voluntourism. Mark's job was to drive the staff van and pick up/drop off the voluntourists from the airport, from the township projects, and from International Voluntourism side trips. Meanwhile, Alisa's job was to cook and clean the volunteer accommodations and to teach new staff Xhosa during the orientation training. In their roles, Mark and Alisa told me they were able to earn a decent living, receive training, and develop experience with International Voluntourism.

While initially it may appear that International Voluntourism is meaningfully involving South Africans in its organization, they also use it as a tool to justify their 
involvement in Cape Town. According to Andrea Cornwall and Karen Brock (2005), there is the possibility that development programs use buzzwords to situate themselves as positive, without defining terms or working to learn what community members want as support, in order to garner support. Similarly, Joanne Ingram (2011) explains that NGOs try to build capacities by working in partnership with local communities and involving them in the process. Thus, through using staff from the townships, International Voluntourism posits itself as an effective program through its impacts, which can attract potential voluntourists and garner support.

Through involving South Africans in the internship program, employing them directly, and working with project partners, International Voluntourism represents itself as a sustainable voluntourism program. This explanation can help voluntourists feel like they are supporting a "good" organization that fosters sustainability. Sarah stated that: "Ideally, I would love for all of [International Voluntourism's] staff to be South African. That's a personal goal of mine." According to Sarah, she felt the use of community members as staff was positive for International Voluntourism and was used to ensure the projects were relevant in the townships and to provide role models for the children they worked with in the townships. Through this framework, the organization attempts to eliminate the moral ambiguities of voluntourism, which promotes its programs, represents it as having a positive and sustainable impact in the host community, and ultimately, makes the voluntourist feel she is "giving back" and "making a difference" through her involvement. 


\section{4 "You Make A Difference": Framing the Experience}

The way that International Voluntourism represents itself provides a basis for the voluntourist to make sense of her experience. The organization's discourse provides an idealized account of how an individual should interpret her experience and navigate the ambiguous experience of voluntourism. In particular, through framing it as a way to "make a difference" and be a "link in a chain," International Voluntourism enables individuals to justify their involvement and mitigate its contradictory intersection of volunteering and tourism. This is important because, as I discuss in Chapters 5 and 6, the voluntourists echoed the organization's rhetoric during their interviews by framing their experience as "a gift" and a "life-changing experience." Through analyzing International Voluntourism's discourse in its literature, I highlight how its self-representation frames the voluntourist's interpretation of her experience.

One of the key concerns that International Voluntourism attempts to address is whether an individual "actually makes a difference" and if they may cause more harm due to it being a short term involvement. The phrase of "making a difference" occurred multiple times on its website, in its training manual, and during the staff interviews both explicitly and implicitly. International Voluntourism's slogan states that "You make a difference!" which deliberately links the individual to the purported positive impact of her involvement. This was also reiterated on its "SIGN UP" link where the subtitle states this is how an individual can "get involved and make a difference."

Similarly, within the training manual, it states that a person's volunteering will "make a difference by helping disadvantaged and poverty-stricken children who are desperate for support." Through using key terms, such as "disadvantaged," "poverty- 
stricken," and "desperate," it creates an impression of need and the necessity of volunteers, which in turn frames how the voluntourist interprets her experience. This was reinforced by staff members, Sarah and John, in their interviews when they explained that "learning English is fundamental" because it is the language of instruction in schools and the children need a good grasp of it to do well in school. International Voluntourism also used the term, "make a difference," to emphasize how their projects, and organization as a whole, has a positive impact on the conditions in the communities in which they work. During the staff interviews, they also focused on how their role was to help the voluntourists see how they were "making a difference." John explained that a huge part of his job is "...to help people see the work they have done and how much of a difference they have made just by coming." He stated that he does this through helping volunteers to manage expectations, such as not anticipating to "change the world," but to take note of the little subtleties in which they are involved. Sarah also stated something similar, which is that her role is to draw the voluntourist's attention to the larger picture. She explained that even someone who volunteers for a short time can teach one child one thing, which makes "...such a massive difference" for the child. For example, Sarah explained that: Sometimes people want to do everything... But you can't change the world, you can't change everything...I often use the example of manners. I had a girl once, there was a class she was teaching and for the whole two weeks she was really focused on good manners and those kids still continue to always say thank you, to always say please... what I tried to explain to her actually, you've taught those children something that's going to stay with them for the rest of their life. That's going to be the difference between maybe them getting a job interview and having friends, just manners, it's a small thing in life, but it's very important.

Sarah and John's statements demonstrate how the staff may use the organization's rhetoric to guide the voluntourist's interpretation of her experience. They do this by 
drawing attention to how she "makes a difference" in order to provide a framework for her to make sense of the contradictions of voluntourism.

One of the main contradictions of voluntourism is that the organizations claim to "make a difference" and help the host community, but the voluntourists are only overseas for a short period of time in a tourist-style role. The staff used the concept of a "link in the chain" to represent the voluntourist as "making a difference." Even if this impact is invisible; they frame the voluntourists' contribution using this concept. As John stated:

Another part of my job is to help people see what they have done. Like how much of a difference they have made just by coming here, even if it's just for two weeks. And I will say this again and again, when you get here, when you leave, and all the way through, that just by coming for two weeks it means that whatever the last group did and whatever the next group does, you are a link in the chain.

The concept of a link in the chain is a metaphor that is used to justify the continual changes in volunteers at the project sites. It implies forged relationships with past and future volunteers, as well as stability for the project partners.

The rhetoric of the voluntourist as a "link in a chain" highlights the cyclical and changing nature of voluntourism, while also appearing to remedy the problem of inconsistency by stating that individuals build on previous participants' work. Using the phrase a "link in a chain" emphasizes the strength and connectivity of the volunteers with each other and within the community, while positing this changeability as a positive aspect of volunteer tourism. It highlights that the voluntourist fits into the organization's pre-existing structure to aid the community members and the staff and training are used to immerse new volunteers into the program. This discourse smoothes over the ambiguities of voluntourism, attempts to justify short-term involvement, and also provides a basis for the voluntourist to make sense of her experience. 


\section{Chapter: The Gift}

Through the discourse in its literature, International Voluntourism attempts to reconcile voluntourism's ambiguities in its combination of volunteering and tourism. As I examined in my content analysis in Chapter Four, the organization uses "feel good" rhetoric to mitigate the contradictions of voluntourism, promote its programs, justify its involvement in the host communities, and guide the voluntourist's interpretation of her experience. By examining International Voluntourism's website, training manuals, and staff interviews, I provided insight into how it represented voluntourism; this created a framework for the voluntourists to interpret their experiences and make sense of it. International Voluntourism suggests that the voluntourism experience will enable an individual to fulfill her goals of "giving back" and "making a difference" by helping people described as being in need. This was pertinent because the voluntourists I interviewed adopted this language when describing their own voluntourism experience. Through framing their involvement as a gift, the voluntourists masked the asymmetry of the exchange between the privileged Westerner and the host community, which created a basis for interpreting this complex experience.

During the interviews, the voluntourists echoed International Voluntourism's buzzwords, representing themselves as going on this trip as a way to "give back" and "make a difference." Through the organization's idealized depiction of a voluntourist, it provided a guideline for the voluntourist to frame her trip. Since the study participants used this language to describe their involvement, it highlighted the links between the organization discourse and its impacts on the voluntourists' perspectives. In my analysis of the voluntourists' interviews, I focused on their responses around the themes of 
"giving back," "making a difference," and the relationships forged overseas. I also looked at when the framework of the gift unraveled when the voluntourists expected to "get" photographs in return for their work. I then intersected this with Mauss' concept of "the gift," and how it establishes a total social fact, in order to unpack what this representation may emphasize for how the individual represents her involvement.

\subsection{The Voluntourist Voice}

In my fieldwork, the voluntourists I interviewed described their experience as a way to "give back." While they stated during the interviews that they were aware that a short-term voluntourist project would not "change the world," they all said that through "giving back" they were "making a difference." In particular, they focused on the benefits of their involvement for the children in the nursery school, with one voluntourist stating that: "...by teaching them English, it will help them in the future. Maybe they can graduate or get a good job." The voluntourists also described their relative wealth in comparison to the township, noting that "I have so much compared to them." Through this, they represented themselves as attempting to support "less-privileged" individuals through initiating an exchange and giving of their time to volunteer. This focus on framing voluntourism as a gift neglects the asymmetry of the exchange, but also provides a framework for the voluntourist to minimize the contradictory aspects of her trip.

I chose to use the voluntourists' narratives from the interviews, as well as participant-observation from the trip, as a tool to explore how they framed their experiences. While it would be possible to analyze voluntourism based on a literature review of prior research or by conducting a content analysis of an organization's 
discourse about its programs, by using the voluntourists' voices to discuss the experience, I hope to convey a concrete lived experience that provides a more nuanced understanding of voluntourism. Although each voluntourist came to the experience with her own positionality, they all described their involvement using similar language, such as "giving back," "making a difference," and having a "life-changing experience." This emphasized that there is a culture of voluntourism that shapes the activities overseas, as well as that these individuals are impacted by the sending organization's discourse since it frames how they represent and interpret their experiences.

\section{2 "I just want to 'Give Back"'}

During my interviews and participant-observation with the voluntourists, one of the most common themes that occurred was that these women were involved on the trip as a way to "give back." This was said both as a vague concept and, more specifically, because of the voluntourists' relative prosperity, which they claimed required them to help those "less fortunate." As Megan explained, she went on a voluntourism trip because she had: "wanted to do what I could to help, you know." While the voluntourists were reflexive about their involvement, and some even noted that it felt cliché that they wanted to "give back," they all kept coming back to this motif when describing their personal life, their reasons for coming on the trip, and their experiences.

Kerry explained her participation in voluntourism as an exchange between her and the people with whom she volunteered. While she noted her increased confidence, a sense of accomplishment for making it to Cape Town without her parents, learning about another culture, beginning to understand other people's way of life, and making new 
friends, Kerry emphasized that it was amazing to see how much her volunteer work helped the children at the nursery school. She explained how even though she was here for a short time, it was fulfilling to see them learning from her short lessons. Through her experiences, Kerry described voluntourism as benefiting those involved:

You get something from it, you get everything. You learn about culture, help people, work with people, see a different culture, but see it from the people who live there, not really a tourist's eye. Like being immersed in the society instead of watching.

This demonstrated her perception of voluntourism as an exchange for both sides, with the voluntourists "giving back," while also getting experience and insight in return.

Similarly, this description of voluntourism as an exchange also demonstrates that "giving a gift" creates what Mauss would describe as a total social fact, wherein the giver offers a piece of herself to the recipient. According to Mauss: "What imposes obligation in the present received and exchanged, is the fact that the thing received is not inactive. Even when it has been abandoned by the giver, it still possesses something of him" (1974: 11-12). This forges a bond between the two individuals when the voluntourist initiates the exchange. I explore the concept of this relationship in more depth later in the chapter, but the phrase "giving back" shows how this exchange is premised on the voluntourist leaving a token of herself by supporting children's learning at the voluntourism project.

The International Voluntourism staff also substantiated the voluntourists' experiences of "giving back," and discussed that volunteers leaves a piece of themselves through their emotional involvement. John said that he believes one of the critical features of voluntourism is that "it breaks down barriers for people and opens their eyes 
to see and begin to understand other people's way of life." This emphasizes the bond between the volunteer and recipient, since the staff represents voluntourism as fostering a relationship. Through her involvement on the trip, International Voluntourism claims that the voluntourist is exposed to how individuals live in the Cape Town-area townships and can begin to acknowledge the innate humanity worldwide. Similarly, on a more practical side, Sarah explains that the voluntourists "give back" through teaching English: "exposing them [the children] to English is the biggest gift and teaching them is the biggest gift we're giving them." By leaving the learned lessons behind for the children the voluntourists help, they are represented by the organization as giving the children a significant advantage in school, while also receiving the gift of experience, personal growth, and understanding in return.

Although voluntourism being framed as a gift may be portrayed as a positive feature, it can also be described through an individualized, charity-oriented perspective. While most of the voluntourists noted that their experience in the townships "opened their eyes" to how other people live, it also evoked comments such as: "they have so little," "this makes me appreciate what I have back home," and even, "I just, it must be so hard for them to live like this, with so little, yet they seem so happy." This charityorientation that was developed by the organization's discourse made the voluntourists feel the gift they were providing was critical because of the difficulties they believed the people in the township had to endure on a daily basis. Similarly, based on this rhetoric, the voluntourists' self-representation of their experience as giving a gift elevated their perception of the value of their role, which made them state they were "making a 
difference" through their actions. This language also masked the asymmetry of the exchange and provided a means to reduce the ambiguity of the experience.

\section{3 "I Want to "Make a Difference"”}

Another recurring theme during the voluntourists' interviews was that they explained how they wanted to "make a difference" or that they felt their volunteer work was "making a difference." This is linked to the concept of "giving a gift" because the voluntourists represent themselves as developing a bond to the South Africans they worked with through the impact of their volunteering. They frame their "giving back" as a way to "make a difference" in the host community, which motivates their involvement and smoothes over any contradictory elements of the experience. This is emphasized by International Voluntourism in its literature, and was also taken up by the voluntourists to explain their trip. I interpreted this concept of "making a difference" as two-fold, with the voluntourists representing themselves as socially conscious and wanting to help, as well as an attempt to justify their trip abroad as a way to "do good." Sin supports this concept, stating that voluntourists are often motivated to volunteer abroad by the desire to "make a difference" and impact those with whom they work (2009). This emphasis on both parties benefiting from voluntourism, and that it should fit into a larger concept of "making a difference," masks its ambiguity and helps individuals to make sense of their complex experience by framing it as a gift.

For example, one of the reasons Hillary said she went on the trip was as a way to "make a difference." She selected South Africa because she had studied apartheid in school and knew about the racial inequities, and wanted to work with children to help 
them in school. Hillary felt giving some of her time to volunteer during summer holidays would help "make a difference" through teaching English to the young children to help them do well in school. Sasha also noted something similar, and said she noticed the impact her volunteer work had once she came to Cape Town, as well as its effect on her: It sounds really cliché, but this makes you realize what you have and how much you help, like, I'll go back to a job where I work in a store, day to day things that would annoy you, will just seem so silly now... You really start to see how what you do makes a huge difference and focus on the small things.

She also noted how she thought she could continue to do this volunteer work as a job because there is so much fulfillment in helping the children, and she wished she could stay a longer time to see more of the difference she actually made with the kids.

During her interview, Sasha also mentioned that although she wanted to see the long term effects, she felt her volunteer work "made a difference," even with the little things she did: "This benefits the kids out here. And hopefully I make some kind of impact. Like if a kid learns their numbers, then I did my job and it's been worthwhile." This focus on making an impact was reiterated by all the volunteers during their time in Cape Town. According to Kerry, she went on the voluntourism trip because: ... it was the experience I wanted, to see a different part of the world. I dunno. I know it's really cheesy, to make a difference, but everyone kind of wants to, you know. To help in a way. They want to think that something they do will help somehow. I think that kind of urge to help someone.

As these two voluntourists explained, one of the key motivating factors to become involved on a voluntourism trip is the ideal to "make a difference" through volunteering abroad. Although there was some ambivalence about the "clichéd" aspects of wanting to "make a difference," this highlights the structural tensions of voluntourism since the organizations claim the individual truly can "make a difference" on a global scale. In 
response, the voluntourists echoed the organization's rhetoric by representing themselves as wanting to see that the work they were doing was "making a difference" and "giving back" to help those whom they perceived of as "in need." This attempted to smooth over the contradictory aspects of the experience and focus on what they interpreted as the positive impacts as a way to remedy this ambivalence.

Sarah, one of the organization's staff, also said that wanting to "make a difference" is a common explanation for why an individual wants to come on the trip. She said these are the type of people who opt to come and work hard, instead of lying on a beach, for their breaks. Through her interview, Sarah reinforced International Voluntourism's discourse by explaining that her role is to help the voluntourists realize that they "make a difference," even through smaller actions, such as teaching shapes or manners. She said it is important for the voluntourists to understand that "making a difference" is not necessarily by doing grand gestures, but through gradually making small impacts, which build on each other and eventually can make a bigger change for the individuals being helped. Explanations, such as Sarah's emphasis on the impact of smaller actions, frame the voluntourists' experiences and provide a basis for them to interpret their involvement overseas. As well, by echoing International Voluntourism's discourse, the voluntourist frames her experience as "doing good" since she represents herself as similar to this idealized concept of the voluntourist who "gives back" and "makes a difference" in the host community. 


\subsection{Developing a Bond}

In addition to the voluntourists describing their experience as a way to "give back" and "make a difference," they also emphasized the importance of the relationships they forged on the trip and the cultural exchange in which they were involved. Through giving "the gift" of volunteerism, voluntourists claimed they felt a bond toward the host community, in particular the children and the project partners. The voluntourists represented themselves as beginning to share an understanding of another culture's way of life from a local's perspective because they were not just a tourist. They also claimed that this cultural exchange was enhanced by the relationships forged with the individuals with whom they worked—both the children and the adults who worked at the nursery school. This sense of a shared bond emphasizes Mauss' concept of the gift encompassing a "total social fact," which contains an aspect of the giver and creates a link between them through the necessity to reciprocate.

During the interviews, all the voluntourists described how welcoming the staff at the nursery schools were, as well as how much the children expressed their love for the volunteers, which they felt emphasized their relationships forged on the trip. As Sasha stated during her interview: "The kids make it really easy. They just love you." John also explained that regardless of why an individual chose to come on a voluntourism trip, "literally everyone" puts working with the kids as the highlight on the feedback form. This focus on working with the kids, and feeling reinforced by the welcoming nature of the children, emphasized the bond the voluntourists felt they developed through volunteering and seemed to strengthen their claims to "make a difference." 
Shaina also represented herself as feeling close to the staff at the nursery school. She explained that she did not know what to expect with regards to her experiences volunteering in the township, but she was pleasantly surprised by the hospitality: " $I$ wasn't expecting it to be so personal. It's [her] house. You feel really close to them. You know, it's really nice how they welcome you into their home." During her interview, Shaina noted that she felt like she had a lot more understanding of how people live, especially through experiencing her work at the nursery school. Meanwhile, Sasha focused on the commonality with the nursery school staff in the townships. She explained that she learned that their culture was actually really similar to her own, which she said was emphasized when one of the nursery school staff had to interview some voluntourists as part of her Early Education Program. As part of the interview, Sasha said they discussed the importance of children and family, single-parent families, and divorce rates, which they both realized they had in common in spite of being from different countries. As these insights demonstrate, the voluntourists represented themselves as having established a rapport with both the children and nursery school staff through their involvement, which reinforced their interpretation of their experience "giving back."

One of the voluntourists was returning for a second year after volunteering in the same township in Cape Town the previous summer, which made her interpretation of her experience interesting to analyze. Megan explained that she was drawn back here for one main reason: "Just the kids. I missed them the second I left." She explained that the bond she had developed with the children and the nursery school staff last year left a lasting impression on her. Megan described one of her pivotal moments last summer, which solidified this perspective. She had been sick for a few days and was unable to volunteer 
at the project location. When she came back, several of the children ran up and hugged her and said they were so happy she was back and they were concerned she was sick. As well, the nursery school staff had created a "Get Well Soon" card and had signed it with a prayer and had the children draw pictures for her. Megan felt this was a huge moment that emphasized her bond with those with whom she worked. Upon her return to the township, Megan was even more shocked when she went back to the nursery school after a year of being home. She was concerned everyone would forget her; however, one of the staff gave her a hug and called her "my daughter" and some of the children came up and said "welcome back teacher [Megan]." Megan felt this simple gesture of the staff and children remembering her name made her feel how genuine their bond was and how much she "made a difference" in their lives by working with them.

However, in spite of the perceived bond between the voluntourists and those with whom they worked in the townships, there is still a divide between them. The voluntourist experience is shrouded by the tension of authenticity, since these individuals are only working in the townships for a short period of time and do not live in it during their trip. There is a segregation of space as the volunteers live separate from the township in a relatively more affluent neighbourhood. As John mentioned, “...living in less comfortable conditions would not change the situation for people at the projects..." and he argued that although it made some more socially-conscious volunteers uncomfortable, it did not make an individual better prepared to volunteer. This highlights the ambiguity of voluntourism and how the organization's discourse, which is adopted by the voluntourists, attempts to mask these contradictions. Thus, while the voluntourists note a relationship and cultural exchange between them and the South Africans they work 
with, this is their perception of their experience and does not take into account the South African individuals' perspectives. Rather, it was impacted by the framework the organization established on its website, in its training manual, and through its staff.

\subsection{A Picture is Worth a Thousand Words}

During one of my informal discussions with Katie, the project coordinator, we noted how individuals take photographs to frame their experience and as a way to take back "what they did" to show their family and friends. This seemed to emphasize the relative importance for a tourist to use photography as a way to showcase their trip. It also highlighted the internal controversy of voluntourism as an individual attempts to resolve her interest to volunteer or "give back" with her desire to take photographs and tour. A voluntourist is caught in the structural tensions of volunteering and tourism, which sometimes have contradictory motives, especially when it involves how an individual interacts with the host community.

While I was conducting my fieldwork, International Voluntourism imposed a nophotograph policy during the volunteer projects, in order to protect the children at the nursery school. Although all the voluntourists I was with understood the reason behind this policy (and even agreed with protecting the children's privacy), most of them were still unhappy because they had wanted to show what it was like at the volunteer project and show where they had worked during their time in Cape Town. They all stated that they came to work with the children, but outside the formal interview, they emphasized that not being able to take photographs meant they could not show what it was like at the volunteer projects, which positioned it as another tourist site. This example showed one 
of the ways in which the voluntourist struggled to combine volunteering with tourism. Specifically, the voluntourist expected to "get something" in return by taking pictures; they did not just give "the gift" without anticipating receiving something themselves.

The International Voluntourism staff all noted that the photo policy being implemented was unpopular with the voluntourists, especially because it was relatively new, but they felt it was the right thing to do to protect the children. In particular, it meant that they could protect the children's privacy by only allowing photographs that do not directly identify the child (which could later end up online on forums, such as Facebook). As Shaina said, although International Voluntourism was making a photo presentation based on the pictures their staff took at the volunteer projects, you could not print out the presentation pictures and it was not really the same. Hillary said she did not think her family would fully be able to understand what she did and saw without having all the pictures she had wanted to take. Interestingly, these discussions occurred outside the formal interviews and were emphasized near the end of the trip when they began planning their returns home. The voluntourists said they were quite upset they were unable to share what they did overseas from their own perspective.

The voluntourists' disappointment in not being able to take their own photographs of their experience is linked to the concept of exchange and giving a gift. The voluntourists wanted to document their involvement overseas as a way to "capture" their relationships and how they made a difference. Similarly, there is an expectation that through giving back, the voluntourists get pictures upon their departure. While part of this may be that the voluntourist wants to craft her own experience through her own lens rather than receiving staff approved pictures, it may also be the unspoken self-interested 
aspect of their exchange. Although the voluntourist may create a bond by "giving back" and "making a difference" in other people's lives, they also want to get a sense of return through being able to show what they did in photographs when they go home.

Additionally, this case also highlights the inherent tensions of voluntourism as the individual attempts to balance her volunteer work with tourism, which contradicted each other regarding the collection of photographs.

\subsection{The Voluntourists' Gift: Mauss}

Through exploring the voluntourists' narratives of their experience, I noted that they focused on framing their experience as a "gift." Thus, in order to examine this perception in more depth, as well as the implications of this term, I employed Mauss' concept of "the gift." Mauss describes the gift as a total social fact, which encompasses the social existence of those involved and is inalienable (1974: 80). Mauss explores aspects of the gift through analyzing the form and reason for exchange in "archaic" societies in The Gift, wherein he notes that gifts:

... are in theory voluntary, disinterested and spontaneous, but are in fact all obligatory and interested. The form usually taken is that of the gift generously offered; but the accompanying behavior is formal pretense and social deception, while the transaction itself is based on obligation and economic self-interest (1974: 1).

This concept is applicable to voluntourism because it is often framed as a way of "giving back," where the voluntourist gives her time and money to volunteer in an overseas community. As Mauss notes, these gifts are not inactive and possess something of the giver (1974: 11-12). Accordingly, “...it follows that to make a gift of something to someone is to make a present of some part of oneself' (1974: 12). Thus, through her 
involvement in voluntourism, an individual gives a piece of herself to the host community and creates the necessity to reciprocate it. By framing this experience as a gift, it covers up the contradictions and ambiguities that result from voluntourism.

Similarly, through framing voluntourism as a gift, it highlights the relationships and bonds between the giver and recipient. The voluntourist represented herself as anticipating to "give back" through volunteering, but she is the one who initiates the exchange by going overseas. In exchange, she is given cultural knowledge, relationships, and experience from the host community. As Mauss argues, through exchanging gifts:

It assumes an aspect that centres on the interest attached to the things exchanged. These are never completely detached from those carrying out the exchange. The mutual ties and alliance that they establish are comparatively indissoluble. (1974: 33)

While this posits the gifts exchanged as equivalent between the voluntourist and the host community, it does begin to articulate the way the voluntourists frame their experiences and connections to those with whom they work. The total social fact of the gift means the two parties exchange a piece of themselves: "In this respect these additional exchanges express, as a fiction, that coming and going of souls and things that are all intermingled with one another" (Mauss 1974: 48). Through "giving back" the voluntourists conceived of themselves as demonstrating the inter-connectedness of humanity within the world and initiate an exchange with the host community.

As well, by utilizing Mauss' concept of the gift to look at how voluntourism may be framed as voluntourists "giving back" to host communities from the developing world, it could help to provide insight into what inspired them to become involved and travel overseas. Brown (2005: 487) argues that voluntourism represents individuals as choosing 
to engage with others as a means to enact their sense of purpose through offering their help overseas. As well, voluntourists believe that it provides the opportunity for them to make a difference for those perceived as less fortunate, instead of just travelling and focusing purely on self-enjoyment (Brown 2005: 488). This may foster a sense of agency in the voluntourist, which the organization staff reaffirms, that an individual can make a difference through giving back; it positions the culture of voluntourism as Western youths' solution to global inadequacies and justifies their involvement overseas. This emphasis on "giving back," "making a difference," cultural exchange, and the relationships forged help to reveal the foundation of voluntourism. It provides a basis for the voluntourists' self-representation and perceptions of their experiences.

\subsection{Key considerations of "The Gift" of Voluntourism}

Through examining the voluntourists' representations of their experiences as "giving back," "making a difference," and creating a bond with the host community, which I intersected with Mauss' concept of the gift, I highlighted the impacts of International Voluntourism's language of voluntourism. The voluntourists all adopted this discourse during their interviews and represented themselves in similar terms as the organization's idealized voluntour who goes overseas to help those "in need." By using this framework, Mauss' concept of "the gift" provides a means for individuals to interpret their experiences and smooth over the contradictions of the commodification of voluntourism by representing it as helping the host community.

One of the main contradictions that the concept of "the gift" mitigates is that voluntourism is an experience that is constructed by the sending organization and it is not 
“authentic ${ }^{5}$. Voluntourism involves an individual paying an organization (typically around $\$ 1500 \mathrm{CAD}$ for two weeks, plus flight) to volunteer in a developing country. The individual selects a pre-existing program based on her interests and when she arrives in the country, she participates in pre-planned volunteer activities with the designated project partners. Through representing voluntourism as "giving back" and "making a difference," International Voluntourism smoothes over the contradictions of the commodification of voluntourism, and the intersection of volunteering and tourism. By adopting this rhetoric, the voluntourists also attempt to make sense of this experience and reduce the focus on the paid aspect of voluntourism, the fact that they initiated the exchange by going overseas, and the ambiguous aspects of the experience. Instead, it creates a voluntourist-centred perspective that maintains the Western individual as the focus of the experience.

\footnotetext{
${ }^{5}$ I will not examine what constitutes authenticity of experience. Instead, I use this term to explain that individuals participate in voluntourism by paying an organization and taking part in a structured program that she fits into with pre-approved project partners, not through an organic exchange between individuals.
} 


\section{Chapter: Shift in Perspectives and the Life-World}

While I was initially shocked when I saw the poverty in the townships, I had kind of expected this prior to coming on my trip to Cape Town. I did not expect people to be living in storage containers and corrugated metal shacks, but I had also realized they would not be in extravagant homes. A part of this understanding was because of my prior trip to Cusco and another part of it was because I had some awareness of township life in South Africa based on media and prior research. I knew I would be working in townships and that apartheid had left a major impact in South Africa. Although the township experience did alter my perspective while I was on the trip, this was a relatively small shift.

The big shock for me came from something else that I was completely unprepared for. In Ontario, I had completed my teacher's education. For me, disciplining a student was based on verbal reprimands and teaching is a hands-off practice. Yet, while I was in the nursery school, the teachers used corporal punishment to discipline the children. The first time I saw a teacher hit a misbehaving student, my heart sank. My stomach was in my throat. I felt glued to the floor as every muscle in my body tensed. Everything about watching this felt wrong. What 3-year-old deserves to be hit? Even though it was "just" a flip flop, watching the teacher hit the child on the head for misbehaving felt horrible. This is when I felt a shift in perspective through witnessing something I did not expect.

In this chapter, I continue my analysis of the voluntourists' narratives about their experiences in Cape Town. Previously, I examined how International Voluntourism represents itself, which provided an initial framework for the voluntourists to interpret 
their experience; this context gave me a basis through which to examine the voluntourists' narratives. Next, I used Mauss' concept of "the gift" to look at how the voluntourists echoed the organization's rhetoric that they want to "give back" to "make a difference" in the community and establish a bond, which masks the ambiguous nature of voluntourism. This chapter addresses how the voluntourists represent themselves as experiencing a shift in perspective, focusing on how they describe this experience and its impact on them. I outline Schutz' concept of the life-world, its relevance to voluntourism, and then examine the voluntourist experience through this lens. By using the concept of the life-world, I can look at how the voluntourists describe a shift in perspective based on their novel experience abroad. This complements their description of their involvement as "giving back" because the rhetoric of describing a "new perspective" attempts to smooth over their "culture shock" and the contradictory aspects of their experiences.

In my analysis of the voluntourists' narratives, I organized their responses based on several recurring themes from the interviews. I looked at their descriptions of their initial change in perspective upon entering the townships, the importance of "being there" to develop relationships with individuals in the township, and the indescribability of the voluntourism experience. Through engaging with these themes, I hope to examine how the voluntourists represent themselves as being changed and having an altered perspective as a result of their experiences voluntouring in Cape Town.

The voluntourists I interviewed described their experience as eye-opening, a catalyst for changing their perspectives, and that it required an individual to "be there." While several of the voluntourists had studied South African apartheid prior to the trip, only one woman had been in a township before, and this was during her childhood in 
Zimbabwe. They all said that going into the townships was quite a shocking experience for them and that it surpassed anything they had expected. Specifically, they explained that going on the trip enabled them to "see what it was really like" in the townships and how other people lived. They also said how important it was to travel to experience South Africa and develop bonds with individuals in the township through volunteering with them. Yet, in spite of how much the voluntourists stressed that the trip had impacted their lives, they also said their experiences were indescribable and an individual had to "be there" in order to understand. These descriptions centered on the voluntourist's belief that her experiences volunteering in Cape Town had impacted her in such a way, that it was difficult to relay the experience to others. This experience was represented by the voluntourists as "creating a new perspective," which echoed International Voluntourism's description of the trip as a "life-changing experience." Through my fieldwork, I noticed that the voluntourists represented themselves as experiencing a shift in their life-world due to a novel experience, which helped them navigate the ambiguous aspects of the trip. By adopting a Schutzian phenomenological approach, I intend to unpack how and why a voluntourist may describe her experience as altering her perspective.

\subsection{The Schutzian Life-World}

According to Schutz in The Structures of the Life-World, the life-world is the everyday taken for granted reality of a normal and awake adult, in which an individual interacts with others and acts in ways that are patterned (Schutz and Luckmann 1973: 3). This includes a taken for granted stock of knowledge that is acquired from the sedimentation of subjective experiences (Schutz and Luckmann 1973: 123). As Schutz 
explains, this: "life-world is thus a reality which we modify through our acts and which, on the other hand, modifies our actions (Schutz and Luckmann 1973: 6). Thus, people shape and are shaped by the reality of their life-world. An individual is situated within her life-world in specific spatial and temporal realms, which structure her specific beingin-the-world and interactions with others. This is significant because it highlights the unison of the subjective, biographical elements of a situation with the social and historical aspects:

...every situation is biographically imprinted. It has its specific prior history, which I "know." Moreover, I come into the situation with a specific, biographically articulated stock of habitual knowledge of skills, practical knowledge, and knowledge of recipes. (Schutz and Luckmann 1973: 114)

By acknowledging the social elements of subjective experience, the life-world concept allows for an exploration of how an individual is situated in her interactions with others and the world around her.

According to Schutz, if an individual is faced with an unfamiliar situation, she is forced to reconsider her everyday reality. While this may be done by making a "leap" from one province of reality to another or bringing the novel experience into a familiar framework (Schutz and Luckmann 1973: 223), it can also involve creating a new meaning structure. By coming upon new circumstances, it may cause an individual to question her "natural" or taken-for-granted reality:

It appears to us as a "natural" reality, and we are not prepared to give up the attitude that is based upon it unless a special shock experience breaks through the meaning-structure of everyday reality and induces us to transfer the accent of reality to another province of meaning. (Schutz and Luckmann 1973: 35)

Adopting Schutz' framework allowed me to interpret how the voluntourists conceived of her change of perspective through her involvement on the trip. Through coming upon a 
novel experience on a voluntourism trip, such as entering a township, the voluntourist may claim that it caused her to reconsider how she lives her own life back home.

An individual's everyday reality not only includes her experience of the natural world, but also of the social world in which she lives (Schutz and Luckmann 1973: 5). This means it is important to analyze her relationships with other individuals, an analysis which is based on her subjective experience. First, it is important to consider the different types of relationships an individual will have with other people. Schutz differentiates between relationships with people based on time and space. He classifies the thouorientation (or consociate) as one which occurs when an individual occupies the same time and space, while also being oriented towards the flow of experiences into the consciousness of the other (Schutz and Luckmann 1973:62). This becomes a we-relation when the individuals are engaged in a reciprocal thou-orientation (Schutz and Luckmann 1973: 63). He also explains that individuals who co-exist in the same time period, but are not bodily present together, are referred to as being in they-orientation towards each other (or: are contemporaries) (Schutz and Luckmann 1973: 74). Finally, Schutz classifies social relations in generational-historical terms. In relation to the individual of focus, others from the past are called predecessors (Schutz and Luckmann 1973: 87) and future individuals are termed as successors (Schutz and Luckmann 1973: 92). While all these types of individuals are conceptually within an individual's social world, she only directly interacts with consociates in we-relations.

In my fieldwork, I focused primarily on the voluntourists' interactions in thouorientations or we-relations with the individuals they volunteered with overseas. Prior to the trip, these individuals were mere contemporaries or "types" for the voluntourist, but 
they became consociates through the voluntourists' involvement on the trip. This is important to note because the voluntourists described the impact of the relationships they experienced in Cape Town and how it altered their perspectives. The voluntourists explained that through meeting people in the township, it helped to put a face to who they were helping, instead of just being an abstract concept of someone "in need." According to Schutz, the direct experience of the Other creates a mediated comprehension of self “...through the immediate experience of an Other, who experiences the developing self immediately" (Schutz and Luckmann 1973: 245). Thus, an individual considers herself based on her interpretation of an Other's experience of her.

By considering how the voluntourism organization, project partners in the township, the other voluntourists, and friends or family back home perceive of volunteering abroad, the voluntourist is able to develop a mediated comprehension of herself in this position, i.e. transforming her sense of self. This is initially based on International Voluntourism's self-representation on its website and in training manuals, which provides a framework for the voluntourist to interpret and represent her own experience. It is also dependent on these different Others, who have distinct impacts on the individual's sense of self based on the circumstances. For example, while overseas, the voluntourist initially appears to be shaped most distinctly by the other voluntourists and the organization by trying to do her best volunteer work, while also being impacted by the perceived experiences of the host community. Yet, the most important Other for the voluntourist is her family/friends, since she refers to how they will interpret her trip (and how she has changed or developed from it) when she comes home, noting how she 
will explain her experience, the photographs she will show them, and how her family is proud of her going overseas to "give back."

In addition to considering the voluntourist's mediated comprehension of herself through an Other, it is also important to discuss how she interprets other people's subjective experiences. The voluntourists described their shock of how they imagined people lived in the townships:

In simple "imaginings," attention can also be directed to the subjective meaning of the experiences of Others, for instance to the observation of the facial expressions of a person who believes himself to be unobserved (Schutz and Luckmann 1973: 253).

Through sharing "...the same spatial and temporal sector of the life-world..." the voluntourists can begin to imagine how the Others they meet in the township may live and perceive of their experience (Schutz and Luckmann 1973: 254). This knowledge gained in imagining how other people live may come up against prior conceptions, which may cause the voluntourist to reconsider her stock of knowledge.

An individual utilizes her stock of knowledge to understand and engage with her surroundings. She only realizes "...the deficient tone of [her] stock of knowledge if a novel experience does not fit into what has up until now been taken as the taken-forgranted valid reference schema" (Schutz and Luckmann 1973: 8). Schutz' uses the example of a mushroom to explain how an individual may address a novel problem; when an individual approaches something, such as a mushroom, she may use her routine succession to classify it into a typically reference scheme, such as poisonous or palatable (Schutz and Luckmann 1973: 10). Yet, if this does not fit within any previous typical experience, such as the back of the mushroom exhibiting something completely 
unexpected, an individual's "... habitual reference scheme meets with opposition" (Schutz and Luckmann 1973: 11). As Schutz' example highlights, if something does not fit into a prior habitual reference schema of interpretation, it interrupts the taken-for-granted flow of experience and chain of self-evidency (Schutz and Luckmann 1973: 11). Based on this example, Schutz describes different degrees of reinterpretation. There are novel experiences that require a broadening of understanding or to reconsider elements of one's stock of knowledge, but which leave its basic structure intact. Some experiences, however, can be so shocking that an individual's complete stock of knowledge is insufficient to solve the problem and they are required to re-evaluate at a greater scale. Thus, there are various degrees of reinterpretation, which can be applied to the voluntourists' experiences in Cape Town.

For example, the voluntourists described how entering the township for the first time was a shocking experience because it did not fit their prior conceptions of a community. Since they were faced with a new experience, they had to reconsider it in order to understand it. I experienced something similar with my first time going into the township. During our first full day in Cape Town, the International Voluntourism staff took us to the various project locations to familiarize us with our environments. I remember being glued to the window of the van, observing the various stores that were run from storage containers and seeing the poor conditions of the houses. I had never seen people living in or running stores in storage containers before, so this experience made me rethink the definitions of "home" and "work."

When the new voluntourists arrived at one of the nursery schools, we got out of the van to go and meet the students and teachers. While it had similar features as nursery 
schools in Ontario, there were several aspects that were strange to me and required me to reconsider my stock of knowledge. The school had crooked and dirty carpets, had small rooms, was overcrowded with children, and seemed chaotic compared to the clean, open, "play station-based" nursery schools I had seen back home. Yet, the biggest shock for me was not entering the township for the first time or visiting the nursery school. Instead, it was watching the teacher hit one of the misbehaving children over the head with her flip flop. I had never been exposed to something like this before, and as Schutz outlined, it required me reevaluate my entire stock of knowledge because I did not have a prior schema to resolve this internal dilemma. Several of the other voluntourists also noted the shock of watching a teacher punish a child by hitting him and that they had never seen anything like it before. As this novel situation highlights, according to Schutzian phenomenology, there are varying degrees of shifts in perspective based on a novel experience. Relatively minor experiences (such as entering the township) require a reexplication of prior knowledge, while sometimes major experiences (such as witnessing a teacher hit a child) require an individual to completely readjust her perspective because she has no prior framework in which to understand her experience.

As an aside, while it is important to accept the voluntourists' narratives of a change in perspective at "face value" because it is their self-representation of their experience, I also acknowledge that this may not be a "true" change. Rather, the voluntourists may claim to have a new perspective because of a prior expectation that voluntourism "changes you" or they want to appear as if it was a significant experience. This emphasizes the ambiguity and structural tension of voluntourism through its intersection of volunteering and tourism, as well as that International Voluntourism 
depicts its program as a "life-changing experience." Regardless, the importance is not if this shift occurred, but how the voluntourist shares her reality in her narratives, as well as how she wants to be characterized in relation to her experience.

\subsection{The Voluntourists' Self-Described Shift in Perspective}

In "Applying a transformative learning framework to volunteer tourism," Coghlan and Gooch discuss how voluntourism may be a catalyst for a shift in perspective because it creates a novel experience for an individual. Specifically, they classify voluntourism as a form of transformative learning (Coghlan and Gooch 2011: 714). Coghlan and Gooch explain that an individual will experience a deep structural shift in her thoughts, feelings, and actions, which they claim ultimately alters her way of being-in-the-world (2011: 716). Specifically, they argue that when an individual is faced with a disorienting experience, such as a strong emotional response on a voluntourism trip, it forces her to undergo a self-examination, create new ways of acting or being, and then re-enter society with a new perspective (Coghlan and Gooch 2011: 717). These researchers' analysis can provide an initial point in which to examine the voluntourist experience. Through adopting Schutz' theoretical framework of the life-world, while also considering Coghlan and Gooch's argument that voluntourism is a transformative experience, I explored the voluntourists' narratives that their experiences in Cape Town were life changing.

While discussing their experiences, the voluntourists I interviewed highlighted several key areas of importance. The voluntourists claimed that these aspects challenged their prior conceptions of their life (or how other people lived, which, according to Schutz/Luckmann, amounts to the same thing) and created a new perspective for them. In 
particular, they noted that the first time they entered the township to volunteer, they were shocked by the living conditions. As well, they experienced a significant shock when they witnessed a teacher hit one of the nursery school children when he/she misbehaved, noting that "this would never happen back home." These experiences they said, changed their worldview by making them realize how differently some people live compared to their own circumstances. The simple fact of being in a new country on their own also challenged their notions of other people. This shift in perspective was also described as occurring because of being physically present in the same time and space as individuals in the township, which emphasized the critical aspect of "being there" in order to challenge prior understandings of the world.

\subsubsection{A New Perspective and the "shock" of the Townships}

When discussing the study participants' experiences in Cape Town, the interview topic inevitably drifted towards the voluntourists comparing their perspectives of home to life in the townships. In particular, the voluntourists all noted that by coming on the trip they began to "see what it is really like" in the townships. When I asked them to elaborate on these comments, they all described their initial shock upon entering the township and how different it was from their houses back home and the volunteer accommodations. As Colleen put it: "You realize how spoiled you are back home, you know. Not as in you're ungrateful, but I never need anything when I'm at home. You see what it's really like for people who maybe weren't as lucky." By focusing their thoughts on this one particular moment, the voluntourists explained that it forced them to re-examine their perspective of the world because they were faced with an unfamiliar and challenging experience. 
Sasha explained that the first time she entered the township, she was shocked by the living conditions, especially because she did not expect people to live "like that these days." She said that during the initial drive into the township: "I was shocked, I think. I expected it to be not as developed as where we would be living or what we have at home and things. But I didn't think the township would be so close together, everything is kind of like on top of each other." Similarly, she said her first opinion of seeing the houses was that: "it's like crazy [gasp]." Sasha said she noticed the material of the houses, which were un-renovated and made out of corrugated metal and storage containers. Yet, as she explained, it was not just the buildings that surprised her, but also the lifestyle. Sasha felt that upon seeing the community, she realized "how different it is. It still shocks me, the living conditions shouldn't be like that nowadays." While entering the township for the first time was a pivotal moment for Sasha, she said her whole experience of working in the townships really put her life into perspective and made her think differently of what she has back home.

Shaina had a similar experience upon entering the township for the first time. She said that initially: "I had pictured a remote school going in; I didn't expect how dense and packed it was. Everything was iron shacks. I thought it was like worse than I originally thought." Shaina also explained that even what the kids did in the nursery school seemed strange to her, especially something as trivial as watching a movie: "In [the nursery school], the kids were watching a movie and I thought 'how can they all stand this?' It's cramped and not what you're used to. But then you start to think it's nice and it's what they do to entertain them." She noted that she overcame this initial shock and began to change her perspective on how people can live: "just a pivotal thing was 
probably just thinking a different way maybe. I wouldn't say I was close minded to begin with. But it's just like you kinda tweak how you see things a bit." Through describing how she tweaked how she saw things, Shaina highlighted how this experience made her change her perspective and consider different ways of living as equally valid and having different merits. She claimed that this shift in thinking also made her become less judgmental of how other people lived.

The main shift in perspective for Emilie was realizing that in spite of her perception that the children lived in poor conditions, they were smiling all the time and she felt they were happy. Through this realization, she said that: "When I reflect, I think I'm so lucky to have so many things I enjoy. When I think of life conditions of the children, it is so bad. I realize how much I have in comparison." Emilie explained that through her experiences volunteering in the township, she realized how different daily life was compared to her life in Belgium. She explained that in her future, when something is wrong, she will think twice about the situation to consider its overall impact on her. According to Emilie, her experience in Cape Town changed her perspective on the importance of material things in her life and that: "I think I will see things differently from before. It's really something you have in you for the rest of your life." Through this statement, Emilie explained that by witnessing life in the townships, it challenged her prior assumptions. She felt this was a catalyst to change her perspective, which she believes was so pivotal that she will take the experience with her for the rest of her life.

During her interview, Colleen explained that she had decided to volunteer abroad because she had wanted to see the world from a different perspective. While she had come onto the trip with this expectation, she felt it did not prepare her for the shock of the 
lifestyle in the townships, which she said ultimately created a shift in worldview. In particular, Colleen said she compared how individuals lived in the townships to her lifestyle at home; "I saw all the little shacks and I thought the chicken shacks on my farm are better built... it just doesn't seem fair people live in these circumstances." Through her exposure to this, Colleen explained that although she expected the poverty, she felt it created a change in attitude and the trip had an impact on her to change her perspective in life. Yet, this response was not related to her experience in Cape Town, but addressed her life back home in Ireland; this highlighted the ambiguity of voluntourism since the claimed shift was focused internally instead of outwards to "make a difference." In particular, Colleen stated that she felt she would appreciate the little things in her life more, be grateful of her family, appreciate where she came from, and use her talents, skills, and knowledge effectively. She also noted that it made her realize that not everyone is given the same chances in life, and she hoped that the project partners were given a chance to improve through their relationship with International Voluntourism. Although Kerry had prior experience going into a township because of her childhood in Zimbabwe, she said she was still kind of shocked by the conditions in Cape Town. She explained that the transformational moments for her occurred during her interactions with South Africans. In particular, Kerry said she was shocked when Angela, the nursery school owner, described her daily life. Angela said that she woke up at 4:30 am each day and had a bath by boiling her kettle six times in order to have warm water. She began the nursery school at $6 \mathrm{am}$ and had children there until $6 \mathrm{pm}$. After the children left, Angela said she worked on her teaching course at the library, in spite of a lack of teaching books and limited computers. Upon reflecting on this, Kerry said that 
this was a shocking experience because it showed how hard Angela worked and how hard her life is compared to hers. She felt that the impact of her involvement in the townships changed her worldview because it came up against her prior knowledge of how people live:

It kind of helps you realize how some people, I don't know, have different classes, and live so close but live such different lives. And even today at [tutoring], when the kids showed us their homework where they had to collect photos of their modes of transport and the teacher had asked them to print stuff. And it just shows you how someone in Ireland could go on a computer and print straight away. And then like other kids don't have a chance because they can't use a computer, or don't have money to print it. It just shocks you a little bit... We just take it for granted, we don't realize.

By highlighting these two examples, Kerry explained that through her interactions in the townships, she experienced a change in perspective; this is similar to what International Voluntourism had forecasted on its website, which may demonstrated the impact its rhetoric had on framing participant's experiences. Kerry said that by going on the trip and volunteering in the township, it changed her and showed different ways of life. This statement highlights the ways in which voluntourists, like Kerry, explain how they overcome the ambiguous aspects of voluntourism by focusing inwards on its personal impact. Since Kerry was unable to "make a difference" in the township or for Angela, since she was only there for two weeks, she claimed to have changed her perspective as a way to emphasize the impacts of voluntourism and make sense of her shock.

In addition to the voluntourists' narratives about experiencing a shift in worldview on the trip, the International Voluntourism staff commented that they perceived that the experience changed people. According to John, the voluntourists are impacted by the cultural differences, such as the teachers hitting the children in the 
nursery school (in spite of a "heads up" of this during training). He stated that this can make them uncomfortable and challenge their prior perspectives. John believed it was these things that challenged their beliefs because the voluntourists arrive already braced to experience poverty and poor quality housing. This was an interesting consideration because the voluntourists had mentioned they were aware of the poverty prior to their trip; yet, they all still emphasized it as the key shocking moment of their experience during their interviews. The focus on the poverty in the townships may have been a way to reaffirm the shift in perspective based on the organization's pre-defined expectations. While witnessing a teacher hit a student may have been more of a shock, and been unexpected, since it was not established as part of the voluntourism experience, it may not have been discussed in favour of the more obvious "new" experience of poverty.

During my participant-observation, I noticed the shock and had several discussions with the voluntourists about how awful it was for teachers to hit the children, but they did not focus on this as a pivotal moment during the interviews. Part of this was because the voluntourists claimed that although they did not like the corporal punishment, they did not want to judge because "maybe the schools in South Africa do things differently." As well, it may have been something they felt was outside their control, so they were unable to incorporate it into their life-world. This also made me think that this situation may have been so dramatic that the shock was not readily absorbed, so the voluntourists focused on the housing instead.

Meanwhile, Katie believed that being exposed to the poverty and living conditions in the townships would create the biggest shift in worldview for the voluntourists because it makes them reconsider how they live back home. During my 
interview with Sarah, she also noted that the voluntourists were impacted by going into the township. Yet, she also explained that after the initial shock wears off, she thinks the voluntourists begin to realize this is just another way of life:

Initially actually going into the townships can be quite different. It's a culture shock; people live very differently. But people are just living their lives as we are. They are working and feeding their families too.

This demonstrates the way the organization expects voluntourists to interpret their experiences by developing a global understanding. Sarah also added that she felt the change in perspective becomes more emphasized upon someone's return home. She feels that it is more of a culture shock when she returns home to England because she wonders who has got their priorities right in life when the townships have such strong community spirit. Since John, Katie, and Sarah have met many groups of voluntourists, they were relatively more aware of whether or not the voluntourists claimed to have had a shift in perspective based on their experiences. They explained to me that this is a common statement expressed by the voluntourists they have worked with in Cape Town.

To sum up: As the narratives from the voluntourists and organization staff show, individuals represent themselves as experiencing a change in perspective based on their experiences in a developing country. They noted how they began to realize how fortunate they are in comparison, became aware of how other people live, and began to broaden their worldview. However, this shift could be expected because many of the voluntourists said that they came on the trip to see the world in a new way, become spiritually richer, and they were aware of the poverty in the townships. Their focus on describing their shock of initial entrance into the township is more controlled and expected within the experience. 
While the voluntourists did not mention it explicitly in their interviews, based on my observations, I noticed that they were significantly shocked by the unanticipated experience of witnessing the teachers hit students. This demonstrates the different degrees of a shift that an individual may come upon in their experiences. Using a Schutzian approach, this is because individuals come up against a novel experience that does not fit into prior reference schema, so they are forced to shift their way of thinking to incorporate this new experience. This includes using the organization's rhetoric of "giving back," "making a difference," and having a "life-changing experience," as a means to manage the uncertain aspects of their lived experience. The voluntourists represent their shift in perspective as occurring because they became exposed to a new way of life overseas and required a way to smooth over the ambiguities and incorporate it into their prior world-view.

\subsubsection{Developing Relationships}

In addition to the voluntourists stating that they experienced a shift in worldview upon entering the townships and volunteering overseas, they also emphasized the impact of developing relationships with people in Cape Town. As Schutz explained through thou-orientation and we-relation, individuals have a different relationship with people they meet face-to-face versus abstract people with whom they do not directly interact. Through this, the voluntourists can empathize by imagining the subjective experience of an Other living in the township through observing him or her (Schutz and Luckmann 1973: 253). By sharing the same spatial and temporal realm in the life-world, the voluntourists can experience directly how other people live, which may come up against 
their prior stock of knowledge and cause them to reconsider their perspectives. Similarly, by meeting individuals from around the world, the voluntourist has the potential to solidify the similarities between humans and collapse the divide between "us" and "them," thereby creating a more inclusive worldview.

According to Shaina, it is important for people to travel and experience more of the world to develop a greater understanding of life. She explained that travelling to South Africa gave her a good life experience and when she goes home she can say: "Yeah, I've seen the world...Not a lot of people go a lot of places or do a lot of things with their lives." Sasha also noted how critical it was to travel to a country to see what it is "really" like and meet "real" people. In school, Sasha had studied South African sociopolitical history and apartheid. She noted that there was a big difference between studying something and actually experiencing it with one's senses and one's body: "You're shown people living in shacks, but you don't believe they actually live like that, I suppose, until you're there." As Sasha explained, there are different lifestyles around the world and you do not notice it until you see it and talk to the people there. Thus, by setting foot in South Africa and entering the townships, the voluntourists explained it expanded and changed their perspectives of the world.

Sasha also noted that one of the changes in her perspective that occurred on her voluntourism trip was that by developing relationships with people in the townships, she realized (or possibly reaffirmed) that people are very similar around the world. In particular, she said she noticed that the children did a lot of the same activities, songs, and games in the nursery school. Similarly, Sasha explained that after the initial shock of entering the township, she began to notice the innate humanity of the people she was 
seeing: “I don't see shacks now, you just see the projects you go to each day. You think more of the people. They make the most of what they have. It's just their house." Through this experience, Sasha explained that her shift in perspective was that she began to see how the people living in the townships had very similar lives to her, in spite of their initial differences. She said that through her shared bond with the people she met and worked with in the township, she began to think differently. Specifically, by meeting people in the township, instead of considering them as an abstract other, Sasha felt she was able to understand how other people live.

During my interview with Megan, she also described the impact her relationships with people in the townships had on her change in perspective. She explained that upon her departure from Cape Town the previous summer, she was devastated and had a hard time returning to her "regular" life because she kept thinking of the people with whom she had worked. Megan described that by meeting people during her trip, she was impacted significantly that it affected her previously taken-for-granted lifestyle in Wales and she had difficulties resuming her prior activities without considering her experiences in Cape Town. Due to the significance of this trip and the bonds she had developed, Megan decided to return to Cape Town again the following summer: "It was one of the best experiences I have ever had, and that's why I had to come back. Especially the people I met here and the kids. I never realized how attached to the kids I would get." During her interview, Megan emphasized more of the bonds she had developed than the shock of her experience because she seemed to have incorporated this experience into her stock of knowledge. As Megan's example highlights, the voluntourists become changed as a result of as the relationships they developed in Cape Town. 


\subsection{3 "Being There" and the Indescribability of the Experience}

The voluntourists also explained that their trip had such a big impact on them that the experience was indescribable and someone would have to "be there" in order to understand. While this seemed counter-intuitive because the voluntourists were able to relay their experiences to me during their interview, I believe this may be because I was on the trip with them and could understand what they meant when they explained volunteering in the township or the initial shock upon seeing the houses. This is a significant comment in analyzing the voluntourists' representation of a shift in life-world because it shows the insurmountable feeling they experienced as a result of the ambiguous aspects of the trip, which they felt to be beyond words. It also showed it to be an embodied experience, based on occupying a shared spatial and temporal realm.

According to Hillary, the experience of voluntourism "touches you" and changes you in such a way that only other people who have done it can "get it." This involvement affects you in such a way that you are not able to relay the change. Instead, you are left describing the experience or showing pictures, but it does not show the whole thing to your audience. During our interview, Shaina described her change in perspective as reliant on "being" in the township, developing relationships, and that ultimately, this experience felt so "significant" that it was indescribable:

Because you've never been somewhere, you make assumptions. I mean I didn't really know about Xhosa culture. I didn't know most of the townships. But you changed your perspective on what people have, you know, things like that. You can watch a documentary, but actually coming out here and being a part of it, makes a big difference. I mean, it's just, you know.

Through using the phrases "you know" and "things like that," Shaina demonstrated the indescribability of her experiences and referred to my personal experiences in Cape Town 
as a way to generate understanding. These indescribable moments seemed to be the critical moments when the voluntourists claim to have experience a shift in perspective or came upon an ambiguous event that required further understanding. Since I was on the trip, I was able to empathize with Shaina's explanations; however, she told me she was worried her family and friends would not understand how critical this trip was for her.

Kerry also noted a similar sentiment that simply describing her experience or showing pictures would not get to "the heart" of her experience. She explained that you need to be in the community and interact with the people in the township in order to learn about their way of life. While she felt photographs on the township tour or from the International Voluntourism farewell presentation would be good to be able to show people at home some of what she did and where she worked, it would not be the same thing. As Kerry stated, you need to actually experience it and have the children call you "teacher" in order to understand what it was like in the townships.

Through emphasizing the indescribability of their experiences, the voluntourists demonstrated its impact on them. In particular, it highlighted the importance of being physically present in order to immerse themselves in it and develop relationships with the people that they met. This included the initial shock of entering the townships, recognizing the shared humanity with people living different lives around the world, and expanding their worldview based on their exposure to novel experiences. While the voluntourists may or may not have experienced a shift in life-world, through their selfrepresentation of this change they show that an individual has to "be there" in order to understand the impact a voluntourism trip may have on an individual's perspective. 


\subsection{Voluntourism's Impacts on Perceptions}

Through examining the voluntourists' narratives about a shift in perspective due to new experiences, I gained insight into how an individual navigates the complex aspects of her trip. The voluntourists echoed International Voluntourism's claims that the trip would be a "life-changing event" by stating it impacted their perspective of the world through seeing the poverty in the township. As I addressed in this chapter, this is also based on the intersection between experiencing "a change in perspective," developing relationships overseas, and the importance of "being there" and the indescribability of the experience. By being physically present in Cape Town, the voluntourists engaged in a thou- or we-orientation relationship with people in the townships. This bond was dependent on the individual "being there" and impacted the individual's sense of self, while also exposing her to other people's way of life. Through this, it expanded her stock of knowledge by incorporating these new experiences. In this, an individual interprets her shift as so significant, that the experience overseas is indescribable.

Through the individuals reflecting International Voluntourism's rhetoric of "making a difference," "giving back," and having a "life-changing experience," it highlights that the voluntourists' interpretation of their shift in perspective is affected by the expectations the organization develops for the trip. While a shift may or may not have occurred, by adopting this discourse, an individual frames her trip within the organization's representation of the idealized "voluntourist" who comes home changed from her experience volunteering overseas. This provides a means for the voluntourist to smooth over the shock of their experience or the ambiguous aspects of voluntourism by describing an internal change, while also validating the organization's discourse. 


\section{Chapter: Conclusion}

Voluntourism forges an ambiguous experience for an individual through its combination of volunteering and tourism. The structural tension in these distinct roles creates contradictions for the voluntourist since she is involved in different types of activities. While the volunteering aspect is represented by researchers and the organization as focusing on "making a difference" by "giving back," the tourist elements put emphasis on sightseeing and documenting the experience by "getting" photographs. Although International Voluntourism claims this combination creates deeper insight into a culture, fosters personal growth, and makes a positive impact in the host community, I noted that it also creates further confusion. The volunteering and tourism elements do not neatly fit together during this experience.

The intersection of volunteering and tourism develops a structural tension, which makes it difficult for the voluntourist to interpret her experience and make sense of this ambiguity. Through intersecting Mauss' concept of "the gift" and Schutz' "life-world," I was able to examine the ways the voluntourist described a shift in perspective based on her novel experience; this appeared to internally justify her description of her involvement as "giving back" as an attempt to limit her described shock of the poverty in the townships. This was demonstrated during the interviews when the voluntourists echoed the organization's discourse from its website, training manuals, and staff about "giving back," "making a difference," and having a "life-changing experience." By adopting this rhetoric, the voluntourist represented herself as able to justify her involvement by claiming she was providing a "gift" to the host community, in addition to experiencing a shift in perspective due to her new experience. 


\subsection{Looking Back: A Chapter Overview}

Through my research project, I have structured my chapters in order to contribute to an understanding of the contours of voluntourism's ambiguity. My first chapter provided an introduction to voluntourism, gave context to my research, outlined my field site, and also presented my theoretical frameworks. It also highlighted my key research questions, which I unpacked for the remainder of the project. This developed an initial understanding of the inherent structural tensions and ambiguities of voluntourism. In Chapter Two, I outlined my research methodology to demonstrate how I conducted my research. I also explored my role as an anthropologist-voluntourist, its impact on my research, and how this affected my interpretations of voluntourism. These two chapters provided a foundation for the trajectory of my research scope.

I used Chapter Three to examine how previous researchers have defined and addressed the topic of voluntourism, focusing on its complex morality. This emphasized the contradictory roles it creates, which were represented by the researchers as having positive or negative impacts. I used this literature review to give insight into the general perception of voluntourism. In addition, I also explored how the different degrees of intersecting volunteering and tourism can change the focus of the program. Using Brown's (2005) exploration of "volunteer-minded" individuals, I looked at how programs can represent themselves as VOLUNtourism or volunTOURISM and how this shapes the voluntourist's interpretation of her experience. I briefly explore the socio-political history of South Africa, focusing on the effects of apartheid, to see how this impacted the study participants' decisions to voluntour in Cape Town and how this framed their trip. Through examining the definition of voluntourism, looking at a range of past literature on 
the topic, differentiating between VOLUNtourism and vounTOURISM, and looking at South Africa as a site, I provided context to the voluntourists' narratives.

Through my content analysis of International Voluntourism's website, training manuals, and staff interviews in Chapter Four, I looked at the discourse the organization uses to explain its programs. By focusing on its self-representation through the use of photographs and key terms, I looked at the framework it establishes for the voluntourists to interpret their experience. International Voluntourism uses this discourse to attract potential voluntourists, promote itself, and justify its involvement in the host communities. It also creates a language for the voluntourism trip, emphasizing how an individual is "making a difference," "giving back," and having a "life-changing experience." This attempts to smooth over the inherent contradictions of voluntourism by adopting this "feel good" terminology. Chapter Four contributed to my overall analysis because the discourse International Voluntourism employed was echoed during the voluntourist interviews, so this gave me a foundation for analysis.

In Chapter Five, I used Mauss' concept of "the gift" to examine how the voluntourists framed their involvement as "giving back" and "making a difference." This highlighted how Mauss' concept of the total social fact of the gift, which creates a bond between the individuals, masks the asymmetry of the exchange in voluntourism. By describing their activities as a gift and discussing the relationships formed, the voluntourists smoothed over the contradictions of their experience. The emphasis on "making a difference" also focused on a voluntourist-centred perception of voluntourism.

Chapter Six contributed to my discussion on the ambiguity of voluntourism through examining why the voluntourists described themselves as gaining a new 
perspective through their experiences overseas. This supports Chapter Five's examination of "the gift" because by describing a shift in perspective based on a novel experience, voluntourists justified their self-representation of "giving back" as a means to reduce their shock overseas. It also explores the impact of voluntourism on the individual since this experience required her to interpret her contradictory roles as a voluntourist. Through echoing International Voluntourism's rhetoric, the voluntourist represented herself as the "ideal voluntourist" who is changed by "making a difference" for those in need. As mentioned previously, this may allow the person to internalize this belief and mitigate the ambiguous aspects of her experience. -

\subsection{Answering my Research Questions}

Through my research, I focused on key questions as a way to guide my fieldwork and analysis. In addressing the research questions, I noted that individuals who engage in voluntourism frame their experience and roles, as well as their overall perception of voluntourism, based on the discourse developed by the organization. This is through representing their involvement as "giving back," "making a difference," and being a "life-changing experience" to make sense of their ambiguous experience. Specifically, these phrases were used because the voluntourists I interviewed described the experience as impacting them by creating a new perspective through being present in the townships. While they may or may not have experience this shift, through their use of International Voluntourism's rhetoric, I noted that their perceptions of their trip were based on the expectations the organization established in its literature. This allowed them to mitigate the contradictory elements of their experience by adopting the organization's pre- 
established framework. I noted that this language also smoothes over the ambiguous aspects as a way for the voluntourists to make sense of their trip.

Figure 1.11: Looking out at Cape Town

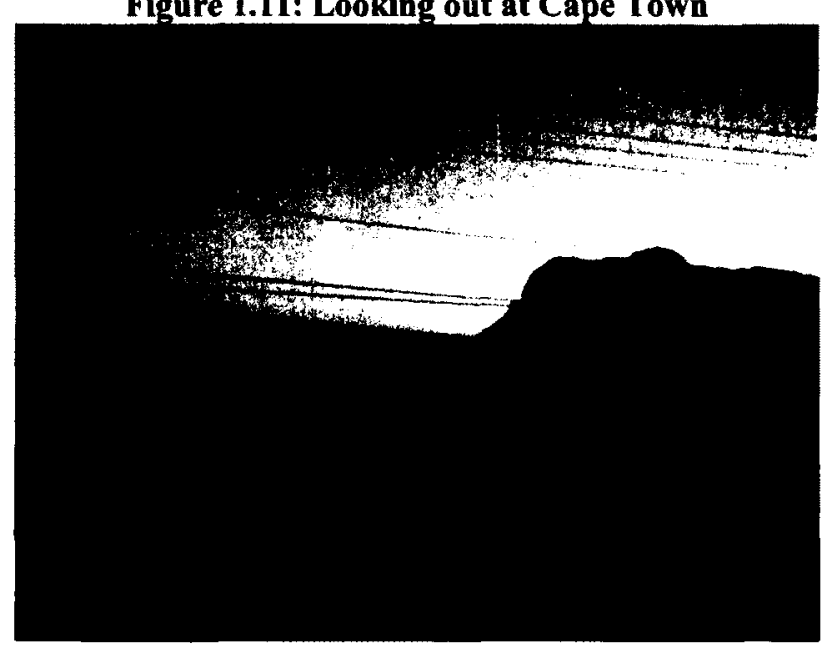

Source: Personal Photograph-August 9, 2012

My research questions also emphasized the challenges I felt as a researcher during fieldwork. In my dual roles as an anthropologist and a voluntourist, I realized that this ambiguity mirrored the contradictory aspects of combining volunteering and tourism. While I was on my trip, I had to be involved in the volunteer project, and travel in Cape Town, while also maintaining a critical stance while conducting participant-observation and interviews. I also struggled with my roles as an anthropologist and voluntourist while analyzing my data. In particular, I was challenged with representing International Voluntourism and the study participants because I wanted them to "look good" and focus on their positive attributes. As well, I had to make sure I did not get caught up in the organization's rhetoric, in order to examine its impacts on how the voluntourists interpreted their experiences. By exploring my positionality, I was able to analyze the study participants' voluntourism experiences from a more critical stance. 


\subsection{Contributions to Anthropology and Voluntourism Literature}

Through my research project, I contribute theoretically and empirically to Anthropology, as well as literature on Voluntourism. I add to Anthropology through my exploration of the challenges of a study-beside method, especially since I was the same demographic as my voluntourist study participants; this also demonstrated the difficulties a researcher may face in representation, since I struggled with any negative or neutral portrayals. I also contribute to Anthropology by studying Western culture, which is still under-explored in the discipline, through my examination of the Western voluntourist's interpretations of her experience.

My project also adds to previous literature on voluntourism because of my methodological approach. As I highlighted in my literature review in Chapter Three, prior researchers typically employ studies or interviews, without participating on the trip, as a research technique. By being in Cape Town and voluntouring alongside my study participants, I provide an insider's account of the experience and establish a rapport with the other voluntourists. Through this, I contribute an additional perspective of voluntourism that complements and adds to existing research.

\subsection{Potential Limits to Research}

While I attempted to mitigate any potential limits in my research, there are some areas that require additional notice. In particular, since I was only on the trip for two weeks, this may impact my depth of knowledge of voluntourism. However, since most of the study participants were only overseas for two weeks, and this is the typical voluntourism trip length, this may not have a significant impact on my findings. Another 
potential limitation of my research is that I was unable to conduct pre- and post-trip interviews because of my study participants' personal limitations (which I addressed in Chapter Two). Through talking to the voluntourists before, during, and after their trip, I would generate a better understanding of how they interpret their ambiguous experience. In addition to these two considerations, my research may have also been limited due to its scope, since I focused on one group of voluntourists within one organization for a two week period. Through examining a larger scope of voluntourism, I could gain further insight into the experience.

\subsection{Future Research Considerations}

My research provides an initial exploration of voluntourism and how the voluntourists perceive of their role within this contradictory experience. Future researchers could take this project as a starting point to consider other aspects of voluntourism. For example, some future research considerations would include examining the impact and interpretation of voluntourism from the host community's perspective to see how they frame the experience. As well, it would be beneficial to observe multiple cycles of voluntourists through a longer fieldwork period in order to compare different groups of individuals. Finally, future research considerations would include conducting interviews before and after the trip, in order to see any differences in interpretation prior to the trip and when an individual reintegrates back into their home country. 


\section{Appendices}

\section{Appendix A}

\section{A. 1 Voluntourist Early Trip Interview Questions}

1. Can you begin by stating where you are going and what you will be doing while volunteering overseas (volunteer tourism)?

2. How long will you be involved on your trip?

3. What do you expect to do (volunteering, tourism, working with other volunteers, etc.) while overseas?

4. Why did you choose to go overseas? Was there a specific event or moment that affected your decision?

5. What is your educational background? Do you feel it is relevant to your work volunteering in Cape Town?

6. What is your personal background? How does volunteering overseas fit within your life? What type of importance will it have for you?

7. What motivated your decision to travel overseas to volunteer?

8. What do you think your experience overseas will be like? Is there anything you are anxious or concerned about?

9. What aspects of your trip are you most anticipating? What are some areas of concern or challenges you expect?

10. What are some of the benefits (personal, emotional, career-related skills) you except to gain through your involvement?

11. What were some challenges to your involvement in going overseas to volunteer?

12. What types of activities are you doing to prepare for your trip?

13. What has been a pivotal moment for you? Describe and explain the experience.

14. What has been a shocking experience for you? Describe and explain.

15. Are there any challenges or concerns you have faced?

16. What do you hope to do for the rest of the trip?

\section{A. 2 Voluntourist Late Trip/ Post-Trip Interview Questions}

1. Compared to what you felt before participating on your trip, how do you feel now about your experience? What are some differences you noted?

2. What is one of your most powerful memories while volunteering in Cape Town?

3. What activities did you participate in while volunteering? Describe a typical day. Was it what you expected?

4. Did you feel the organization was helpful while you were involved and they fulfilled their proposed claims about the trip?

5. What did you learn (about yourself, Cape Town, the children, etc) from the trip? Do you feel you gained anything? Please describe

6. Do you think you would participate on another voluntourism trip? Do you think you will volunteer "back home"? Please explain 
7. How do you feel the cultural awareness activities fit into your experience?

8. What impact did your involvement have on you? Do you feel it has changed anything about your perspectives of the world?

9. Did any part of the trip shock you or make you uncomfortable?

10. If you had to pick a key moment that has impacted your life, what would it be? If it has, how has it changed your perspective?

\section{A. 3 For Individuals from the Sending Organization/Project Partners}

1. What is your role in the volunteer tourism organization? Do you interact directly with the volunteers?

2. What is your educational background?

3. What is your personal background?

4. Describe a typical day in your position

5. How do you (or the company) recruit potential volunteers?

6. What features make an ideal volunteer tourism candidate?

7. What are some concerns you may have about volunteers?

8. How do you select volunteer projects?

9. What impact do the projects have on their intended beneficiaries (ie. Children in the orphanage or schools)?

10. What do you think are the highlights of the trip?

11. Are they any parts of the trip that make volunteers uncomfortable? Why do you think this is?

12. Are there any aspects you would like to change about the volunteer projects?

13. How do you think volunteer tourism benefits the individual who participates in it?

14. Do you get any returning volunteers?

15. Are there important or defining features about your organization that make it different than other volunteer tourism organizations? 


\section{Bibliography}

Altheide, David

1996 Qualitative Media Analysis. London: SAGE Publications, Ltd.

Benson, Angela

2011 Volunteer Tourism: Theory and Practice In A.M. Benson (Ed.) Volunteer

Tourism: Theory Framework to Practical Applications (pp.223-239) New York:

Routledge.

Brown, Sally

2005 Travelling with a Purpose: Understanding the Motives and Benefits of Volunteer Vacationers In Current Issues in Tourism, 8(6): 479-496.

Clark, Nancy L. and William H. Worger

2011 South Africa: The Rise and Fall of Apartheid $\left(2^{\text {nd }}\right.$ Edition). Great Britain: Pearson Education Limited.

Coghlan, Alexandra and David Fennell

2009 Myth or Substance: An examination of altruism as the basis of volunteer tourism In Annals of Leisure Research, 12(3/4): 377-402.

Coghlan Alexandra and Margaret Gooch

2011 Applying a transformative learning framework to volunteer tourism In Journal of Sustainable Tourism, 19(6): 713-728.

Connan, Mary

2011 They Really Love Me! Intimacy in Volunteer Tourism In Annals of Tourism

Research, 38(4): 1454-1473.

Cornwall, Andrea and Karen Brock

2005 What do buzzwords do for development policy? A Critical Look at

'Participation,' 'empowerment,' and 'poverty reduction.' In Third World

Quarterly, 26(7): 1043-1060.

Cortazzi, Martin

2001 Narrative Analysis in Ethnography In Atkinson, Coffey, Delamont, Lofland and

Lofland (Eds.) Handbook of Ethnography (pp. 384-394) London: SAGE

Publications Ltd.

de Saussure, Ferdinand

2004 "from Course in General Linguistics (1916)" In A. Easthope and K. McGowan

(Eds.) A Critical and Cultural Theory Reader (pp. 5-11) Toronto: University of Toronto Press. 
Fee, Liam and Anna Mdee.

2011 How does it make a difference? Towards 'accreditation' of the development impact of volunteer tourism In A.M. Benson (Ed.) Volunteer Tourism: Theory Framework to Practical Applications (pp.223-239) New York: Routledge.

Guttentag, Daniel A.

2009 The Possible Negative Impacts of Volunteer Tourism In International Journal of Tourism Research, 11: 537-551.

Ingram, Joanne

2011 Volunteer Tourism-How do we know it is 'making a difference?' In A.M. Benson (Ed.) Volunteer Tourism: Theory Framework to Practical Applications (pp.211-222) New York: Routledge.

LeCompte, Margaret D. and Jean Schensul. 1999 Analyzing and Interpreting Ethnographic Data. London: SAGE Publications, Ltd.

Lyons, Kevin and Stephen Wearing 2008 Volunteer Tourism as Alternative Tourism: Journeys Beyond Otherness In K. Lyons and S. Wearing (Eds.), Journeys of Discovery in Volunteer Tourism: International Case Study Perspectives (pp. 3-11) Oxfordshire: CABI International. 2012 Reflections on the Ambiguous Intersections between Volunteering and Tourism In Leisure Sciences, 24 (1): 88-93.

Mandela, Nelson 1995 Long Walk To Freedom. New York: Little, Brown and Company.

Manning, Peter K.

2001 Semiotics, Semantics and Ethnography In Atkinson, Coffey, Delamont, Lofland and Lofland (Eds.) Handbook of Ethnography (pp.145-159) London: SAGE Publications Ltd.

Marcus, George E.

1995 Ethnography in/ of the World System: The Emergence of Multi-sited Ethnography. Annual Review of Anthropology, 24: 95-117.

Mauss, Marcel

1974 The Gift. London: Routledge and Kegan Paul Ltd.

Maylam, Paul

2001 South Africa's Racial Past: The History and Historiography of racism. segregation, and apartheid. Burlington, USA: Ashgate.

O' Reilly, Karen

2008 Ethnographic Methods. New York: Routledge. 
Pancer, Mark, Steven D. Brown, Ailsa Hendersen, and Kimberly Ellis-Hale.

2007 The Impact of High School Mandatory Community Service Programs on Subsequent Volunteering and Civic Engagement: Research Report. Toronto: Imagine Canada.

Parry, Jonathan

1986 The Gift, The Indian Gift, and the 'Indian Gift.' In Man, New Series, 21(3): 453-473.

Pearce, Philip L. and Alexandra Coghlan.

2008 The Dynamics Behind Volunteer Tourism In K. Lyons and S. Wearing (Eds.), Journeys of Discovery in Volunteer Tourism: International Case Study Perspectives (pp.130-143) Oxfordshire: CABI International.

Scholte, Bob

1974 Toward a Reflexive and Critical Anthropology" In Dell Hymes (Ed.), Reinventing Anthropology (pp.430-457). New York: Vintage Books.

Schutz, Alfred and Thomas Luckmann.

1973 R. M. Zaner and H. T. Engelhardt, Jr. (Trans.) The Structures of the Life-World. Evanston: Northwestern University Press.

Sin. Harng Luh

2009 Volunteer tourism-'Involve me and I will Learn'? In annals of Tourism Research, 36(3): 480-501.

2010 Who are we responsible to? Locals' tales of volunteer tourism In Geoforum, 41: 983-992.

Voluntourism

2013 What is Voluntourism? Electronic document, http://voluntourism.org/inside.html, accessed May 7, 2013.

Wearing, Stephen.

2001 Volunteer Tourism: Experiences That Make A Difference. Wallingford: CABI Publishing. 